\title{
Clinical Engineering Effectiveness in Developing World Hospitals
}

\author{
by \\ Shauna Mullally \\ A thesis submitted to
The Faculty of Graduate Studies and Research
in partial fulfilment
of the requirements for the degree of
Master of Applied Science in Electrical Engineering \\ Department of Systems and Computer Engineering
}

The Ottawa-Carleton Institute for Electrical and Computer Engineering

Carleton University

Ottawa, Ontario

May 21, 2008

(C)2008, Shauna Mullally 


$\begin{array}{ll}\begin{array}{l}\text { Library and } \\ \text { Archives Canada }\end{array} & \begin{array}{l}\text { Bibliothèque et } \\ \text { Archives Canada }\end{array} \\ \begin{array}{l}\text { Published Heritage } \\ \text { Branch }\end{array} & \begin{array}{l}\text { Direction du } \\ \text { Patrimoine de l'édition }\end{array} \\ \begin{array}{l}\text { 395 Wellington Street } \\ \text { Ottawa ON K1A 0N4 } \\ \text { Canada }\end{array} & \begin{array}{l}\text { 395, rue Wellington } \\ \text { Ottawa ON K1A 0N4 } \\ \text { Canada }\end{array}\end{array}$

Your file Votre référence ISBN: 978-0-494-40642-7

Our file Notre référence

ISBN: 978-0-494-40642-7

NOTICE:

The author has granted a nonexclusive license allowing Library and Archives Canada to reproduce, publish, archive, preserve, conserve, communicate to the public by telecommunication or on the Internet, loan, distribute and sell theses worldwide, for commercial or noncommercial purposes, in microform, paper, electronic and/or any other formats.

The author retains copyright ownership and moral rights in this thesis. Neither the thesis nor substantial extracts from it may be printed or otherwise reproduced without the author's permission.
AVIS:

L'auteur a accordé une licence non exclusive permettant à la Bibliothèque et Archives Canada de reproduire, publier, archiver, sauvegarder, conserver, transmettre au public par télécommunication ou par l'Internet, prêter, distribuer et vendre des thèses partout dans le monde, à des fins commerciales ou autres, sur support microforme, papier, électronique et/ou autres formats.

L'auteur conserve la propriété du droit d'auteur et des droits moraux qui protège cette thèse. $\mathrm{Ni}$ la thèse ni des extraits substantiels de celle-ci ne doivent être imprimés ou autrement reproduits sans son autorisation.
In compliance with the Canadian Privacy Act some supporting forms may have been removed from this thesis.

While these forms may be included in the document page count, their removal does not represent any loss of content from the thesis.
Conformément à la loi canadienne sur la protection de la vie privée, quelques formulaires secondaires ont été enlevés de cette thèse.

Bien que ces formulaires aient inclus dans la pagination, il n'y aura aucun contenu manquant.

\section{Canada}




\section{Abstract}

Effective clinical engineering (CE) and health technology management are essential for improving health in the developing world. Building on the work of previous CE researchers, a novel, appropriate research instrument was developed and used to collect primary data from health technology managers in the developing world. A total of 207 valid responses were received. Responses profile the state of CE services, medical equipment, and equipment procurement and donation practices in secondary and tertiary care developing world hospitals. Results show African hospitals profiled are the least effective and most resource-poor, followed by Latin American hospitals. Asian hospitals deliver the most effective CE services. This work tested the hypothesis that Frize's CE effectiveness model for the developed world is applicable to the developing world as well. It is, and a refined developing country model is presented. Finally, this work developed a preliminary model for the relationship between CE effectiveness metrics and the state of medical equipment within developing world hospitals. 


\section{Acknowledgements}

I am incredibly grateful to my supervisor, Dr. Monique Frize, for being a strong role model and for guiding me through the highs and lows of the research process with patience and understanding. I am also deeply indebted to more kind individuals than I can name, who went well above and beyond the call to mentor and help an eager student: Kevin Taylor, Rob Dickinson, and Billy Tenity are just a few. Finally, I am grateful to the participants, without whom this thesis would not have been possible.

This thesis is for all those who believed in me when I didn't believe in myself. Daphne and Irena, thank you for keeping me sane. Matt and Charles, thank you for carrying me when I needed it. Kathryn, thank you for being a champion in every sense; I couldn't have done it without you and the gang. Ryan, Chriso, and so many more friends and family - thank you for your unwavering love and support.

Above all, this thesis is for my parents. You are the best models I could hope to have in life. Thank you for always loving and supporting me, in your own words, "unconditionally"; I am truly blessed. The next chapter - the summer - is mine. Hooray! 


\section{Contents}

1 Introduction $\quad 1$

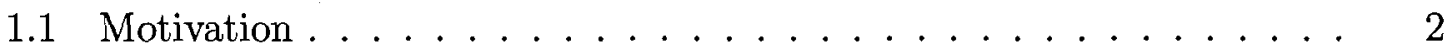

1.2 Problem Statement . . . . . . . . . . . . . . 3

1.3 Thesis Objectives ...................... 4

1.4 Thesis Outline ....................... 5

2 Clinical Engineering and Health Technology Management $\quad 7$

2.1 Clinical Engineering .................. 7

2.1.1 A Model Clinical Engineering Department . . . . . . . . 8

2.2 Health Technology Management . . . . . . . . . . . . . . . 10

2.2.1 Health Technology ................. 10

2.2.2 The Economic Impact of Poor HTM . . . . . . . . . . . . . 12

2.3 CE and HTM in the Developing World . . . . . . . . . . . . 13

2.3.1 Public Health and Health Systems . . . . . . . . . 13

2.3.2 CE and HTM Challenges . . . . . . . . . . . . 15

2.3 .3 Current Global Initiatives . . . . . . . . . . . . 20

3 Literature Review 22 
3.1 Clinical Engineering Effectiveness . . . . . . . . . . . . . 22

3.1.1 Benchmarking Effectiveness . . . . . . . . . . . . 24

3.2 Clinical Engineering Worldwide $\ldots \ldots \ldots \ldots \ldots$

3.2 .1 International Surveys . . . . . . . . . . . . . . 28

3.2.2 Individual Developing Country Profiles . . . . . . . . . 41

3.3 Technology Acquisition, Diffusion and Maintenance Models . . . . . 42

3.3.1 Equipment Procurement . . . . . . . . . . . . . . . 43

3.3.2 Equipment Donations . . . . . . . . . . . . . 43

3.3.3 Technology Complexity Model . . . . . . . . . . . . . . 45

3.3.4 Medical Technology Assessment Model . . . . . . . . . . . 47

3.4 Gaps Analysis . . . . . . . . . . . . . . . . . 49

4 Methodology $\quad 50$

4.0 .1 Exploratory Research . . . . . . . . . . . . . . . . 50

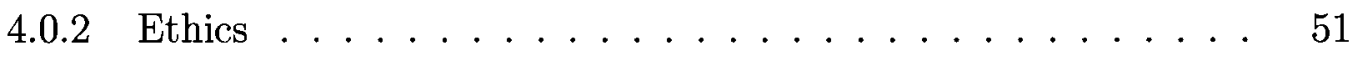

4.1 Data Collection . . . . . . . . . . . . . . . . . 52

4.1 .1 Research Instrument . . . . . . . . . . . . . . . . 52

4.1 .2 Sampling . . . . . . . . . . . . . . 60

4.1 .3 Distribution Methods . . . . . . . . . . . . . 66

4.2 Data Preparation . . . . . . . . . . . . . . 68

4.3 Data Analysis . . . . . . . . . . . . . . . . 70

4.3 .1 Statistical Methods . . . . . . . . . . . . . . . 70

4.3.2 Hypothesis Testing . . . . . . . . . . . . . . . 73

5 The Sample $\quad 76$

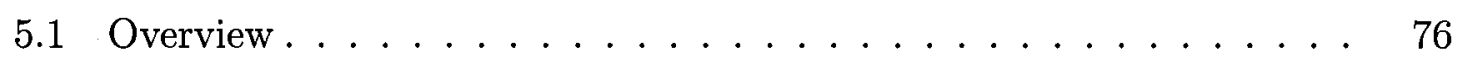


5.1 .1 Hospital Profile . . . . . . . . . . . . . . . 78

5.1.2 Equipment Maintenance Department Profile . . . . . . . . 86

5.1.3 Equipment Maintenance Department Personnel . . . . . . . . 90

5.1 .4 Equipment Inventory . . . . . . . . . . . . . . . . . 99

5.1.5 Medical Equipment . . . . . . . . . . . . . . . . 101

$5.1 .6 \quad$ Repairs . . . . . . . . . . . . . . . 107

5.1 .7 Procurement . . . . . . . . . . . . . . 112

5.1 .8 Donations . . . . . . . . . . . . . . . 116

5.2 Discussion . . . . . . . . . . . . . . 120

6 Quantitative Analysis 122

6.1 Clinical Engineering Effectiveness Model . . . . . . . . . . . . . 122

6.1 .1 Variable Selection . . . . . . . . . . . . . . . . 123

6.1 .2 Correlation Analysis . . . . . . . . . . . . . . 126

6.1 .3 Discussion . . . . . . . . . . . . . . . . . . . . 132

6.1.4 Refined Model. . . . . . . . . . . . . . . . . . . 132

6.2 Medical Equipment Functionality Model . . . . . . . . . . . . . . 132

6.2 .1 Variable Selection . . . . . . . . . . . . . . . . . . 134

6.2 .2 Simple Equipment . . . . . . . . . . . . . . . 135

6.2 .3 Complex Equipment . . . . . . . . . . . . . . 138

6.2 .4 Discussion . . . . . . . . . . . . . . . . . . 139

6.3 Limitations . . . . . . . . . . . . . . . . . . . 140

6.4 Discussion . . . . . . . . . . . . . . . . . . . 143

7 Conclusions $\quad 144$

7.1 Summary . . . . . . . . . . . . . . . . . . . . 144 
7.2 Contributions . . . . . . . . . . . . . . . 146

7.3 Future Work . . . . . . . . . . . . . . . . . . . . . 147

7.3.1 Model Refinement . . . . . . . . . . . . . . . . . 147

7.3.2 Qualitative Research and Modelling . . . . . . . . . . . 148

References

$\begin{array}{ll}\text { Appendix A } & 158\end{array}$

A.1 Ethics Approval Certificate and Letter of Information . . . . . . . 158

$\begin{array}{ll}\text { Appendix B } & 161\end{array}$

B.1 Research Instrument . . . . . . . . . . . . . . . . . . . . . 161

$\begin{array}{ll}\text { Appendix C } & 175\end{array}$

C.1 Variables in Data Set . . . . . . . . . . . . . . 175

$\begin{array}{ll}\text { Appendix D } & 179\end{array}$

D.1 Removed Infrastructure Questions . . . . . . . . . . . . . . 179 


\section{List of Figures}

1.1 Relationship between CE Effectiveness and Patient Outcomes . . . . 3

2.1 Medical Equipment Life Cycle . . . . . . . . . . . . . . . 11

2.2 HTM Problem Tree . . . . . . . . . . . . . . . . . 15

2.3 Medical Equipment Acquisition Iceberg . . . . . . . . . . . . . 18

3.1 Model of CED Effectiveness . . . . . . . . . . . . . 25

3.2 Scorecard for Benchmarking . . . . . . . . . . . . . . . 29

3.3 Revised Model of CED Effectiveness for Developing Countries . . . . 38

3.4 Diagrammatic Inventory of Medical Equipment . . . . . . . . . 46

3.5 Equipment Complexity and Cost to Repair . . . . . . . . . . . . . 47

4.1 Questionnaire Sections - Part A . . . . . . . . . . 58

4.2 Questionnaire Sections - Part B . . . . . . . . . . . 59

4.3 Steps for Testing Hypotheses . . . . . . . . . . . . . 75

5.1 Variability Due to Sampling - Total Valid Response Rate . . . . . . 77

5.2 Regional Responses $(\mathrm{n}=207) \ldots \ldots \ldots \ldots 78$

5.3 Hospital Size $(n=186) \ldots \ldots \ldots$. . . . . . . . . 83

5.4 Average Occupancy $(\mathrm{n}=180) \ldots \ldots \ldots$. . . . . . . . 84 
5.5 Proportion of ICU Beds $(\mathrm{n}=178) \ldots \ldots \ldots \ldots \ldots$

5.6 Highest Education Level of Engineer $(\mathrm{n}=132) \ldots \ldots \ldots$

5.7 Highest Education Level of Technician/Technologist $(n=140) \ldots \ldots 96$

5.8 EMD's Level of Involvement in Procurement by Region . . . . . . . 115

5.9 Level of Consultation Prior to Donation $(n=76) \ldots \ldots \ldots$

6.1 CE Effectiveness Model - Potential IVs . . . . . . . . . . . . . . 124

6.2 CE Effectiveness Model - DVs . . . . . . . . . . . . . . 125

6.3 Refined CE Effectiveness Model . . . . . . . . . . . . . . . 133

6.4 Relationship between CE Effectiveness and Patient Outcomes (replication of Figure 1.1) . . . . . . . . . . . . . . 137

A-1 Certificate of Ethics Approval . . . . . . . . . . . . . . . . . 159

A-2 Letter of Information . . . . . . . . . . . . . . 160

B-1 Page 1 - Research Instrument $\ldots \ldots \ldots \ldots \ldots$

B-2 Page 2 - Research Instrument $\ldots \ldots \ldots \ldots \ldots$

B-3 Page 3 - Research Instrument . . . . . . . . . . . . . . . 164

B-4 Page 4 - Research Instrument $\ldots \ldots \ldots \ldots \ldots$

B-5 Page 5 - Research Instrument $\ldots \ldots \ldots \ldots \ldots$

B-6 Page 6 - Research Instrument $\ldots \ldots \ldots \ldots \ldots$

B-7 Page 7 - Research Instrument $\ldots \ldots \ldots \ldots \ldots$

B-8 Page 8 - Research Instrument . . . . . . . . . . . . . . . . . . 169

B-9 Page 9 - Research Instrument $\ldots \ldots \ldots \ldots \ldots \ldots$

B-10 Page 10 - Research Instrument . . . . . . . . . . . . . 171

B-11 Page 11 - Research Instrument . . . . . . . . . . . . . . 172

B-12 Page 12 - Research Instrument . . . . . . . . . . . . . . 173 
B-13 Page 13 - Research Instrument . . . . . . . . . . . . . . . . 174

D-1 Page 1 - Removed Infrastructure Section . . . . . . . . . . 180

D-2 Page 2 - Removed Infrastructure Section . . . . . . . . . . . . 181 


\section{List of Tables}

2.1 HTM Impacts on Health Care Provision $\ldots \ldots \ldots \ldots \ldots$

3.1 Summary of International CE Surveys $\ldots \ldots \ldots \ldots$

3.2 Levels of CED Functional Involvement (Frize, 1988) . . . . . . . . 32

4.1 Questionnaire Sections . . . . . . . . . . . . . . 57

4.2 Confidence Ranges for Variability Attributable to Sampling . . . . . . 65

4.3 Response Rates . . . . . . . . . . . . . . . . . . . . . . 67

4.4 Correlation Tests Based on Variable Types . . . . . . . . . . . 72

5.1 Regional Response Distribution: Africa and Latin America . . . . . 79

5.2 Regional Response Distribution: Asia, Middle East and Eastern Europe 80

5.3 Hospital Type $(\mathrm{n}=202) \ldots \ldots \ldots \ldots \ldots \ldots$

5.4 Hospital Size by Region $(\mathrm{n}=186) \ldots \ldots \ldots \ldots \ldots$

5.5 Average Occupancy by Region $(\mathrm{n}=180) \ldots \ldots \ldots \ldots \ldots$

5.6 Proportion of ICU Beds by Region $(\mathrm{n}=178) \ldots \ldots \ldots \ldots$

5.7 Reporting Authority and Satisfaction Rates $(\mathrm{n}=150) \ldots \ldots$

5.8 Shared Services by Region $(\mathrm{n}=152) \ldots \ldots \ldots \ldots \ldots$

5.9 Number of Shared Hospitals and Health Centres . . . . . . . . . 89

5.10 Number of Staff . . . . . . . . . . . . . . . . . . . . . . 91 
5.11 Adequate Staff by Region $(\mathrm{n}=152) \quad \ldots \ldots \ldots \ldots \ldots \ldots$

5.12 Difficulty Finding Qualified Engineers and Technicians Locally (n=148) 92

5.13 Prior Staff Training . . . . . . . . . . . . . . . . 93

5.14 Prior Staff Training by Region . . . . . . . . . . . . . . . 93

5.15 'On the Job' Training by Region . . . . . . . . . . . . . . . . . 94

5.16 Highest Education by Region $\ldots \ldots \ldots \ldots \ldots$

5.17 Engineers and Technicians Responsibilities $(n=152) \ldots \ldots \ldots 9$

5.18 Infrastructure Responsibilities $(\mathrm{n}=153 \ldots \ldots \ldots \ldots$

5.19 Inventory Information $(\mathrm{n}=152) \ldots \ldots \ldots \ldots \ldots$

5.20 Equipment Complexity . . . . . . . . . . . . . . . . . . 102

5.21 Proportion of OOS Equipment . . . . . . . . . . . . . . 103

5.22 Proportion of Most Common Equipment Condition . . . . . . . . . 104

5.23 Proportion of Standardised Equipment . . . . . . . . . . . . 104

5.24 Proportion of Equipment with In-hospital Resources . . . . . . . . 105

5.25 Rate of Discontinued Equipment Resources . . . . . . . . . . 106

5.26 Adequate Budget for Spare Parts by Region $(n=112) \ldots \ldots \ldots \ldots$

5.27 Sources of Spare Parts $(\mathrm{n}=112) \ldots \ldots \ldots \ldots$

5.28 Proportion of In-house Repairs ～. . . . . . . . . . . . . . . 109

5.29 Average In-house Repair Time (Hours) ․ . . . . . . . . . . 110

5.30 Average Time OOS Due to Repair (Days) _ . . . . . . . . . . 111

5.31 Average Cost of External Repair) . . . . . . . . . . . . . . . . 112

5.32 Personnel Involved in Equipment Acquisition Decision Making $(n=105) 113$

5.33 Equipment Base Sources . . . . . . . . . . . . . . . . . . 114

5.34 Requirements Considered/Consulted on for Procurement/Donation . 116

5.35 Donated Equipment Base Sources . . . . . . . . . . . . . . 117 
5.36 Proportion of Donated Equipment by Complexity . . . . . . . . . 118

5.37 Proportion of Donated Equipment by State . . . . . . . . 118

5.38 Rate of Resource-accompanied Donation . . . . . . . . . . 119

6.1 OOS Simple Equipment - All Correlated Variables . . . . . . . . . 135

6.2 OOS Complex Equipment - All Correlated Variables . . . . . . . 136

C-1 General, Hospital Info and Equipment Maintenance Department Variables . . . . . . . . . . . . . . . . . 175

C-2 Equipment Maintenance Personnel and Medical Equipment Variables 176

C-3 Equipment Inventory and Repair Variables . . . . . . . . . . . 177

C-4 Equipment Procurement and Donation Variables . . . . . . . . . 178 


\title{
Nomenclature
}

\author{
AAMI Association for the Advancement of Medical Instrumentation \\ ACCE American College of Clinical Engineers \\ ACEW Advanced Clinical Engineering Workshops \\ AFR Africa \\ AUS Australia \\ BMET BioMedical Engineering Technician \\ CE Clinical Engineering / Clinical Engineer \\ CED Clinical Engineering Department \\ CIDA Canadian International Development Agency \\ CV Confounding Variable \\ DV Dependent Variable \\ EEC European Economic Community \\ EMD Equipment Maintenance Department \\ EUR Europe \\ FI Functional Involvement \\ GAME Global Assistance for Medical Equipment \\ GFR Global Failure Rate
}


GNP Gross National Product

GTZ Deutsche Gesellschaft fr Technische Zusammenarbeit

HDI Human Development Index

HIV/AIDS Human Immunodeficiency Virus/Acquired Immune Deficiency Syndrome

HR Human Resource

HT Health Technology

HTM Health Technology Management

HVAC Heating Ventilation and Air Conditioning

ICHTM International Center for Health Technology Management

ICU Intensive Care Unit

ID Identifier

IFMBE International Federation for Medical and Biomedical Engineers

iHTP Integrated Health Technology Package

IV Independent Variable

JICA Japanese Internationa Collaboration Agency

LA Latin America

LOI Letter of Information

MIRG Medical Informatics Research Group

MRC Medical Research Council

MTAM Medical Technology Assessment Model

MV Moderating Variable

NA North America

NMAR Not Missing At Random

NOR Nordic

OOS Out Of Service

xvi 
OTH Other

PAHO Pan American Health Organization

PM Preventive Maintenance

SPSS Statistical Package for the Social Sciences

TB Tuberculosis

UK United Kingdom

UNDP United Nations Development Program

USD United States Dollars

WB World Bank

WHO World Health Organization 


\section{Chapter 1}

\section{Introduction}

Health matters to us all. Without it, we have nothing. For the three billion people who live in extreme poverty around the world, health can be compromised on a daily basis and access to healthcare is often out of reach. With healthcare becoming increasingly technology-dependent, from a sophisticated Western teaching hospital to a health post in rural Africa, mismanaged medical equipment has a direct, detrimental effect on the health outcomes of patients. Yet the rapid proliferation of health technologies has greatly outpaced the development of technology management capacity, placing immense burdens on health systems worldwide [1].

Nowhere is this more acute that in the developing world ${ }^{1}$ where an estimated 50 $75 \%$ of medical equipment is out of use [3]. In some African countries, up to $80 \%$ of equipment is donated [4]. These 'poisoned gifts' are often completely unusable, having been donated to recipient hospitals with no resources or support. They become a burden on already stretched health systems.

\footnotetext{
${ }^{1}$ The terms developing world and developing countries are used interchangeably in this thesis. For the purpose of this thesis, a developing country is defined as one that has a U.N. Human Development Index (HDI) ranking in the medium to low category [2].
} 
So dire is this situation that the World Health Organisation (WHO) has identified the low health technology management (HTM) capacity of most developing countries as a critical barrier to achieving the United Nations health-related Millennium Development Goals (MDGs) [1]. The eight MDGs, which include combating HIV/AIDS, malaria and other diseases and increasing maternal health, represent a comprehensive blueprint for global poverty reduction agreed by to the majority of the world's countries and international development organisations [5]. For the world's poorest, the critical importance of better health technology management cannot be overstated.

\subsection{Motivation}

Research into clinical engineering and HTM practices has grown significantly over the past three decades, yet the vast majority of literature studies the developed world. In 2004, Cao and Frize performed the first survey of clinical engineering departments (CEDs) exclusively in the developing world [6]. This research profiled the state of CED services in Latin America and Asia. Africa, however, was not profiled ${ }^{2}$. Nor was the sample size of 64 deemed statistically significant to test the hypothesis that Frize's model for CE effectiveness within developed world hospitals can be applied, with modification, to developing world hospitals.

Frize's CE effectiveness model was the first to establish a causal relationship between indicators of a hospital's organisational climate and the effectiveness of its CED; it has yet to be statistically validated in developing world hospitals. And while it is widely accepted that $\mathrm{CE}$ effectiveness within hospitals (i.e. the output of the model) has an impact of the state/functionality of medical equipment, which in turn

\footnotetext{
${ }^{2}$ Despite facing the most severe health burdens and health system challenges, Africa has yet to be adequately profiled in any international study of $\mathrm{CE}$ services.
} 


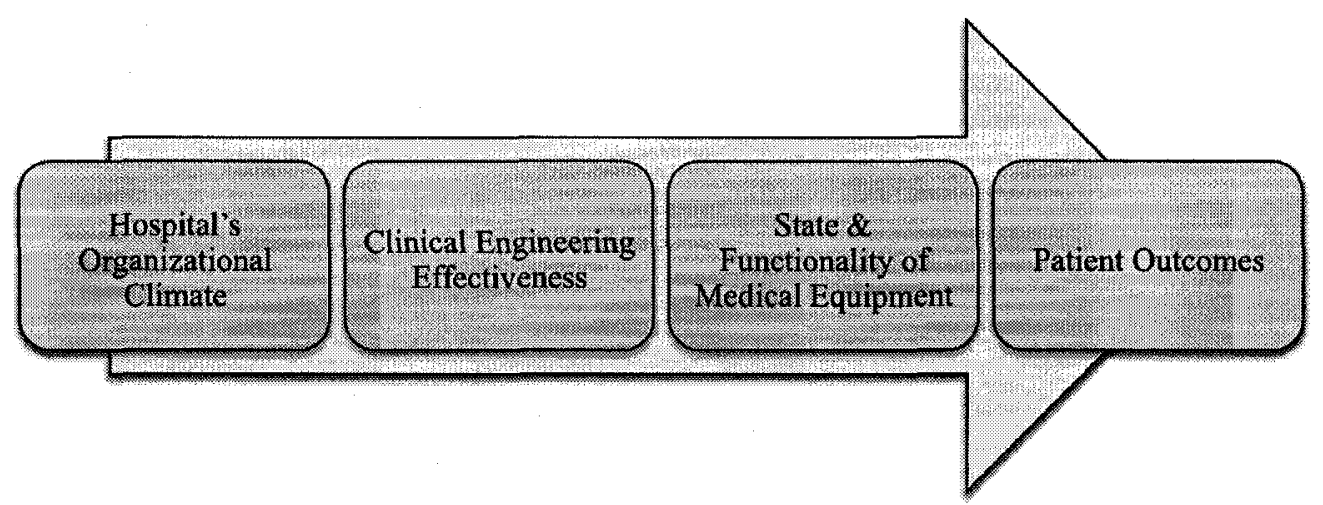

Figure 1.1: Relationship between CE Effectiveness and Patient Outcomes

impacts patient outcomes in the hospital, this relationship has yet to be studied in a developing world context either. The theoretical relationship between these four constructs is illustrated in Figure 1.1. Studying these relationships in the developing world provides the motivation for this research.

\subsection{Problem Statement}

Based on these motivations, this thesis will attempt to answer three questions:

1. What is the state of CE services, medical equipment, and procurement and donation practices in developing country hospitals worldwide?

2. Is Frize's model for CE effectiveness in developed world hospitals valid, with modification, in developing world hospitals?

3. What is the relationship between $\mathrm{CE}$ effectiveness indicators and the state of medical equipment in hospitals in the developing world? 
Two null hypotheses are derived from these problem statements that will be addressed by this work:

1. Frize's model for CE effectiveness in developed world hospitals is valid, with modification, in developing world hospitals.

2. A relationship between $\mathrm{CE}$ effectiveness indicators and the state of medical equipment in hospitals in the developing world exists.

\subsection{Thesis Objectives}

The first objective of this thesis is to develop a comprehensive, appropriate data collection tool to measure $\mathrm{CE}$ effectiveness, the state of medical equipment and equipment procurement and donation practices in developing world hospitals. This tool will be used to collect data for this research and to build a database of these metrics for use by future researchers as well.

The second objective of this thesis is to collect a statistically significant amount of data using this tool from health technology managers working at primary and secondary care hospitals in the developing world. This data will be used to assess the level of $\mathrm{CE}$ service development, the state of medical equipment, and procurement and donation practices within these hospitals. Regional trends and differences will be presented.

The third objective of this thesis is to use this data to test the hypothesis that Frize's CE effectiveness model for hospitals in the developed world is also appropriate, with modification, for the developing world. The model will be tested for validity and if deemed valid, refined to reflect the developing world context. 
The fourth objective of this thesis is to develop a preliminary model for the relationship between $\mathrm{CE}$ effectiveness metrics and the state/functionality of medical equipment in developing world hospitals. This preliminary work can be used by future researchers to further study how $\mathrm{CE}$ effectiveness metrics influence the state of medical equipment in developing world hospitals.

\subsection{Thesis Outline}

This thesis is divided into seven chapters:

Chapter 1 has presented the research motivation, problem statement and objectives. Chapter 2 presents a background of clinical engineering, health technology management and their application in the context of developing world hospitals.

Chapter 3 presents a literature review of clinical engineering effectiveness, international studies of clinical engineering departments, profiles of $\mathrm{CE}$ services in specific developing countries and models designed to guide the application, diffusion and maintenance of medical equipment in the developing world.

Chapter 4 presents the research methodology for this work. It briefly covers exploratory field research undertaken in Africa and the ethics protocol for this work. The chapter then presents the metholodolgy for the three main phases of work: primary data collection from developing world participants with a novel research instrument, data preparation, and statistical data analysis to meet the research objectives. Chapter 5 presents a detailed description of the state of CE services, medical equipment, and procurement and donation practices from the sample of 207 health technology managers in developing world hospitals profiled.

Chapter 6 presents a quantitative analysis of the two hypotheses of this thesis. A 
refined model for $\mathrm{CE}$ effectiveness in developing world hospitals is presented, as are the preliminary results of a study of the relationship between CE effectiveness metrics and the state of medical equipment. Limitations of this research based on data collection methodology are also outlined.

Chapter 7 presents conclusions drawn from the research, and outlines contributions to knowledge and future work. 


\section{Chapter 2}

\section{Clinical Engineering and Health Technology Management}

This chapter presents background information on clinical engineering and health technology management. Both the history of clinical engineering and a model clinical engineering department are presented, followed by a discussion of health technology management and its economic consequences. These two concepts are presented in the developing world context, where the following challenges are especially acute: equipment maintenance, human resources, training, resources, budgeting, infrastructure and policy. Finally, this chapter presents current global initiatives aimed at overcoming these challenges.

\subsection{Clinical Engineering}

The American College of Clinical Engineers defines a clinical engineer (CE) as "a professional who supports and advances patient care by applying engineering and 
managerial skills to health care technology" [7]. The field has evolved greatly since the 1960s when it emerged in Canada and the United States in response to the increasing amount of technology used to deliver health care. These original clinical engineers were primarily concerned with patient safety with respect to medical devices, and their acceptance rates among nurses and doctors were very low [8], [9].

Clinical engineering departments (CEDs) began to emerge in hospitals in the early 1970s, and CEs became interested in equipment acquisition, user training, and user education. In the 1980s, budget restraints in health care spending saw CEs become more involved in pre-purchase consultation and the evaluation of new technologies. At the same time, the proliferation of new information management technologies introduced management software for CEDs to manage both their departmental responsibilities and their equipment inventory. By the 1990s, many CEs were also involved in research and development activities and comprehensive technology assessments. Thus, clinical engineering evolved to a profession of health technology managers, overseeing the management of a hospital's health technologies throughout their entire life cycle and performing high level technology planning [10].

\subsubsection{A Model Clinical Engineering Department}

Clinical engineering departments (CEDs) emerged somewhat independently in the 1970s and 1980s, and there still exists variability in the profile of CEDs between hospitals and across countries and regions of the world. A model CED has all resources needed to most effectively accomplish its responsibilities. The most necessary resources have been identified as [11], [12]:

- Staffing - adequate staffing of both CEs and biomedical equipment techni- 
cians/technologists (BMETs)

- Training - training of staff both prior to employment in the CED, and 'on the job' training which has been identified as a strong retention tool

- Space - administrative space, adequate workspace and storage space for equipment inventory

- Computerised Maintenance and Management System - has been identified as the foundation of a successful CE program

- Test Equipment and Tools - adequate to perform maintenance duties

- Communications Equipment - to facilitate communication between CED staff and equipment users, manufacturers and vendors

These resources enable model CEDs to perform these responsibilities effectively; policy leadership has been identified as a critical enabler of well-resourced CEDs. The responsibilities of a successful CED include [11]:

- Corrective Maintenance - substantial involvement in corrective maintenance of the hospital's equipment base

- Preventive Maintenance - routine maintenance of the hospital's equipment base

- Acceptance Testing - performing incoming inspections (IIs) on new equipment acquisitions

- User Training and Education - carried out in cooperation with equipment manufacturers and suppliers 
- Clinical Research and Development - equipment design and modification, developing hospital-specific solutions to technology challenges

- Quality Assurance - evaluating the services of the department

- Productivity Assessment - evaluating staff productivity within the department

Several international surveys have assessed CED effectiveness with respect to these resources and responsibilities [6], [8], [13]. They are presented in Section 3.2.1.3.

\subsection{Health Technology Management}

Health technology management is defined as "a systematic process in which qualified healthcare professionals, typically clinical engineers (with their unique ability to visualise a wide range of systems issues and to determine important linkage and solutions), in partnership with other health care leaders, plan for and manage health technology assets to achieve the highest quality care at the best cost" [14]. Good HTM practices encompass the entire life cycle of devices, shown in Figure 2.1, from planning to acquisition and throughout the cycle to replacement or disposal.

\subsubsection{Health Technology}

The World Health Organisation defines health technology as "all drugs, devices and medical and surgical procedures used in the prevention, diagnosis and treatment of diseases, and for their rehabilitation, including traditional medical technologies; the knowledge systems associated with these; and the organisational and supportive systems within which the care is provided including facilities that house both patients 


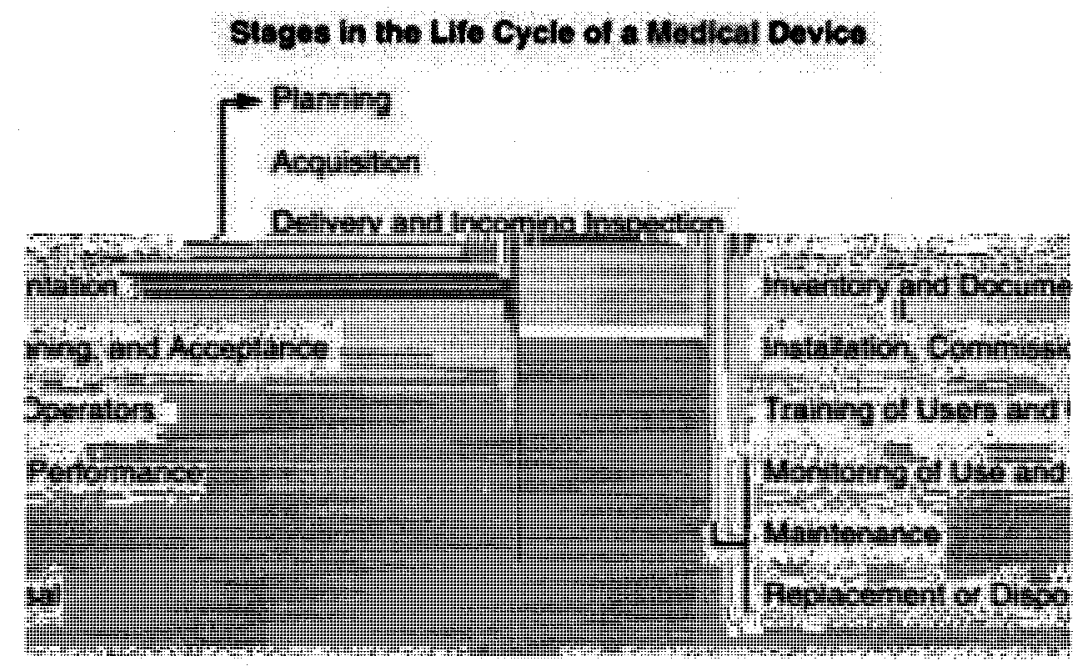

Figure 2.1: Medical Equipment Life Cycle [15]

and products; as well as environmental, food and information technologies; and technologies used in health promotion" [1].

This definition is quite broad, and illustrates the complexities of health technology management and planning. Practically, health technologies can be categorised as either clinical technology or ancillary technology. Clinical technologies consist of medical technologies used in direct patient care. Ancillary technologies consist of all other technologies used to support the provision of healthcare services, including administration, transportation, communication and infrastructure systems both within and among healthcare facilities. [16]. This thesis examines medical equipment ${ }^{1}$ and its management, which is the primary responsibility of CEDs.

\footnotetext{
${ }^{1}$ From this point onwards, the terms 'health technology' and 'medical equipment' are used interchangeably in this thesis.
} 


\subsubsection{The Economic Impact of Poor HTM}

HTM activities typically consume more than $20 \%$ of health care capital expenditures [14], and the importance of effective HTM cannot be overstated. In 1998, the WHO analysed case studies of HTM practices in over 20 developed and developing countries to demonstrate the quantitative impacts of HTM on health care costs [17]. Table 2.1 presents the results of this analysis.

The WHO estimated the economic losses of $15 \%$ of out of service equipment in the developing world at $\$ 12.8$ billion US annually, or $22 \%$ of the total health spending in the WHO's African region [1]. Considering that $50-75 \%$ of equipment is out of use in the developing world [3], the economic losses are immense.

Table 2.1: HTM Impacts on Health Care Provision [17]

\begin{tabular}{|l|c|}
\hline System Element & Cost (or Time) Savings \\
\hline Medical Devices & $20-30 \%$ \\
\hline - Maintenance & $10-20 \%$ \\
\hline - Reduced investment through plannning & $(2-4$ weeks) \\
\hline - Reduced development time for acquisition specifications & $10-90 \%$ \\
\hline - Appropriate technology introduction & $10 \%$ \\
\hline - User training, reducing maintenance & \\
\hline Health Facilities & $10-20 \%$ \\
\hline - Reduced investment through planning & $20 \%$ \\
\hline - Utilisation of ambulatory care & $20 \%$ \\
\hline - Utilisation of impatient care & $50 \%$ \\
\hline - Utilisation of diagnoses and treatment & \\
\hline Health Delivery System Processes & $20 \%$ \\
\hline - Chronic disease treatment & $10-20 \%$ \\
\hline - Supplies and logistics process redesign & \\
\hline
\end{tabular}




\subsection{CE and HTM in the Developing World}

Despite the fact that health technologies account for a high proportion of healthcare expenditure, the majority of developing countries do not recognise the management of medical devices as a public health priority [18]. Considering the immense and immediate public health and health system challenges in the developing world, this is not surprising.

The emphasis imbalance between attention paid to medical equipment and pharmaceuticals in developing countries exemplifies this. For example, in one Latin American country with a stock of equipment valued at $\$ 5$ billion USD, $40 \%$ of the equipment is out of use, representing a loss of $\$ 2$ billion US dollars. The pharmaceutical program in the country receives far more attention from policy makers, the public and the media - and it has an annual operating cost of several hundred million US dollars [1]. Similarly, in one African nation there was a public outcry when one year's worth of drugs valued at $\$ 3$ million US dollars had to be destroyed because their expiry date had passed. At the same time in the country, thirty times that value of medical equipment was out of use ( $\$ 90$ million US dollars), yet this received little attention by the public, the media or policy makers [1].

\subsubsection{Public Health and Health Systems}

Public health status in the developing world is much poorer than in the developed world. Disease burdens are immense and often present themselves in the absence of functional health care systems. In 2006, malaria, tuberculosis and AIDS claimed 6 million lives worldwide [19], and malnutrition claims the lives of 6.5 million children annually [20]. In many Sub-Saharan African countries, life expectancy has fallen by 
up to 15 years in the last decade due in part to HIV AIDS, and across the continent tuberculosis rates have been increasing steadily since 1980 [21]. Infant and maternal mortality rates are high, and healthy life expectancy years in the developing world are often less than half those in the developed world [22].

There is no 'one size fits all' description of developing world health systems, and many developing countries do have world class teaching hospitals in major urban centres. However, many challenges characterise the majority of health systems in the developing world: high disease burdens; chronic underfunding; human resource shortages; technical resource shortages; poor infrastructure and a huge rural/urban divide. Additionally, health technology diffusion into rural areas is often lacking or very inappropriate ${ }^{2}$. In Ghana, for example, Quaye determined that $85 \%$ of health expenditures were made at the secondary and tertiary care levels to service only $10 \%$ of the population. The $90 \%$ of the population that is served by primary health care - where simple, cheap technologies can have the greatest impact - received only $15 \%$ of total expenditures [23].

Health care is also increasingly being delivered by non-state actors, i.e. national and international development agencies, non-governmental organisations and the private sector, in the absence of functional health care systems [24]. In 1987, the WHO estimated that $80 \%$ of medical equipment in some developing countries was financed by bi- and mulit-lateral aid agencies [25]. More recently, in 2006 the Bill and Melinda Gates Foundation had an operating budget greater than that of the entire World Health Organisation [24]

\footnotetext{
${ }^{2}$ Appropriate technology is defined as: being scientifically sound and acceptable to those who apply it and to those for whom it is used [16].
} 


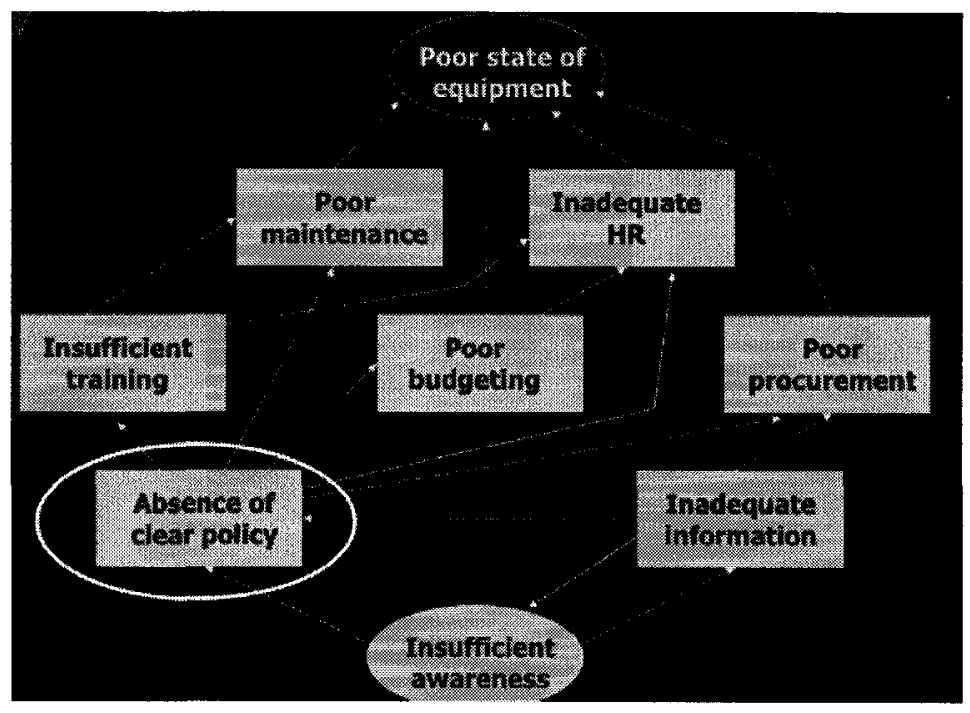

Figure 2.2: Health Technology Management Problem Tree [1]

\subsubsection{CE and HTM Challenges}

Many factors contribute to poor health technology management, and are especially acute in the developing world. These challenges are best illustrated in Figure 2.2.

\subsubsection{Poor Maintenance}

Effective equipment maintenance is fundamental to a hospital's ability to deliver health care and is the most common responsibility of CEDs in the developing world. However, without trained maintenance technicians, equipped with manuals, resources and support, maintenance is incredibly poor. A World Bank study of equipment maintenance budgets in public hospitals in Nigeria, Tanzania, Guinea-Bissau and Malawi concluded that a disproportionately small budget was allocated for equipment maintenance, despite the fact that properly maintaining existing equipment is much more economical than purchasing new equipment when unmaintained equipment falls 
into disrepair [6].

\subsubsection{Inadequate Human Resources}

The developing world is sorely lacking adequate numbers of health technology professionals. CEs and BMETs are both in short supply. The majority of technicians have no previous training in biomedical technology, and therefore training of HT professionals is of utmost importance to effective HTM. Doctors and nurses - the users of equipment - are also in short supply in much of the developing world. WHO statistics cite the lowest figures for the developing world as one doctor and five nurses per 10,000 inhabitants; in the developed world, figures are typically 20 doctors and 50 nurses per 10,000 inhabitants [26].

\subsubsection{Insufficient Training}

Technology user training is generally poor and results in the abuse of equipment by operators. Improper use and maintenance of equipment reduces the lifetime of a device by $30-80 \%$ [1]. Training of CEs and BMETs in the developing world is also low, and is one of the highest priorities of global HTM capacity building initiatives, which are outlined in Section 2.3.3. While universities in several developing countries, including Brazil, Mexico, China and South Africa, have offered undergraduate and graduate programs in clinical engineering for over 15 years, the majority of developing countries lack education in the area, and $\mathrm{CEs}$ are often trained elsewhere [6]. The Gambia, for example, does not have a single bachelor degree program for engineering; the highest technical education Gambians can receive within their own country is a three year electronics technician program from the Gambian Technical Training Institute. 


\subsubsection{Resources}

Many developing world hospitals lack basic resources for equipment maintenance such as maintenance manuals, user manuals, spare parts and test equipment. Basic operational resources, such as reagents and accessories, are also lacking, thus rendering the equipment unusable regardless of its state. Study results on resources are presented in Section 3.2.1.3.

\subsubsection{Poor Budgeting}

Most developing countries do not spend more than $0.5-1.5 \%$ of their Gross National Product (GNP) on health care; in developed countries, between 5 and $14 \%$ is spent on health care [6]. With the immediate disease burdens and human resource crises outlined above, it is not surprising that medical equipment spending accounts for a very small proportion of health spending in the developing world. Globally, only $7 \%$ of spending on medical equipment is done by developing countries, who account for the majority of the world's population [6].

An additional challenge is the inadequate budgeting for health technologies across their entire life cycle. Often only capital costs of equipment are considered, yet the majority of costs associated with a device occur as a result of service contracts or maintenance costs; this is known as the medical device acquisition iceberg, illustrated in Figure 2.3.2.5. For many devices, the cost of accessories and reagents are much larger than the capital cost of the device. A WHO life cycle cost assessment of an anesthesia machine, for example, determined that $50 \%$ of the total operating cost was spent on device consumables; capital cost accounted for only $18 \%$ of the total, and maintenance $(16 \%)$, staff $(13 \%)$ and overhead $(3 \%)$ accounted for the rest [1]. 


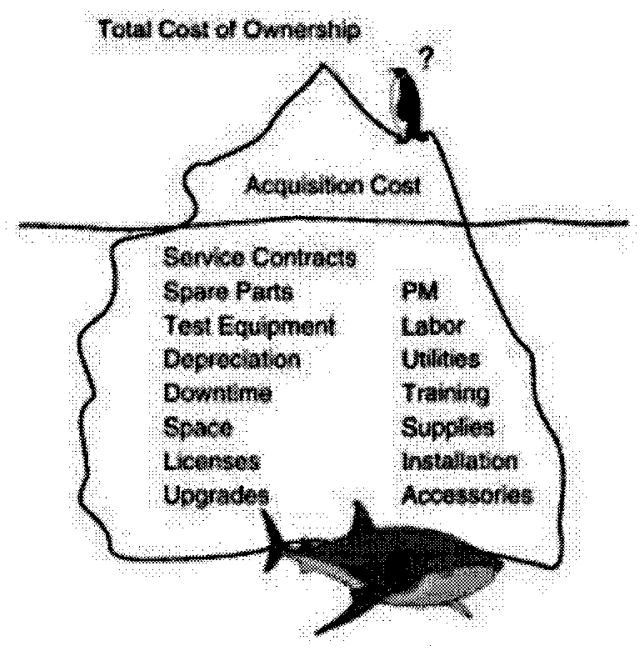

Figure 2.3: Medical Equipment Acquisition Iceberg [15]

\subsubsection{Poor Procurement}

Appropriate technology introduction can save between 10 and $90 \%$ of a medical device's total cost [14]. But poor procurement is one of the biggest challenges facing effective health technology management. Ideally, procurement occurs through consultation with technology users, clinical engineers, hospital administrators and other stakeholders and is based on clinical need and rigourous life cycle cost analysis. In reality, equipment acquisition is often done in the absence of consultation with health technology managers and is highly political. Hospitals are told what they need by development organisations; hospital administrators choose equipment based on politics and relationships with manufacturers; and equipment is donated with no consultation by organisations in the developed world. It is estimated that $80 \%$ of donated equipment is out of use in the developed world [4]. 


\subsubsection{Weak Infrastructure}

The state of infrastructure is poor in much of the developing world. Power and communications infrastructure are unreliable and largely concentrated in urban areas. While $90 \%$ of internet users worldwide are in developed countries, Africa and the Middle East combined account for only $1 \%$ of internet users worldwide [6]. Critical hospital infrastructure - power, communications, medical gases, water, sterilisation, refrigeration and heating, ventilation and air conditioning (HVAC) pose immense challenges to the functionality of medical equipment. In developing world hospitals power cuts are not a matter of 'if', but of 'when', 'how often' and what will be affected. Unreliable infrastructure also underscores the need for more appropriate, simple health technologies that are less infrastructure-dependent, such as improved diagnostic technologies designed for the developed world. The global health impact of these technologies is assessed by the Bill and Melinda Gates Foundation, and grouped into infrastructure development specific categories [27].

\subsubsection{Absence of Clear Policy}

The absence of a clear health technology policy, both at a national level and a hospital level, results in the uncoordinated non-evidence based introduction of technologies into health systems. The purpose of a national health technology policy is to define national priorities for health technology management that improve health system performance, and to formulate strategies for the safe and effective introduction, Utilisation and management of health technologies into the system. A robust health technology policy addresses the challenges presented in the HTM problem tree. Many developing country health ministries have created national health technology policies with the assistance of the WHO and PAHO [28]. 


\subsubsection{Current Global Initiatives}

Many partnerships between the developed and the developing world exist which are improving HTM capacity in the developing world. The main coordinating agency for many of these initiatives is the WHO's Health Technology and Facilities Planning and Management Division in the Department of Health Policy, Development and Services.

\subsubsection{The Integrated Health Technology Package (iHTP)}

The WHO's iHTP is a resource planning methodology and tool that provides guidance on a mix of health technologies needed for critical healthcare interventions that is specific to the local needs and conditions of a health system. It is a unique planning tool because it links all possible resource information healthcare needs, disease profiles, patient demographics, clinical practice, technology requirements, availability and constraints, and system capacity to produce the healthcare technologies required to deliver an intervention. To date, iHTP has been implemented in over fourteen developing countries worldwide and the tsunami affected area of Banda Aceh, Indonesia. Improvements to the tool are ongoing; it is currently being translated into many languages, and packages based on the WHO's Technical Programs are being created, including: Making Pregnancies Safer, Integrating Management of Childhood Illnesses, Rural Health Research, District Surgery, Malaria, HIV/AIDS, and TB) [29].

\subsubsection{The International Federation of Medical and Biomedical Engi- neers (IFMBE)}

The IFMBE is an international federation of individuals and organisations working in the medical and biomedical engineering field. It's mission is to support these members worldwide in the pursuit of the application of technology to safe and effective health- 
care. The IFMBE also includes several divisions and working groups, including the Division for Clinical Engineering and the Working Group for Developing Countries, both of which are active in HTM promotion in the developing world. [30]

\subsubsection{Advanced Clinical Engineering Workshops (ACEWs)}

The American College of Clinical Engineers (ACCE) has conducted more than 40 ACEWs in developing countries over the last 10 years. The workshops educate clinical engineers and other health technology managers about HTM systems in the U.S. and create networks between ACCE members and workshop attendees. [4]

\subsubsection{Global Assistance for Medical Equipment (GAME)}

The GAME program is a WHO-supported global coalition of clinical engineering and technicians devoted to addressing the HTM needs of resource-limited countries, specifically those who have hosted ACEW workshops and therefore have an HTM knowledge base and open policy environment. GAME's first program began in Kosovo in 2004. It included a one week HTM training course, a country-wide health technology assessment, and recommendations for capacity building. Several GAME programs are planned for East African countries in 2008. [31]

\subsubsection{International Centre for Health Technology Management (ICHTM)}

Based at the University of Cape Town in South Africa, the ICHTM is a global centre for networking and resource sharing between HTM professionals from around the world. ICHTM and the WHO host INFRATECH, which is an online discussion forum for HTM professionals from around the world, with a strong presence in developing countries. [32] 


\section{Chapter 3}

\section{Literature Review}

This chapter presents the literature review for this work. Three main topics are covered: clinical engineering effectiveness, studies of clinical engineering worldwide, and models for the acquisition, diffusion and maintenance of medical equipment in developing countries. Within each of these topics, literature and models by several authors are presented.

\subsection{Clinical Engineering Effectiveness}

Since the beginning of the clinical engineering profession, CEs have struggled with how to measure their departments' productivity and effectiveness, thus proving their usefulness within their hospital. Several models for clinical engineering effectiveness have been proposed in the literature.

In 1986, David and Rohe presented a model for measuring the effectiveness of a clinical engineering program through productivity measurements [33]. Factors which influence productivity (i.e. the outputs) in their model included: 
- integration into the decision-making process surrounding acquisition and standardisation

- integration into the facility management process

- marketing surplus skills to other organisations

- involvement in nurse training programs with respect to equipment

- providing growth opportunities for employees

- encouraging employee problem-solving and method improvement techniques

- encouraging cross-training of specialties

- providing sufficient employee training

- defining and following operational policies and procedures

- establishing a comprehensive system of communication for transferring and filtering information

- matching and balancing workload demand with staffing availability

- providing useful information to management

- planning HR to meet expected equipment turnaround times

- identifying the appropriate levels of preventive maintenance

- evaluating maintain-vs-replace decisions

- inspecting quality of work performances 
- setting priorities for incoming work

- balancing the need for equipment turnaround and cost of staff idleness

- optimising the automation process to secure information while alleviating administrative work for technicians

- optimising client relations and communications

David and Rohe proposed monitoring the outputs of these factors through performance indicator reports, which included metrics to quantify quality of work, productivity of staff, labour recovery, repair turnaround days, and attendance factor. They also proposed methods for CEDs to create strategic plans for productivity improvements, based on these factors and output metrics in the unique context of individual CEDs [33].

In 1989, Frize proposed a model to measure the effectiveness of Canadian CEDs in her doctoral thesis [13], [11], [34]. The model is comprised of system inputs or indicators that reflect the organisational climate of the institution, and outcomes which measure $\mathrm{CE}$ effectiveness and are a result of the climate. These system inputs and outcomes are presented in Figure 3.1.

Frize's model was refined and validated by the results of her doctoral research, which are presented in Section 3.2.1.1; the first to test a model of effectiveness in an international study.

\subsubsection{Benchmarking Effectiveness}

Several studies in the 1980s and 1990s attempted to produce a valid benchmark for CED effecitiveness. Cohen et al. proposed five criteria for a 'good' benchmarking 


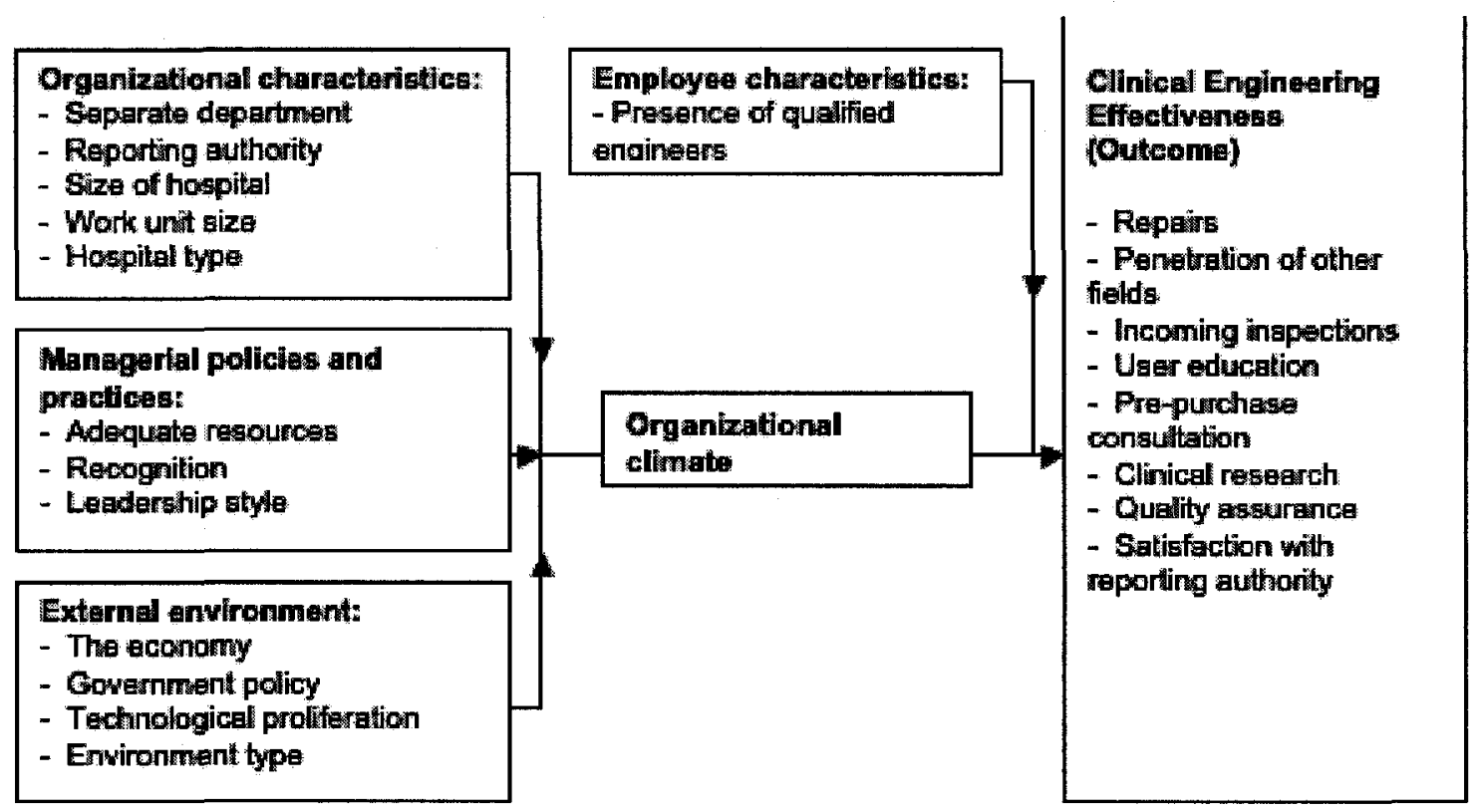

Figure 3.1: Model of CED Effectiveness [13]

metric [35]:

1. Well defined (i.e. accurately and consistently defined to allow data collection at multiple sites by multiple people)

2. Objective (i.e. factual without subjective influence)

3. Measurable (i.e. can be quantified)

4. Based on current knowledge and experience (i.e. known to practitioners in the field without requiring academic research)

5. Valid (i.e. have a direct relationship with the structure, process, or outcome that is being measured)

These studies all concluded that the most valid, and only overall 'good' benchmark metric for CED effectiveness and productivity was a purely financial one that 
determines the ratio of total CED expenses and total equipment acquisition costs [36]:

$$
\text { value }=\frac{\text { total } \mathrm{CE} \text { expenses }}{\text { total equipment costs }}
$$

In the mid 1990s, the Association for the Advancement of Medical Instrumentation convened a subcommittee on benchmarking validation to explore the possibility of establishing a uniform benchmarking standard across the CE profession (in the U.S.) that included a measure of quality. The goal of the committee was to find an effectiveness metric that integrated both cost and quality:

$$
\text { value }=\frac{\text { quality }}{\text { cost }}
$$

The subcommittee wasn't able to achieve consensus on a single metric, and instead suggested several, including 'failure rate vs. hours per device maintained' and 'failure rate vs. cost per device maintained'. They collected and analysed data from 13 hospitals over two years to test these two quality metrics. Their results showed a very poor correlation between the number of work orders and the total number of devices (correlation coefficient of 0.15) [37], and they eventually concluded that the the only reliable metric was the standard financial metric (i.e. equation (3.1)) [37]. The results of this study produced skepticism among the CE community about valid quality-based metrics [38], [39], and very little research was conducted for the next decade. 
In 2006, Wang et al. revisited the quality metric problem, theorising that a larger data set would yield a stronger correlation between the number of failures (as measured by completed work orders) and the total number of devices in a one year period. They used three different data sets from a total of 116 U.S. hospitals to test their hypothesis, and Cohen's original data set [40]. Wang et al. found a much stronger correlation between number of device failures and total number of devices. The mean correlation coefficient for the entire data set (i.e. all four data sets) was 0.76 , compared with the AAMI's subcommittee result of 0.15 with a significantly smaller data set. Thus the 'global failure rate' metric was established:

$$
\text { global failure rate }=\frac{\Sigma \text { completed repair work orders }}{\Sigma \text { total devices }}
$$

For example, a GFR of 0.28 denotes 0.28 failures/device/year. The GFR metric was tested for three categories of medical equipment - imaging, laboratory and biomedical equipment ${ }^{1}$. Linear correlation was significantly stronger for biomedical equipment than imaging equipment or laboratory equipment. The authors attribute this difference to the complexity of interactive components in imaging systems at one end and the simplicity of the majority of lab devices at the other end (with the exception of sophisticated analysers). Additionally, lab technicians routinely perform preventive maintenance of their own equipment, skewing the failure rate [37].

The GFR provides a benchmark based partially on quality, and is therefore an outcome metric that measures the 'output' of a CED, i.e. in terms of equipment failures, compared to prior metrics which traditionally measured operational or process

\footnotetext{
${ }^{1}$ Biomedical equipment in [37] is what is referred to as 'medical equipment' in this thesis; the primary responsibility of CEDs.
} 
metrics of the the department.

Wang et al. also recommend a GFR type metric to measure CED efforts invested in equipment acquisition and planning, preventive maintenance, user training and controlling environmental factors, in addition to equipment repair activities. While the results were promising, the authors cautioned against using GFR as a sole metric for benchmarking; instead it should be used in conjunction with other financial and operational metrics to produce a balanced scorecard.

In early 2008, Wang et al. analysed operational and financial CED data from 253 acute care hospitals in the U.S. to determine additional, statistically valid metrics for measuring, monitoring and improving CED performance [41]. While their results are preliminary, they found a ratio of 2.5 CED employees per 100 beds to be ideal, and that only larger departments have and require additional administrative support (i.e. personnel) within the department. The majority of $\mathrm{CE}$ budgets were spent on service contracts; only $20 \%$ on average is spent on internal labour. The ideal maintenance workload was reported as one repair per device per year (i.e. a GFR of 1.0); the rate was higher for imaging equipment and lower for laboratory equipment, supporting their previous findings [37]. The traditional financial benchmark (i.e. equation (3.1)) was found to be ideal at $4 \%$. Based on their results, Wang et al. present a scorecard for assessing effectiveness, presented in Figure 3.2.

\subsection{Clinical Engineering Worldwide}

\subsubsection{International Surveys}

Several studies have been conducted to explore the state of clinical engineering worldwide: $[13],[8],[6],[42]$ and most recently [43]. Table 3.1 presents the regional coverage 


\section{Operational (internal process)}

1.1 Scheduled maintenance completion rate

1.2 Percentage of repairs completed within 24 hours and 1 week

1.3 Full time employees / number of capital devices

1.4 Number of scheduled maintenance / number of capital devices

\section{Staff (learning and growth)}

2.1 Staff turnover rate

2.2 Percentage of CE budget devoted to training

2.3 Staff qualification and competency

2.4 Employee satisfaction score

\section{Customer}

3.1 Customer satisfaction score

3.2 Global failure rate (GFR) and group failure rate for high-risk equipment

3.3 Uptime for mission critical equipment

3.4 Percentage of equipment-related patient incidents

\section{Financial}

4.1 Total CE expense as a percentage of total acquisition cost (equation (3.1))

4.2 Total CE expense per adjusted patient discharge and/or patient day

4.3 Total CE expense per staffed patient bed

4.4 Total CE expense as a percentage of hospital total operating cost

Figure 3.2: Scorecard for Benchmarking [41] 
each study, using the following regional codes: NA=North America, EUR=Europe, $\mathrm{NOR}=$ Nordic Countries, $\mathrm{AUS}=$ Australia, $\mathrm{LA}=$ Latin America, AFR=Africa, and $\mathrm{OTH}=$ Other.

Table 3.1: Summary of International CE Surveys [13], [8], [6], [42], [43]

\begin{tabular}{|l|c|c|c|c|c|c|c|c|c|}
\hline Author(s) & \multicolumn{7}{|c|}{ Responses by Region } & Total \\
\cline { 2 - 9 } & NA & EUR & NOR & AUS & LA & AS & AFR & OTH & \\
\hline Frize [13] & 78 & 20 & 18 & - & - & - & - & - & 122 \\
Glouhova et al. [8] & 45 & 43 & 18 & 8 & 16 & - & - & - & 130 \\
Cao and Frize [6] & - & - & - & - & 27 & 34 & - & - & 61 \\
ACCE [42] & 116 & - & - & - & 4 & 2 & - & 14 & 136 \\
IFBME [43] & 54 & 150 & - & - & 307 & 44 & 5 & - & 559 \\
\hline
\end{tabular}

\subsubsection{CE in the Developed World (Frize, 1988)}

Frize's study [13] was performed in 1988 to evaluate the level of functional involvement of CEDs in the technology management process within Canadian hospitals, and to study the effect of specific organisational factors on their effectiveness. Her null hypothesis was that the degree of CE effectiveness in Canadian hospitals (and comparatively in other developed country hospitals) is influenced by organisational factors which contribute to the climate of the institution.

These organisational factors are the inputs in the system model presented in Figure 3.1. Inputs (i.e. independent variables) studied were: existence of the unit as a separate department, organisational size, work-unit size, hospital type, staffing level in the CED, authority to whom CEDs report to, education level of the staff, and recognition achieved within their institution. Outputs of the model (i.e. dependent variables), used to determine the degree of substantial involvement of the CED in 
equipment management support within the hospital, were: substantial repairs on medical equipment, penetration of other fields, incoming inspections, user education, substantial level of consultation, $10 \%$ or more staff involved in research and development, performing quality assurance, assessing productivity of staff, and satisfaction with reporting authority.

Frize collected a total of 122 replies to her questionnaire, distributed regionally as follows: Canada (41), the U.S. (37), Europe (mainly from France, the Netherlands and the UK) (20), and the Nordic countries (18). Her results cover the following areas: organisational setting, functional involvement, recognition, budgets, staffing, resources and financial strategies [11], [34]. Based on analysis performed on these results, her null hypothesis was accepted.

\section{A. Organisational Setting}

The majority of respondents were from teaching hospitals, with the exception of the U.S. which had $47 \%$ teaching institutions. Teaching institutions generally supported more equipment (based on value of equipment supported in U.S. dollars) than their non-teaching counterparts. This was partially accounted for by the fact that teaching institutions has a higher proportion of intensive care beds, which are more technologyintensive; it also corroborated previous studies within the U.S. which determined that teaching hospitals typically spend six times as much on equipment as non-teaching hospitals. The majority of respondents also stated that their departments existed as a separate entity within the hospital $(86 \%)$, which was linked to the reporting authority (i.e. $95 \%$ of departments that reported to a senior administrator existed as a separate unit, while one third who reported to a Plant Operations manager did not). Existence as a separate unit was also found to have a positive correlation with 
their satisfaction with their reporting authority. There was no standard reporting structure for CEDs.

\section{B. Functional Involvement and Responsibilities}

Frize defined significant functional involvement for each activity type, including: corrective maintenance, acceptance testing, user training and education, pre-purchase consultation, clinical research and development, quality assurance and staff productivity. This data is presented by region in Table 3.2 .

Table 3.2: Levels of CED Functional Involvement [11]

\begin{tabular}{|l|l|c|c|c|c|}
\hline \multirow{2}{*}{ Activity } & Significant FI Level & \multicolumn{4}{|c|}{ Regions } \\
\cline { 3 - 6 } & & Canada & U.S. & EEC & Nordic \\
\hline Corrective Maintenance & $>75 \%$ in house repair & $96 \%$ & $83 \%$ & $56 \%$ & $59 \%$ \\
\hline Acceptance Testing & $>75 \%$ new equipment & $91 \%$ & $100 \%$ & $50 \%$ & $67 \%$ \\
\hline User Training \& Education & $>75 \%$ of hospital's needs & $12 \%$ & $37 \%$ & $6 \%$ & $44 \%$ \\
\hline Pre-purchase Consultation & $>75 \%$ of new acquisitions & \multicolumn{3}{|c|}{ varied by equipment type } \\
\hline Clinical R \& D & $>10 \%$ of staff time & $19 \%$ & $30 \%$ & $42 \%$ & $14 \%$ \\
\hline Quality Assurance & for $>$ one year & $35 \%$ & $53 \%$ & $15 \%$ & $29 \%$ \\
\hline Staff Productivity & for $>$ one year & $35 \%$ & $53 \%$ & $15 \%$ & $29 \%$ \\
\hline
\end{tabular}

\section{Recognition}

In Canada, 38\% of respondents felt recognised by their institution. Comparatively, in the Nordic countries the figure was $44 \%$; in the U.S. it was 54\%; in the EEC it was 70\%. Recognition appeared to be correlated with reporting authority and also with the level of pre-purchase consultation undertaken.

\section{Staffing and Education}


The majority of respondents reported needing more staff (63\%). In Canada, 39\% reported needing more engineers, $53 \%$ reporting needing more technicians, and $39 \%$ needed more clerical staff. These figures were comparable in the EEC and Nordic countries, and lower in the U.S. Twenty-nine percent of Canadian respondents reported CEDs without an engineer with a university education; the figure was lower in the three other regions. In CEDs with engineers, the majority hold either an M. Sc. or a PhD. The majority of technicians (65\%) have completed a two-year technical program. Another $18 \%$ had completed a four-year technical program.

\section{E. Resources}

Respondents also reported their levels of test equipment, spare parts inventory and space allocation. The U.S. had the most significant stock of spare parts, with $28 \%$ stock for more than $1.5 \%$ of their equipment base, while both the EEC and Nordic countries reported less than $0.5 \%$ of their equipment base for 60 and $65 \%$ of respondents respectively. U.S. respondents also reported the highest rate of test equipment, with $25 \%$ reporting test equipment for more than $1.5 \%$ of their equipment base, while only $3 \%$ and $6 \%$ of Canadian and Nordic respondents reporting the same level of test equipment. The EEC and Nordic respondents reported the largest work unit size, with $47 \%$ and $39 \%$ respectively reporting more than 20 square metres.

\subsubsection{CE in the Developed World and Latin America (Glouhova, 1999)}

In 1999, Glouhova et al. performed a similar survey to Frize's [8]. The purpose of their research was to map the current situation of the field of clinical engineering by different regions and to identify common practices and trends. Four main features of CEDs were analysed: structure, personnel, responsibilities and resources. A total 
of 150 valid responses from six regions were collected and analysed. The regions and respective response rates were: North America (30\%), West Europe (21\%), Nordic Countries (12\%), Latin America (11\%), South Europe (9\%), Australia (5\%), and other $(12 \%)$.

\section{A. Structure}

The majority of responses from all regions came from CEDs that existed as separate units. Most CEDs in developed countries had been in existence for 20 - 30 years, with the exception of Latin America, where most were established in the mid 1980s. Reporting authorities varied significantly within and across regions, however more than $70 \%$ of all respondents were satisfied with their position within the hospital.

\section{B. Personnel}

The educational level of CEs and BMETs varied greatly. A general trend across all regions was that the majority of CED staff were BMETs, however there were significant levels of CE staff in some Nordic and Latin American respondents (even more than BMET staff in some instances). In Europe, many CEs held PhDs; in North America equal numbers held M. Sc.s and PhDs. A trend towards longer educational programs for BMETs compared with Frize's results was noted; in 1988 Frize reported the majority $(65 \%)$ of BMETs completing a two-year technical program, while Glouhova found that $41 \%$ of BMETs were then completing a four year technical program. More than $50 \%$ of the respondents also reported at least one female staff in their department.

\section{Responsibilities}

The number of devices and the equipment value supported per full time equivalent 
staff member was highest in West Europe, followed by North America and Australia. Generally, CEDs in smaller hospitals supported smaller equipment bases (this corroborates many previous studies showing a strong correlation between number of devices supported and hospital size). Ninety-six percent of respondents indicated that they perform corrective and preventive maintenance, and a large majority also performed all other services polled (inventory, pre-purchase consultation, acceptance testing, management of service contracts and education and training), with the exception of risk management, quality control, and research and development, which was the only responsibility a minority of respondents (47\%) reported doing.

\section{Resources}

Respondents were asked to state the value of their test equipment, spare parts inventory and budget, as a percentage of the vale of equipment inventory under the CED's responsibility. However, similar to prior studies, many respondents skipped these questions and large variation in the data was found. This reflected past studies as well; that CEDs often cannot readily provide financial data, even in the developed world. All regions reported needing more BMETs, many needed BMETs more than engineers. The need for more engineers was lowest in North America and Western Europe.

\subsubsection{CE in the Developing World (Cao and Frize, 2004)}

In 2004, Cao and Frize repeated Frize's original survey in developing countries [6]. They received a total of 61 valid responses from nine countries, and grouped them into two regions: Asia (India, Bangladesh, China, Indonesia, Saudi Arabia and South 
Africa ${ }^{2}$ ) and Latin America (Venezuela, Mexico and Brazil). The proportion of respondents from teaching hospitals was $65 \%$ in Asia and $44 \%$ in Latin America. Results were compared with those of Frize and Glouhova to determine the differences between $\mathrm{CE}$ effectiveness in the developed and developing world.

\section{A. Reporting Structure}

In both regions, more than $80 \%$ of departments exist as a separate unit. More than $80 \%$ of respondents also reported being satisfied with their reporting authority, which was distributed as follows: senior administrator (51\%); plant directors (25\%); medical directors $(71 \%)$; and other $(13 \%)$. Those reporting to senior administrators were the most satisfied (91\%) of respondents, while those reporting to medical directors were the least (71\%). This agreed with previous findings from both [13] and [8].

\section{B. Personnel}

Both education levels and staff ratio of clinical engineers to technicians varied greatly by region. In Latin America, staffing was similar to developed countries as found in [13] with technicians making up the majority of the staff. Education levels were also lower than developed world respondents in [13] and [8]; only $6 \%$ of CEs in Latin America and $4 \%$ of CEs in Asia had an M. Sc. or a PhD. A few CEDs in Asia employed more CEs than technicians, while a third employed only technicians.

Latin American respondents had a slightly lower level of education for technicians than Asia. The highest level of education obtained by a technician in Asia was a 3 year technical school program, compared to a 2 year technical program in Latin

\footnotetext{
${ }^{2}$ The sole response from Africa was from South Africa and it was therefore grouped into the Asia region.
} 
America. Generally, both regions reported lower education levels for technicians than the developed world. Ninety percent of respondents trained staff at special centres and/or 'on the job'.

\section{Responsibility}

The number of devices supported and their replacement value was dramatically lower in Latin America and Asia than in previous studies. Both engineers and technicians ranked their activities in the following order, from most time spent to least: repair, incoming inspection, preventive maintenance, user training, pre-purchase consultation, and research. Many respondents reported doing no research, which differed from previous developed country findings.

\section{Resources}

Two thirds of respondents reported inadequate staffing. Technicians were the staff type most in need, especially in Latin America. Thirty percent overall reported inadequate manuals; this figure was higher in Asia (41\%) as compared with Latin America $(15 \%)$. The majority of respondents in both regions reported inadequate test equipment, space allocation and spare parts.

\section{E. Equipment Management}

All Latin American respondents use computers for their equipment management (inventory), while all Asian respondents use manual records. One third who use computers developed the management program themselves (based on generic software). Quality assurance was carried out by $70 \%$ of respondents in both regions. Only $44 \%$ of respondents felt recognised in their hospitals, which was similar to the findings of 
[13] but much lower than the findings of [8].

\section{F. Testing the Null Hypothesis}

The null hypothesis of Cao and Frize's work that was Frize's original model for CE effectiveness (Figure 3.1) was applicable to developing countries as well as developed countries. The response rate of 61 was deemed insignificant for statistical analysis of the null hypothesis, however an analysis was performed nonetheless that resulted in a revised model presented in Figure 3.3.

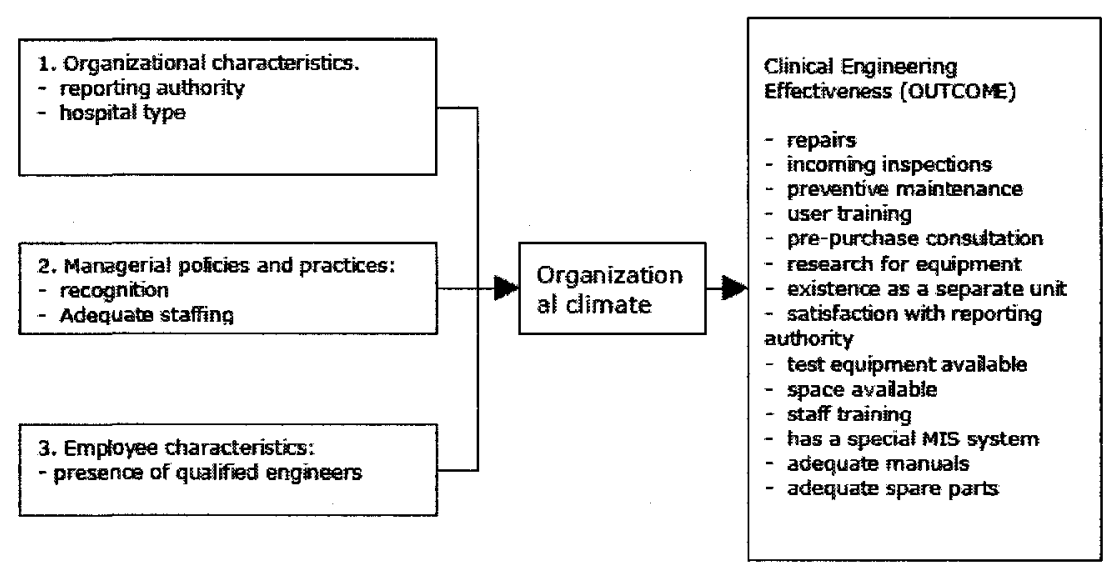

Figure 3.3: Revised Model of CED Effectiveness for Developing Countries [6]

\subsubsection{International Survey of CE Knowledge (ACCE, 2006)}

In 2006, the ACCE conducted an international survey into CE's body of knowledge to determine the scope of CE practice in their day to day work [42]. The results 
were used to aid in designing the Clinical Engineering Certification program. Areas surveyed included: years of experience, current employer, highest degree obtained, knowledge (ranked in terms of day to day importance of different knowledge areas), and responsibilities.

A total of 136 responses were received, 116 of which were U.S. responses. Of the remaining 20, the following developing countries contributed: Bahrain (1), Brazil (1), Lebanon (1), Nepal (1), Pakistan (1) and Venezuela (1), Jordan (1), Chile (2), and Saudi Arabia (4). Thus, the results of this survey mainly reflect the CE body of knowledge in the U.S.

Results showed that more that half of respondents had worked in the CE field for over 20 years ( $36.4 \%$ for $20-29$ years, and another $21.4 \%$ for $30+$ years), and the majority also worked in the health system $(28.5 \%)$ or at a hospital/clinic $(32.6 \%)$. The highest degree obtained was a 6 year degree ( $55.2 \%)$, followed by a 4 year degree (28.5\%). Knowledge required for day to day activities was distributed fairly uniformly over 23 areas. Responsibilities were ranked in terms of the amount of time spent on each major category of work. Results, in order of decreasing percentage of time are:

1. Technology management ( $26.5 \%$ on average)

2. Service delivery management ( $19 \%$ on average)

3. General management ( $16.9 \%$ on average)

4. Risk management / safety ( $10.4 \%$ on average)

5. Education of others (9.6\% on average)

6. Other (9.5\% on average) 
7. Product development, testing, evaluation and modification ( $8.3 \%$ on average)

8. Information technology / telecommunications ( $8 \%$ on average)

9. Facilities management ( $5.4 \%$ on average)

These categories of work were further broken down into specific tasks, such as product and vendor selection, etc. for technology management, to provide a snapshot of what CEs spend their time on. The results show that in the U.S., technology management comprises more than a quarter of $\mathrm{CE}$ workloads, and administration and general management account for almost $1 / 5$ of their daily workload. Very little time is spent on facilities management, demonstrating the separation of facilities and biomedical technologies management in more developed CEDs.

\subsubsection{Worldwide CE Survey (IFMBE, 2007)}

Most recently, the IFBME conducted a survey into CE practices worldwide, to attempt to obtain a clearer picture of similar trends across the world, and differences between regions in order to build on the results of the ACCE's body of knowledge survey (Section 3.2.1.4) [43]. Information was collected on age, employer, years of experience, and activities/responsibilities.

Results published in October 2007 indicated that 559 responses had been received. They were distributed across regions as follows: Latin America (54\%), Europe (27\%), North America (10\%), Asia (8\%) and Africa(1\%, or five surveys). In Latin America, $64 \%$ of respondents were from Brazil, and an additional 22.3\% were from Mexico.

The majority of respondents were between 30 and 49 years old (63\%); specifically for Latin America and Asia, $66 \%$ and $63 \%$ were in this age bracket. The North American demographic was older: $63 \%$ of respondents were 50 or older and the majority 
of respondents had a post-graduate degree (53\%), similar to the ACCE survey. In Latin America, it was noted that due to a lack of undergraduate programming in clinical engineering, many had to attend a one year specialisation course in CE after obtaining a general undergraduate engineering degree. Levels of eduction in Asia and Africa were significantly lower than in North America and Europe.

Thirty-seven percent of respondents were managers, and technology management and service delivery were again listed as the main responsibilities $(60.8 \%$ and $60.6 \%$ of respondents reported carrying out these activities respectively). Other responsibilities varied significantly by region. While $53 \%$ of Latin American respondents are very involved in education, only $36.4 \%$ of Asian respondents performed this activity. Only $12 \%$ of Latin American and $13.6 \%$ of Asian respondents reported being involved in IT, compared with the majority of developed world respondents.

\subsubsection{Individual Developing Country Profiles}

A body of literature exists on CE services in specific developing countries and/or hospitals. These 'vertical' analyses of services and challenges complement the findings of the 'horizontal' studies presented. Vertical analyses provide greater detail of individual CE service programs (nation-wide or hospital-specific), while horizontal analyses expose trends and differences between and across regions.

National services that have been profiled include: Brazil [44]; Mexico [45]; Colombia [46]; Ecuador [47]; Paraguay [48]; Peru [49]; Venezuela [50]; Mozambique [51]; Palestine [52]; Bangaldesh [53]; and the Middle East at large [54]. While these countries vary in development of CE services (Brazil and Mexico are more advanced than most developing countries), several challenges at the hospital level were common in the literature. These include: 
- mainly only tertiary care hospitals staffed with CEs

- low recognition of equipment maintenance staff within the hospital

- equipment acquisition mainly the responsibility of hospital administrators

- HTM often neglected; CEs viewed only as maintainers of equipment

- poor inventory of medical equipment within the hospital

- infrastructure challenges at the hospital level

- weak equipment policy at hospital and national level

- insufficient budgets for CEs and BMETs

- insufficient training opportunities for CEs and BMETs

\subsection{Technology Acquisition, Diffusion and Main- tenance Models}

A body of literature exists surrounding technology acquisition, diffusion and maintenance in developing countries; some specifically addresses medical technology. Decades of international development experience have shown that technology introduction is only sustainable when accompanied by social and economic capacity building. This is particularly important in primary health care delivery in rural settings. Many stress the necessity of incorporating communities' unique socio-cultural contexts into all health technology planning and education [23], [53], [55], [56]; this is achieved through multi-disciplinary collaboration between clinical engineers and social scientists at the programming level, and community leaders at the implementation level. 


\subsubsection{Equipment Procurement}

In 1998, the World Bank (WB) commissioned a study on medical equipment procurement practices of their programming in developing countries [57]. It was estimated that WB projects finance an estimated $\$ 200-400$ million U.S. dollars of medical equipment annually. The study reviewed a total of 2,262 tender records covering 539 different devices. The following three priorities were identified by the study for improved procurement:

1. Borrower needs assessment and training

2. Internationally accepted quality and safety standards (regulations)

3. Life-cycle costing as a tool for investment decisions

Improved equipment maintenance support and training were identified as critical to improved equipment functionality, and recurrent costs associated with equipment consumables were also identified as a major hindrance to equipment functionality [57].

\subsubsection{Equipment Donations}

Much equipment arrives in developing countries through donation. The only horizontal study of equipment donations was performed in 1998 by the WHO and Germany's technical cooperation agency GTZ, which is heavily involved in building HTM capacity in the developing world [58]. They found that as much as $80 \%$ of equipment in some developing countries has been donated, and that it is not uncommon for $80 \%$ of donated equipment to be out of use. 
Equipment donors, often hospitals in the developed world, get a tax deduction on the equipment they donate; they also experience the 'feel good' effect of sending their old equipment overseas to needy recipients. However, coordination between donors and recipients is often poor to non-existent, and often even basic considerations (manuals, availability of trained users and maintenance staff, infrastructure requirements such as proper voltage and power outlets, spare parts, cost of supplies) are overlooked. Import tariffs for recipient hospitals are high, and often the bulk of equipment is unusable, and placed in storage to be scavenged for spare parts.

Examples of unusable donations are numerous. Just one such case was a shipment of donated equipment that arrived at the main teaching hospital in the Gambia from a U.S. hospital valued at $\$ 2$ million U.S. dollars; only metal hospital beds and gurneys were useable from the entire bulk shipment. Donations often introduce highly inappropriate equipment into hospitals, and this is exacerbated by the increasing rate at which Western hospitals are acquiring and replacing highly specialised equipment.

Equipment donation organisations do exist which coordinate donations between donors (hospitals, equipment manufacturers and pharmaceutical companies) and recipients in the developing world. These include: REMEDY, MedShare and ECHO Health. The WHO, the ACCE and many national health ministries have also formulated equipment donation guidelines [59], [60], [61]. These guidelines outline steps required by both the donor and recipient to ensure the donated equipment will be of use and sustainable in the recipient hospital. They recommend assessing and planning for the following prior to donation:

1. suitability for donation (clinical need, general quality, safety, specifications and standards, obsolescence ${ }^{3}$, and technology appropriateness)

\footnotetext{
${ }^{3}$ obsolescence is defined as having less than two years of manufacturer sales support (a minimum
} 
2. readiness to absorb the technology (human resources, environment, material resources, maintenance resources, financial feasibility)

3. pre-donation planning (installation, operation and maintenance requirements)

4. assembly, packaging and shipment requirements

5. customs clearance, unpacking, installation and commissioning

The guidelines represent the ideal situation for equipment donation. The reality, however, is that guidelines such as these are often ignored or unknown. Donations can be highly politicised, and there is a trend among developing country recipients to appear grateful; many fear the repercussions (perceived or real) of rejecting donated equipment.

\subsubsection{Technology Complexity Model}

A country's medical equipment inventory is represented by the pyramid shown in Figure 3.4. While equipment maintenance services are generally found in tertiary care hospitals in the developing world, the majority of relatively simple equipment that supports primary health care is found in areas outside of these maintenance services. This basic and simple equipment requires only basic maintenance and user training; yet it is the equipment that supports the majority of health delivery in the country [62], [23].

To improve the effectiveness of a country's large base of simple technologies, Cheng recommends large scale, national training programs to harness the capacities of local of 4 years is preferable) [59] 


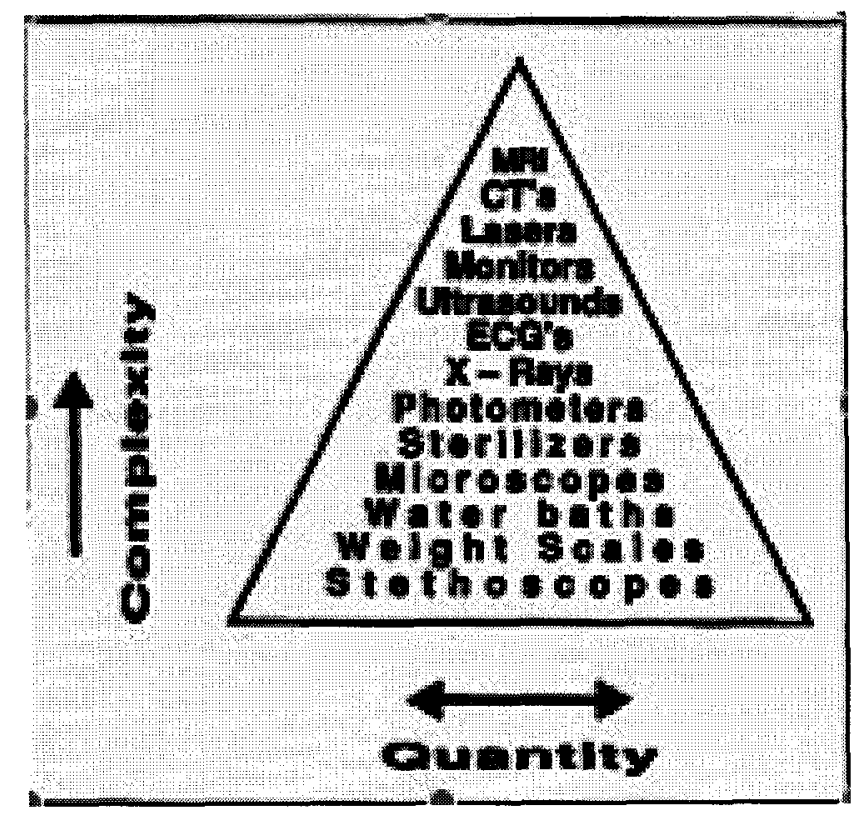

Figure 3.4: Diagrammatic Inventory of Medical Equipment [62]

technicians and train them on basic equipment maintenance. In addition, he recommends that basic equipment workshops be set up in the district and community level hospitals and health centres that use this equipment. This strategy complements the market economy which is a reality in developing countries as well; that it is more cost effective to have complex and highly specialised equipment repaired externally by the manufacturer or a third party. The relationship between equipment complexity and cost to repair is shown in Figure 3.5 [62].

Cheng's model was applied to national equipment maintenance services in Morocco by Frize and Cornillo over a period of 10 years with the support of the United Nations Development Programme (UNDP) [63]. Two equipment service centres were established at national teaching hospitals in Rabat and Casablanca; several years later centres were established at an additional five hospitals. Four of these centres were 


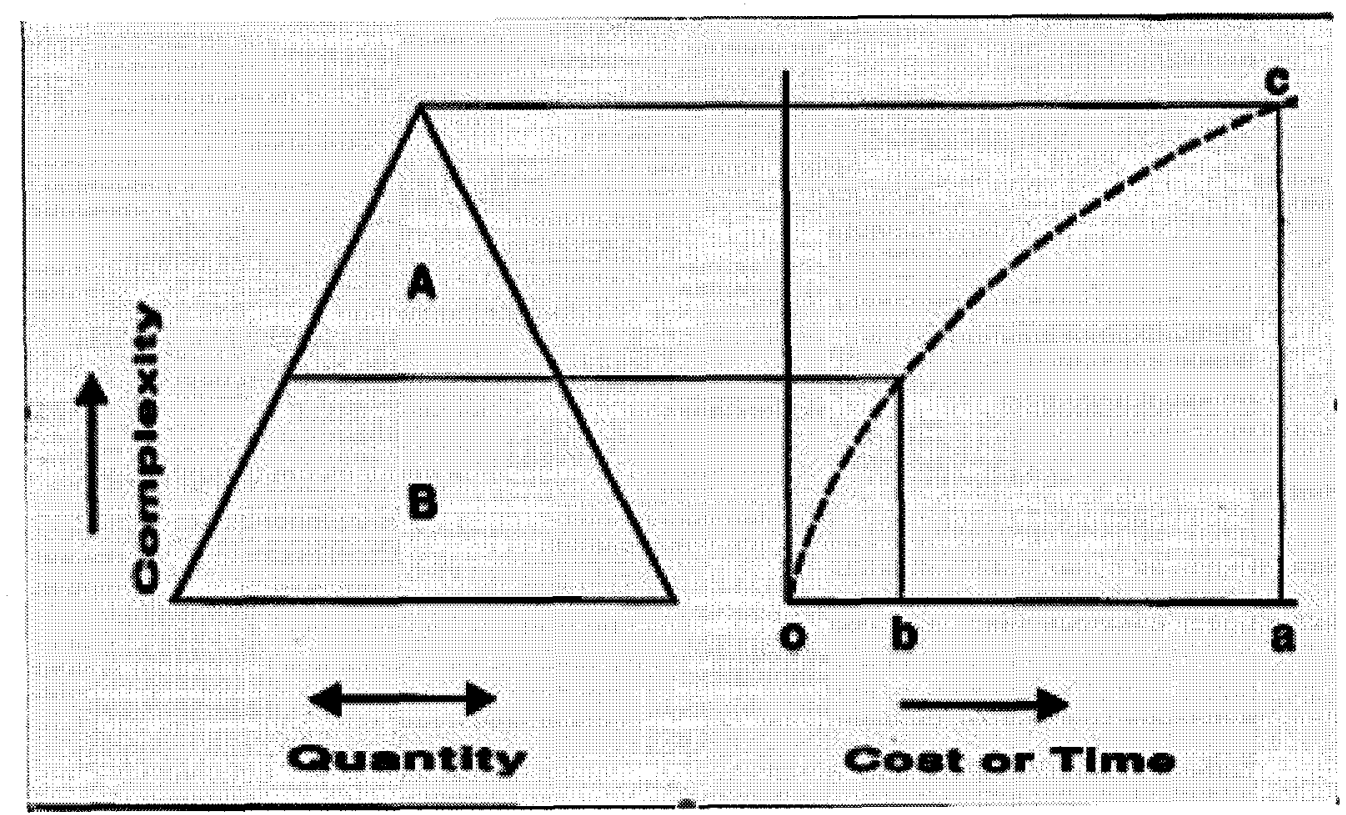

Figure 3.5: Equipment Complexity and Cost to Repair [62]

headed by CEs and three were not. In 1994, Frize evaluated the program to determine whether it was successfully meeting its goals [63]. She found centres headed by engineers greatly outperformed those not. CE-headed centres were able to repair 70-90\% of the equipment in their care; they had more user and maintenance manuals; worked more closely with hospital administrators; and technicians in the departments had clearly defined roles. High political will for the program was noted, which is essential to any HTM improvement efforts.

\subsubsection{Medical Technology Assessment Model}

In 2004, Roy, a technology specialist at the Canadian International Development Agency, developed a model to asses a developing country's readiness to acquire, diffuse and manage medical technologies [16]. Her model builds on Cheng's complexity model 
by predicting which level of technology in Figure 3.4 a country is likely to sustain through maintenance programs.

Roy's research was exploratory in nature, as no risk model existed that was specific to medical technology and she found that e-government and e-commernce models were not applicable. She used the case study approach to examine technology enabling factors from two polar opposite countries with respect to the level of $\mathrm{CE}$ services offered - Mali and Brazil. Through this examination, the medical technology assessment model (MTAM) was created. It scores countries on seven attributes which were found to be either technology enablers or constraints, depending on their level of development. These attributes are:

1. epidemiological capacity

2. government spending per capita on health care

3. whether the country has a strategic plan and policy for its medical equipment

4. regulatory environment for medical devices

5. connectivity (telephone and internet services to population)

6. organisational capabilities to manage medical devices

7. current health technology diffusion

The MTAM scores these attributes as high, medium, or low. Their addition provides an overall score for the country that recommends the level of medical technology likely to be sustained and therefore suitable for introduction by CIDA's health programming. A high overall score indicates that the country is low risk and therefore ready for the introduction of highly sophisticated technology, while a low overall score 
indicates that only basic services and accompanying technologies are recommended. Overall risk scores are correlated with levels of equipment sophistication in a pyramid model similar to Figure 3.4.

\subsection{Gaps Analysis}

Gaps exist in the current literature. These include:

1. a systematic study of $\mathrm{CE}$ effectiveness in developing world hospitals with an instrument designed for the developing world using language and metrics appropriate for the context

2. applying Cheng's equipment complexity model which was designed for the developing world to a systematic study of $\mathrm{CE}$ effectiveness in this context

3. a systematic study of equipment procurement and donation practices in the developing world

4. a systematic study of the state of equipment in developing world hospitals

5. an adequate profile of African $\mathrm{CE}$ effectiveness and challenges

6. testing Frize's CE effectiveness model in developing countries

7. investigating the relationship between $\mathrm{CE}$ effectiveness metrics and the state of medical equipment

This thesis attempts to address these gaps in the remaining chapters. 


\section{Chapter 4}

\section{Methodology}

This chapter presents the research methodology for this thesis, starting with brief coverage of the exploratory research performed in West Africa and the ethics protocol for this research. The research protocol is then presented in its three distinct phases: primary data collection with a novel research instrument from health technology managers in developing world hospitals; data preparation; and data analysis to meet the goals of this thesis which include presenting the state of CE effectiveness and medical equipment in developing country hospitals and testing the two hypotheses.

\subsubsection{Exploratory Research}

Preliminary field research was undertaken by the author between May and August 2006 at the United Kingdom's Medical Research Council (MRC UK) in the Gambia, West Africa [64]. The MRC UK has been conducting research and providing $50 \%$ of health care in the Gambia for over 50 years, and has a strong relationship with the Gambian health ministry. The author was based at the Biomedical Engineering Department at the main MRC UK site, which had a staff of one Canadian manager 
(a clinical engineer), four local technicians and two local students from the Gambian Technical Training Institute who oversaw equipment management and maintenance for all five MRC UK facilities.

This research was exploratory in nature, and provided the author with firsthand experience with HTM challenges in a developing world context. Unstructured, indepth interviews with equipment maintenance staff and technology assessments were performed at 5 MRC UK laboratory and clinical facilities (4 in the Gambia and 1 in Guinea-Bissau) and at 4 public hospitals in the Gambia, including the main teaching hospital in the capital city of Banjul. This exploratory research provided context for this thesis, and guided portions of the research instrument development.

\subsubsection{Ethics}

Much research in developing countries can be qualified as ethically ambiguous. It is characterised by a history of exploitation of participants, and challenges arise when applying global research ethics guidelines in the context of a developing country [65]. Research is often undertaken by Western researchers on local participants; the power differential that exists between researcher and participant must be mitigated by ethical considerations in the study protocol in order to minimise participant coercion and exploitation.

It was of utmost importance to the author that this research be undertaken in as ethical a manner as possible. Ethics approval for the research protocol was received from Carleton University's Research Ethics Committee; the certificate and Letter of Information (LOI) are presented in Appendix A. The LOI must be read and understood by participants prior to participation as it outlines risks and benefits of involvement in the research, as well as confidentiality and anonymity protocols. In- 
formed consent is inferred by participation and therefore no documentation of consent is required.

The potential risk of this research to participants was one of workplace (political) security. Hospitals can be very political environments, especially in developing countries, and participants were advised not to participate if they felt their workplace security was threatened in any way. This risk was mitigated by ensuring confidentiality and anonymity of personal information; only identifiers such as country and hospital type were published in the research. Two benefits were available to participants: results of the research will be shared with them and respondents were entered into a draw for one copy of the Clinical Engineering Handbook, edited by Joseph Dyro [66]. The Handbook is an excellent resource for clinical engineers worldwide, with contributions from 180 of the profession's leaders.

\subsection{Data Collection}

Several options for data collection were assessed. A questionnaire was determined to be the most appropriate research instrument for data collection for an international study of this kind. Field research through personal interviews and telephone interviews were considered inappropriate due to cost and time limitations. These research methods provide certain advantages, however, and would be useful for the future work that is presented in Section 7.3.

\subsubsection{Research Instrument}

The research instrument is a questionnaire, designed to collect sufficient data to perform statistical analysis. Questionnaire-based research has strengths and weaknesses. 
Questionnaires are efficient tools for collecting large volumes of data with standardised responses. However, self-administered questionnaires tend to have much lower response rates than interviews, and uniform questions with fixed responses limit a researcher's ability to adjust for cultural differences and provide interpretation feedback to interviewees [67].

\subsubsection{Online Questionnaires}

Online questionnaires are easy to deliver, collect and monitor, and minimise data entry error by researchers. They also enable automatic randomisation of answer choices which help reduce response bias, skip logic based on responses, and data verification at the time of collection (i.e. ensuring the total sum of entries for a particular question add up to a fixed value). However, online questionnaires can pose problems with privacy of data and can be technically frustrating to users. A significant concern with online questionnaires is that they limit access to those who are proficient with and have access to a computer and the internet. This concern is valid for this research which solicits developing world participants exclusively [67], [68].

\subsubsection{Instrument Design}

Questionnaire design is an iterative process. The initial draft of the research instrument was based on the literature review and gaps analysis, and it went through multiple design iterations. The quality of data collected depends on how well questions are constructed to meet the objectives of the research. Questions can be close-ended with a list of acceptable answers and a fixed response, or open-ended to provide respondents with the opportunity to express their own thoughts and words. The great 
majority of questions in the research instrument were close-ended for efficiency, however each section contained an open-ended question at the end to enable respondents to further elaborate on the content of that section. Different variables (or levels of measurement) are used for data collection, and they determine which statistical tests are performed on the data. The four categories of variables are:

1. Nominal variables are the simplest and least statistically useful measurement. They are discrete values that represent named categories of classification with no numerical meaning and no ordering between values, although numerical values are assigned for analysis. An example in the research instrument is the 'country' variable.

2. Ordinal variables assume a rank-order of the possible values, based on some criteria. Order is the only mathematical characteristic of this type of measurement; the distance between values is not meaningful. An example in the research instrument is 'highest level of education obtained by a technician in the department' which can have a value of 'under high school', 'high school', 'technical school (1-2 years)', 'technical school (3-4 years)', 'university (bachelors)', 'university (masters)', 'university (doctorate)' or ' $\mathrm{n} / \mathrm{a}$ ' in the event that the department has no technicians.

3. Interval and Ratio variables, also referred to as scale variables, allow ordering between categories and equal size intervals, i.e. they allow distance to be defined in terms of fixed units. Interval measurements have no absolute or fixed zero, while ratio measurements do. There are no interval measurements in this research (an example would be temperature). An example of a ratio variable in the research instrument is 'percentage of overall equipment base that was 
donated'; its value can be between 0 and 100 .

4. Dichotomous variables can take on two possible values, and may or may not be ordered. During analysis, dichotomies can be coded as any variable type, depending on the tests being run. An example or an ordered dichotomy in the research instrument is the commonly used 'yes' or 'no' variable.

Some ordinal variables can be treated as ratio measurements because an equal size interval is inferred in the variable categories themselves. This type of measurement is used extensively in this research to collect a maximum amount of ratio data from participants with a reasonable amount of effort on their behalf. An example of ordinal variable in the research instrument that can be treated as ratio in some analyses is 'proportion of simple equipment that is out of service', which can have a value of 'none', '<25\%', '25-50\%', '50-75\%', '>75\%' or 'all'. Similarly, some researchers also treat intensity measurements, such as the 5-point Likert scale ('strongly agree', 'agree', 'neutral', 'disagree' and 'strongly disagree') as ratio measurements rather than ordinal measurements because they assume the amount of agreement or disagreement varies in equal intervals along the points of the measure [67].

The following good design practices were also considered during questionnaire design: clear and adequate question wording that was appropriate for the participant population, reducing response bias during instrument design (for example, randomising categories in multiple response questions), moving from simple to complex questions and general to specific ones, placing sensitive information at the end, and clearly indicating changes in the frame of reference.

Many HTM experts were generous with their advice through multiple iterations of questionnaire design, and It was pre-tested on five respondents from CEDs with 
varying levels of development (two in Latin America, two in West Africa and one in Northern Canada where some challenges are similar to the developing world). Feedback from the consultations and the pre-test was extremely valuable. For example, one HTM expert recommended changing the wording from 'clinical engineering department' to 'equipment maintenance department' to appeal to a wider base of participants and four of five pre-test respondents identified the same question as the most confusing one in the questionnaire.

The questionnaire and all associated documentation were translated into Spanish and French from English to ensure it was available for most developing country participants. Spanish translation was performed by research associates at the CES University (Escuela de Ingeniera de Antioquia) in Medellin, Colombia, and French translation was performed by Medical Informatics Research Group (MIRG) research associates at Carleton University. Both translations were verified by independent readers with $\mathrm{CE}$ knowledge to ensure accurate translation of CE terminology as well as language.

The questionnaire was posted online using the SurveyMonkey engine [69]. The engine offers SSL encryption to ensure data privacy, which is a concern to many online questionnaire participants. To aid in distribution, the engine manages three online distribution methods : (a) sending a link to the survey embedded in an email, (b) mailing invitations to potential respondents directly from the engine and managing responses and (c) generating a link to post on external websites. All three methods were used. 


\subsubsection{Presentation of Instrument}

Appendix B presents the research instrument, which is comprised of 10 sections: an introduction and conclusion to the survey, and the eight different sections of the questionnaire. These sections are presented in Table 4.1 along with their corresponding number of questions.

Table 4.1: Questionnaire Sections

\begin{tabular}{|c|c||l|c|}
\hline Part & & Section & Number of Questions \\
\hline A & 1 & Hospital Profile & 4 \\
& 2 & Equipment Maintenance Department Profile & 9 \\
& 3 & Equipment Maintenance Department Personnel & 8 \\
& 4 & Equipment Inventory & 3 \\
& 5 & Equipment Repairs & 11 \\
\hline B & 1 & Medical Equipment & 7 \\
& 2 & Equipment Procurement & 6 \\
& 3 & Equipment Donations & 9 \\
\hline & & TOTAL & 57 \\
\hline
\end{tabular}

Figure 4.1 and Figure 4.2 provide a brief list of section content for each, and a complete list of all variables collected with the instrument (including section, name, type, and possible values) is presented in Appendix C. One section was removed in one of the last iterations of instrument design; it gathered information on the state of the hospital's infrastructure - power, medical gas, sterilisation, computers and heating, ventilation and air-conditioning (HVAC)). This infrastructure section may be of use to future researchers, and is included in Appendix D. 


\section{Hospital Profile}
(a) type
(b) size
(c) occupancy
(d) proportion of ICU beds

2. Equipment Maintenance Department Profile
(a) structure
(b) department and staff titles
(c) reporting authority
(d) satisfaction with reporting authority
(e) shared services

3. Equipment Maintenance Personnel
(a) number of staff
(b) training
(c) education level
(d) responsibilities

\section{Equipment Inventory}
(a) management system
(b) information

\section{Equipment Repairs}
(a) spare parts ordering
(b) in-house vs. external repairs
(c) average turnaround time
(d) average cost of external repairs

Figure 4.1: Questionnaire Sections - Part A 


\section{Medical Equipment}
(a) complexity
(b) state
(c) condition
(d) standardisation
(e) resources (spare parts, user manuals, maintenance manuals, test equip- ment, trained users, trained maintenance technicians)

\section{Equipment Procurement}
(a) source (acquisition, donation, lease/rental/loan)
(b) formal policy
(c) decision making
(d) requirements considered

\section{Equipment Donations}

(a) source (donation organisations, hospitals in other countries, aid agencies)

(b) complexity

(c) state

(d) resources

(e) consultation level and quality 


\subsubsection{Sampling}

Choosing an appropriate sampling strategy is an important aspect of data collection. The strategy will determine the sampling method, the sample frame, the minimum sample size required and specific selection criteria.

\subsubsection{Probability and Non-probability Sampling Methods}

Sampling methods can be classified as probabilistic or non-probabilistic. Probability sampling occurs when a sample is selected with a method involving knowledge of the likelihood of a unit of the population being sampled. In other words, each unit in the population has an equal, known probability of being selected. The sample selected is a small proportion of the whole population, and units are often selected using randomised selection. Methods of probability sampling include simple random sampling, stratified random sampling, systematic random sampling and cluster or multistage sampling [67]. Often probability sampling is not practical or feasible; in these cases, non-probability sampling methods are used.

Non-probabilistic methods are used to clarify and deepen understanding of specific cases, events or actions. They infer a certain knowledge about the population under study, and are chosen according to expert intuition, self-selection, historical documentation or long field experience in the area [6]. Therefore it is impossible to estimate the probability of a unit being included in the sample, and the sampling variability and reliability. Non-probabilitic methods are still widely used, however, and have been selected for this research based on three criteria:

1. Cost and Time: the cost and time of attempting a probabilistic sampling of CEDs in developing countries would have been exorbitant. 
2. Sampling Frame: when researchers do not know the limits of the data or population they are studying, there is an incomplete sampling frame [68]. In this case, it is virtually impossible to know all CEDs in developing countries, therefore non-probability sampling is the only feasible method. The frame must be derived based on the sampling strategy used, and not the entire population.

3. Exploratory Study: when a study is exploratory in nature, non-probabilistic sampling methods are appropriate. This research is exploratory; it is the first to determine the impact of CED effectiveness on the state of medical equipment in developing world hospitals, and the first to collect statistically significant amounts of data characterizing CED effectiveness as well.

Based on these criteria, non-probability sampling is appropriate for this research. There are four different methods of non-probabilistic sampling: (a) convenience or accidental sampling, (b) quota sampling, (c) snowball sampling and (d) purposive or judgmental sampling [67].

\section{(a) Convenience or accidental sampling}

Convenience or accidental sampling arises when units are selected solely on their willingness to participate in the research, and not based on any specific characteristic that they may exhibit. It produces the weakest sample as it is based solely on availability of participants.

\section{(b) Quota sampling}

Quota sampling is similar to probabilistic stratified sampling, in which quotas are established for certain kinds of respondents and the researcher disproportionately 
stratifies or categorizes the sample based on these quotas. Within each stratum, a simple random sample is taken until either an even distribution or a proportion desired by the researchers presented itself for the stratum. Non-probabilitic quota sampling is similar because researchers want to ensure there is a certain representation in the final sample and respondents are therefore solicited until the quota is met.

\section{(c) Snowball sampling}

Snowball sampling is used when respondents are difficult to find or identify. Researchers start with a small number of known units with the desired characteristic, and ask these units to disseminate the research instrument to others who present the same characteristic. Responses increase as the number of potential respondents 'snowballs', and the final sample is therefore not random; it is made up of a network of participants who know each other.

\section{(d) Purposive or judgmental sampling}

Purposive or judgmental sampling occurs when a sample is selected on purpose, based on some criteria pertaining to characteristics of the unit of analysis. It is a commonly used sampling technique as researchers generally approach sampling problems with a specific plan and population in mind. The target group is defined at the beginning of the study, based on certain selection criteria.

A combination of quota, snowball and purposive sampling was used for this research. Quota techniques ensured sufficient representation from African hospitals (one goal of this research); snowball techniques were used to encourage participants to distribute the research instrument to their colleagues; and purposive sampling was 
used based on the selection criteria for participation (i.e. health technology managers (CE or otherwise) working at a secondary and tertiary care hospitals in developing countries were targeted).

\subsubsection{Sample Frame}

With non-probabilistic sampling, the sample will never represent a whole population; representation is limited to the pool of solicited participants. The sample frame for this research is all health technology managers (CEs or otherwise) in secondary and tertiary care hospitals in developing countries. The sample itself from within this frame is biased by the distribution channels presented in Section 4.1.3.

\subsubsection{Sample Size}

How big must a sample be to adequately represent a population? There is no simple answer to this question. Fowler notes four common misconceptions of what can independently determine an adequate sample size [68]:

1. A sample size is adequate when a certain proportion of the total population, such as $1 \%$ or $5 \%$, is represented in the sample.

2. A sample size is adequate as defined by 'rules of thumb', such as national samples of 1500 or community samples of 500 .

3. A sample size can be determined solely by the margin of error researchers are willing to tolerate in their results.

4. The larger the sample, the better. In reality, a sample of 150 will describe a population of 15000 or 1.5 million with virtually the same degree of accuracy assuming all other aspects of the sample design and procedures are the same. 
These four determinants can contribute to the final judgement of adequate sample size, but none can be used in isolation. Judgements must be made on a case-by-case basis. Nardi recommends weighing the following when determining sample size: (a) examples set by prior research, (b) consideration for the planned analysis and (c) margins of sampling error and confidence limits/intervals [67].

\section{(a) Prior Research}

Frize, Glouhova et al. , and Cao and Frize had sample sizes of 122, 151 and 61 respectively for their studies. Cao and Frize's sample size of 61 was not deemed sufficient for statistical analysis to test their hypothesis, based on confidence ranges for variability attributed to sampling (see Table 4.2). Frize's sample size of 122 produced strong results and significant correlation between independent and dependent variables, which suggests this sample size is adequate for the (similar) type of analysis performed in this thesis.

\section{(b) Analysis Considerations}

Similar to quota sampling, researchers often require a quota of certain variables to perform their analyses. One goal of this research was to profile African CEDs, thus a quota of African responses within the larger sample was considered necessary for analysis. Another goal was to compare findings with those of Cao and Frize, thus a regional quota for Latin America and Asia was also deemed necessary. For each region, a minimum of 30 samples was considered adequate for this purpose.

\section{(c) Sampling Error and Confidence Intervals}

Sampling error is the variation around the true value, based on the chance that a 
sample differs from the population as a whole. The confidence interval indicates the reliability of an estimate, i.e. how likely an interval is to contain the parameter determined by the confidence level. The confidence level is pre-defined, for example $95 \%$ or $99 \%$. Research findings are often declared statistically significant if the probability of obtaining a statistic by chance alone is less than $5 \%$; this represents a confidence level of $95 \%$. A confidence level of $99 \%$ would correspond to a $1.0 \%$ probability of obtaining the statistic by chance alone (or $0.5 \%$ at either end of the distribution).

Table 4.2 presents the confidence ranges for variability attributed to sampling, based on sample size and the percentage of the sample with a given characteristic. Chances are 95 in 100 that the real population figure lies in the range defined by \pm the entry in the table. These ranges do not account for errors based on non-response or reporting errors, and further variability may be introduced by sample design. It can be seen that precision increases steadily up to a sample size of $100-200$, and then only modestly past 200 . Based on the values in Table 4.2 , a minimum sample size of 100 was desired.

Table 4.2: Confidence Ranges for Variability Attributable to Sampling [68]

\begin{tabular}{|c||c|c|c|c|c||}
\hline \multicolumn{1}{|c||}{ Sample Size } & \multicolumn{5}{c|}{ Percentage of Sample with Characteristic } \\
\cline { 2 - 6 } & $5 / 95$ & $10 / 90$ & $20 / 80$ & $30 / 70$ & $50 / 50$ \\
\hline 35 & 7 & 10 & 14 & 15 & 17 \\
50 & 6 & 8 & 11 & 13 & 14 \\
75 & 5 & 7 & 9 & 11 & 12 \\
100 & 4 & 6 & 8 & 9 & 10 \\
200 & 3 & 4 & 6 & 6 & 7 \\
300 & 3 & 3 & 5 & 5 & 6 \\
500 & 2 & 3 & 4 & 4 & 4 \\
1000 & 1 & 2 & 3 & 3 & 3 \\
1500 & 1 & 2 & 2 & 2 & 2 \\
\hline
\end{tabular}


Based on these three criteria, a minimum sample size of 100 was required, with a minimum of 30 samples from Africa, Latin America and Asia. The sample size was larger in the end, and is presented in Section 5.1.

\subsubsection{Distribution Methods}

Data was collected over a period of three months. Again, HTM professionals were very generous with their time and contacts in this phase of data collection. Broad categories of dissemination are categorised as:

1. emails sent to contacts (with the WHO, IFBME country associations, field contacts, past respondents to Cao and Frize [6], etc.) with an embedded survey link, which they were encouraged to 'snowball' to their contacts

2. email addresses collected from these contacts that were managed with the SurveyMonkey engine

3. listserv posts to professional $\mathrm{CE}$ associations

4. an advertisement placed on professional $\mathrm{CE}$ association websites

5. researchers in Colombia who personally collected 10 responses

The questionnaire was also available in hard and soft (.pdf) copy as well for respondents with sporadic internet access; for example, several association websites posted soft copies and fax information. However, the primary method of communication was email, and all responses collected were through the online questionnaire or field visits by the Colombian researchers. 


\subsubsection{Response Rate}

Response rates represent the proportion of a selected sample from which data was collected, usually reported as a percentage. Low response rates can increase response error and lead to the acceptance of false hypotheses [68]. Table 4.3 presents the response rates by language and collector method. Due to the nature of dissemination, the response rate for many distribution channels can only be estimated (i.e. listservs, snowball emails, websites). Those that are estimated are denoted with an '*' and presented with their estimated error ranges.

Table 4.3: Response Rates

\begin{tabular}{|c|c|c|c|c|c|}
\hline Language & Collector & Details & Sent & Received & Response Rate \\
\hline \multirow[t]{8}{*}{ English } & Survey Link & & $600 \pm 150^{*}$ & 75 & $12 \pm 3 \% *$ \\
\hline & SM Email Lists & South Africa & 131 & 11 & $8 \%$ \\
\hline & & Ghana & 8 & 5 & $63 \%$ \\
\hline & & Uganda & 15 & 2 & $13 \%$ \\
\hline & & Malaysia & 77 & 11 & $14 \%$ \\
\hline & & Brazil & 15 & 4 & $26 \%$ \\
\hline & & Middle East & 22 & 2 & $9 \%$ \\
\hline & & MET Grads & 52 & 10 & $19 \%$ \\
\hline \multicolumn{3}{|c|}{ Subtotal } & 868 & 120 & $13 \%$ \\
\hline \multirow[t]{4}{*}{ Spanish } & Survey Link & & $450 \pm 100^{*}$ & 56 & $12 \pm 3 \% *$ \\
\hline & SM Email Lists & Mexico & 134 & 13 & $10 \%$ \\
\hline & & Honduras & 33 & 10 & $30 \%$ \\
\hline & Field Visits & Colombia & 10 & 10 & $100 \%$ \\
\hline \multicolumn{3}{|c|}{ Subtotal } & 617 & 89 & $14 \%$ \\
\hline French & $\begin{array}{l}\text { Survey Link } \\
\text { SM Email Lists }\end{array}$ & Morocco & $\begin{array}{c}30 \pm 10^{*} \\
13\end{array}$ & $\begin{array}{l}5 \\
3\end{array}$ & $\begin{array}{c}17 \pm 6 \% * \\
23 \%\end{array}$ \\
\hline \multicolumn{3}{|c|}{ Subtotal } & 43 & 8 & $19 \%$ \\
\hline \multicolumn{3}{|c|}{ Total } & 1361 & 217 & $16 \%$ \\
\hline \multicolumn{3}{|c|}{ Valid Total } & $1361 \pm 181 *$ & 207 & $15 \pm 2 \% *$ \\
\hline
\end{tabular}


A total of 207 valid responses were received; ten responses were removed from the data set because they were invalid. It must be noted that response rates vary significantly by question because participants were instructed to skip any questions they did not wish to answer. Therefore, 207 represents the valid respondents who filled out part of the questionnaire and selected the 'submit' button at the end of the questionnaire. Response rates (Ns) for individual questions are presented throughout Chapter 5. The approximate overall response rate is $15 \pm 2 \%$, which is quite good for online surveys; Cao and Frize [6], for example, reported a response rate of $8.61 \%$.

\subsection{Data Preparation}

Data collected with the online survey was downloaded from SurveyMonkey into Microsoft Excel, and then converted to SPSS format ${ }^{1}$. Once the data set was imported into SPSS, the following steps were taken to prepare the data for analysis:

1. Invalid responses were removed. This removed five developed country responses, three from CEs who did not work in hospitals, and two duplicate responses (based on the IP address as a unique ID, and additional responses).

2. Variable types, values and labels were set for each variable. For example, for the variable representing whether an EMD exists as a separate department, the type was set to 'ordinal', the values were coded as 'yes' $=1$ and 'no' $=2$, and the labels were set to 'yes' and 'no' would appear in the output of all operations on this variable. See Appendix $\mathrm{C}$ for a complete list of variables.

\footnotetext{
${ }^{1}$ SPSS is the Statistical Package for the Social Sciences tool, which is a statistical modelling program that provides a wide range of data analysis techniques. It was used for all statistical analyses in this thesis.
} 
3. New variables were created (region, HDI, HDI ranking, etc.). For example, the 'HDI' value was tied to the 'country' variable, and the 'region' variable was coded in ascending order of the average HDI of all responses from that region.

4. New variables were calculated based on existing variables. For example, a new variable was computed when the highest level of education of an engineer was at least a B. Sc. to signify a university-trained CE in the department.

5. Variable responses were combined when response categories had very few responses. For example, the response categories for 'proportion of simple equipment that is out of service' were: 'none', ' $<25 \%$ ', '25-50\%', '50-75\%', ' $>75 \%$ ' and 'all'. No respondents selected 'all' and only two selected ' $>75 \%$ ', so a new category, ' $>50 \%$ ' was coded to merge the three final categories.

6. Cut-off values for some scale variables with large variances were set and coded to eliminate outliers. This was done for all scale variables used in the quantitative analysis because outliers can skew the results of correlation tests. For example, for any in-house repairs of simple equipment that took more than 10 hours, a new variable was set to denote $>10$ hours (coded as 11).

\subsubsection{Data Validation}

During the design phase, two different questions that collected the same information were placed in different sections of the questionnaire to check for inconsistencies. For example, two questions asked whether preventive maintenance is performed: Q.8 in the Equipment Maintenance Department Personnel section and Q.10 in the Equipment Repairs section (see Appendix B). A cross-tabulation of responses exposed two conflicting cases $(\mathrm{n}=109)$ whose responses were removed (and replaced by system 
missing values). This indicates a detectable error rate of $1.83 \%$ for this question. Limitations of the research instrument are discussed in greater detail in Section 6.3.

\subsubsection{Missing Values}

Imputation of missing values based on complete cases is a common procedure for randomly missing variables. In this data set, however, missing values are not missing at random (NMAR); they are missing because respondents have chosen to skip certain questions for various reasons. For example, people who don't report their weight in a survey tend to be overweight by more than the average amount, so missing weight values cannot simply be imputed using complete cases. The researcher would need to replicate the mechanism motivating respondents to skip questions, which is not feasible for this research. Imputation of missing values was not undertaken by previous researchers ([6], [8], [13], [42] and [43]) on their data sets either.

\subsection{Data Analysis}

The three statistical methods used to analyse the data (frequency analysis, crosstabulation and correlation) are presented, as is the process for testing the two hypotheses.

\subsubsection{Statistical Methods}

Three main types of statistical methods were selected for this analysis: frequencies, cross-tabulations and correlation. 


\subsubsection{Frequency}

Frequency analysis yields the distribution of categories within a variable. The type of variable determines which frequency parameters are the best measure. Nominal and ordinal variables are presented with very simple statistical measures such as mean, median, and proportional and overall frequency within a sample. Scale variables are presented by mean, standard error, median, standard deviation, variance and quartile. Frequency analysis was used to present the descriptive statistics in Chapter 5; they capture a snapshot of the state of $\mathrm{CE}$ services and medical equipment in the developing world hospitals sampled.

\subsubsection{Cross-tabulation}

Cross-tabulation tables, such as those produced with the Chi-squared method, show the relationship between two or more variables in table format. They are ideally suited for nominal and ordinal data, or scale data with very limited number of discrete values [67] and do not measure the strength of an association. Cross-tabulations are widely used both in Chapter 5 to categorise the sample (for example, by region), and in Chapter 6 to present the relationship between IVs and DVs in both models.

\subsubsection{Correlation}

Many different statistical methods exist to establish whether there is a relationship between two variables. Correlation measures the association of the relationship between two variables in terms of percent of variance explained. For example, when the correlation coefficient is 0.25 , the independent variable is said to explain $25 \%$ of the variance in the dependent variable [70]. The correlation method to use depends on the types of variables being analysed; Table 4.4 presents the appropriate methods for 
Table 4.4: Correlation Tests Based on Variable Types [67]

\begin{tabular}{|l|l|l|}
\hline Variable 1 & Variable 2 & Correlation Method \\
\hline \hline nominal & nominal & Chi-square, Lambda, Goodman, Kruskal's Tau \\
\hline ordinal & ordinal & Chi-square, Gamma, Kendall's Tau, Somers, Spearman \\
\hline scale & scale & Pearson r \\
\hline nominal/ordinal & scale & Eta \\
\hline
\end{tabular}

different variable types.

The majority of variables in the data set are rank-order ordinal data, meaning categories are ascending or descending ranks with equal, known distances. Table 4.4 suggests five possible correlation tests for ordinal variables. Of these, only two are appropriate for rank-order ordinal data: Kendell's Tau and Spearman. Kendell's Tau requires an equal number of rows and columns in the correlation table (i.e. an equal number of categories for both ordinal variables being correlated). This condition is not satisfied for many of the analyses, and therefore the Spearman correlation was chosen for use in this thesis. Spearman correlation can be used for dichotomous nominal data with inherent ranks as well (such as yes/no) and for scale variables with outliers removed. The Pearson correlation, from which the Spearman correlation is derived, is appropriate for scale (or interval) data and therefore was not chosen for this work [13], [67].

The Spearman method is a symmetrical statistic, meaning that it does not determine the direction of causality; this is determined by the researcher based on expert knowledge. It does not require an assumption of a bivariate normal distribution, and possesses a power efficiency of 0.9 when compared with parametric methods such as the commonly used Pearson correlation. The Spearman method computes a corre- 
lation coefficient between \pm 0 and 1.0, which signifies the direction and strength of the relationship between two variables. The Spearman correlation coefficient $r_{s}$ is calculated as follows [67]:

$$
r_{s}=1-\frac{6 \sum d^{2}}{n^{3}-n}
$$

where $\mathrm{n}$ is the number of cases and $\mathrm{d}$ is the difference for a pair between the two ranks. When $\mathrm{n}>30$, the following formula can be used [6]:

$$
r_{s}=\frac{ \pm Z}{\sqrt{n-1}}
$$

where $\mathrm{Z}$ is the significance level. Spearman correlation is used to test the relationship between all independent and dependent variables (IVs and DVs) in the analysis performed to test the hypotheses.

\subsubsection{Hypothesis Testing}

Two goals of this research were to test the following two hypotheses:

1. Frize's model for $\mathrm{CE}$ effectiveness in developed countries can be applied to developing countries, with modification.

2. CE effectiveness has an impact on the state/functionality of a hospital's equipment base.

Models represent the relationships between or among variables. To test the two null hypotheses, their models must be tested. Variables within the model construct 
can be broadly categorised as either explanatory or extraneous. Explanatory variables explain a situation; one relates to another in an explainable way. They include independent, dependent, and moderating variables (IVs, DVs and MVs). IVs are model inputs that effect the outputs of the model, or the DVs. MVs are secondary IVs that are chosen for inclusion because they have a strong effect on the IV-DV relationship. Extraneous variables, such as confounding variables (CVs), do not explain relationships within the model construct; instead they may obscure them [70].

\subsubsection{Clinical Engineering Effectiveness Model}

In Frize's model (Figure 3.1), the factors comprising the hospital's organisational climate are inputs (IVs), and the degree of CE effectiveness is measured by the outputs (DVs). In order to test Frize's original model, the research instrument was designed to collect the variables of the original model from the developing country context. Some adjustment for this context was made; some variables were modified, some were added and some were removed. For example, a question was added to the list of outputs to gauge the EMD's functional involvement in the equipment donation process. The steps taken to test this hypothesis are listed in Figure 4.3, and the results are presented in Chapter 6 .

\subsubsection{Medical Equipment Functionality Model}

The development of this model is exploratory, as it is the first investigation to examine the relationship between $\mathrm{CE}$ effectiveness indicators and the state or functionality of equipment in developing world hosptials. Model variables were limited by the data collection methodology, i.e. it was deemed unfeasible to collect data on very specific metrics of equipment functionality (for example, length of number of patient 
1. Test the statistical independence of purported IVs.

2. Reduce the set to wholly independent IVs (confounding variables are eliminated, moved to the DV set or retained as MVs if it is determined that they have a significant impact on the IV-DV relationship).

3. Test the dependence of IV-DV pairs to determine all inputs and outcomes of the model.

4. Refine the model as necessary.

5. Present the relationship between weakly and strongly significant IV-DV pairs (i.e. significance levels of 0.05 or 0.01 respectively), either with cross-tabulation tables or descriptively.

6. Accept or reject the null hypothesis.

Figure 4.3: Steps for Testing Hypotheses

safety issues/year, number of equipment repairs/year, etc.). Instead, two variables representing the proportion of simple and complex equipment that is out of service were chosen as indicators of the state of equipment. These were correlated with other variables in the data set, starting with $\mathrm{CE}$ effectiveness metrics from the first model, to search for relationships between variables. These results are presented in Chapter 6. 


\section{Chapter 5}

\section{The Sample}

This chapter presents the state of $\mathrm{CE}$ services and medical equipment in the developing world hospitals that comprise the sample. Following an overview of the sample, the following results are presented comprehensively: hospital profile, equipment maintenance department profile, equipment maintenance department personnel, equipment inventory, medical equipment, equipment repairs, procurement and donations. Finally, results are compared to those of previous research.

\subsection{Overview}

In total, 207 valid responses were collected; Figure 5.1 shows that this number of responses yields very low variability due to sampling, and thus is highly significant. Figure 5.2 shows the regional distribution of responses, and countries within regions are broken down in Table 5.1 and Table 5.2. Just over one half of responses are from Latin America (104/207), and an additional quarter (53/207) are from Africa. The remaining responses are from Asia (38/207), and the Middle East and Eastern 


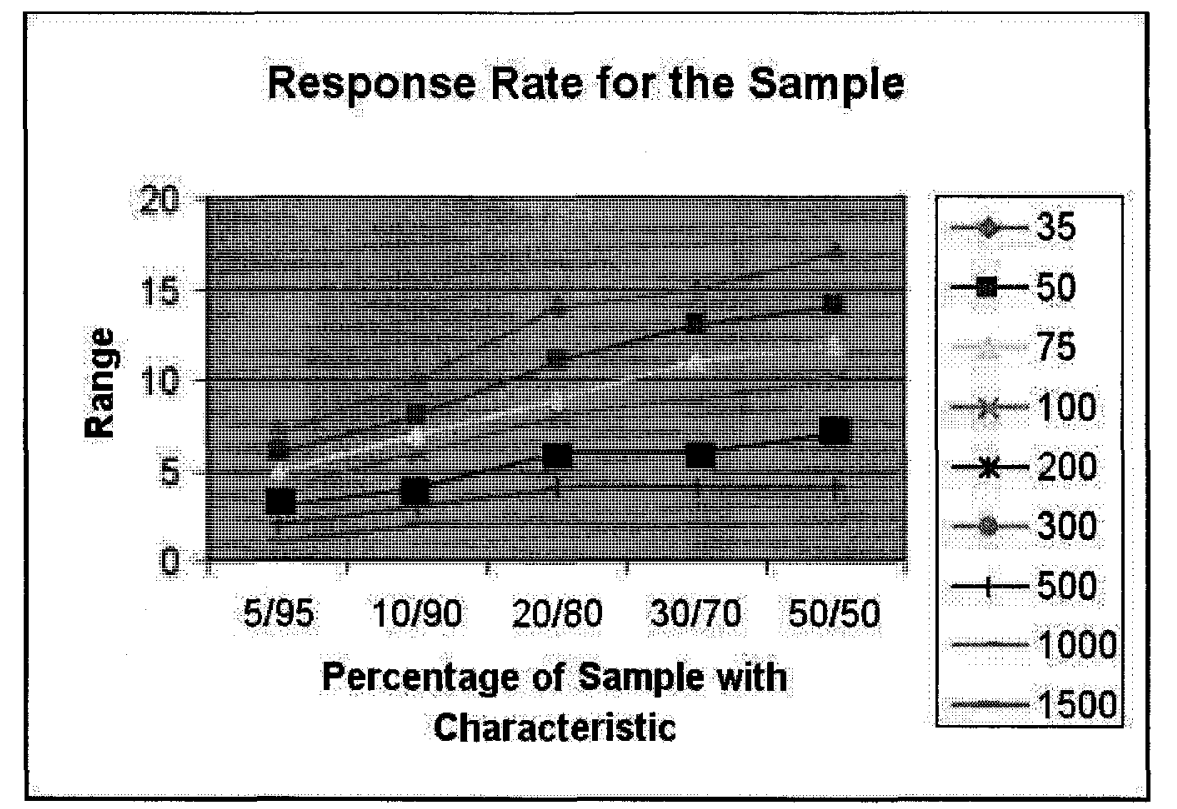

Figure 5.1: Variability Due to Sampling - Total Valid Response Rate

Europe (with a combined total of 12/207 responses).

Within Latin America, Table 5.1 shows that Brazil, Mexico and Colombia - countries that have been recognised as leaders within the developing world with respect to clinical engineering - account for a total of $64.4 \%$ of Latin American responses. Within Africa, Ghana and South Africa account for a total of $53.8 \%$ of responses and within Asia, Malaysia and Taiwan (both with relatively high HDIs ${ }^{1}$ ) account for $57.9 \%$ of responses (22/38). Finally, within the combined regions of the Middle East and Eastern Europe, 58.3\% of all (12) responses are from Iran and Saudi Arabia. The high proportion of responses from certain countries in each regions is explained by the distribution methods outlined in Section 4.1.3.

\footnotetext{
${ }^{1}$ Both Taiwan and Hong Kong have HDIs that place them in the 'developed country' category, however they have been retained in the results because they both belong to the People's Republic of China which is a developing country with an HDI of 0.777. Further, Taiwan's HDI is self-calculated and not formally recognised by the U.N.
} 


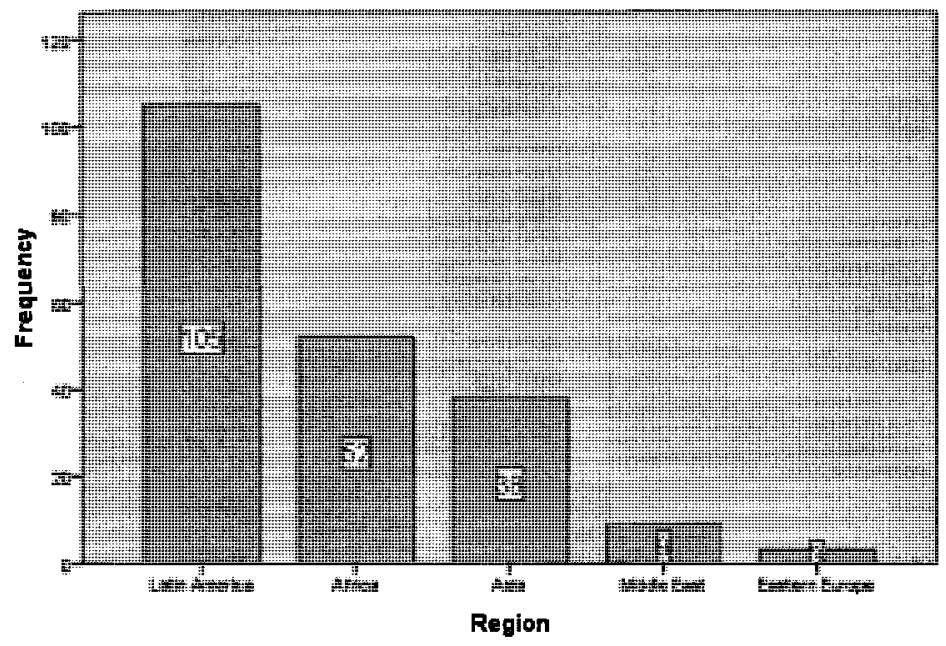

Figure 5.2: Regional Responses $(\mathrm{n}=207)$

Table 5.1 and Table 5.2 show that many of the countries with the highest responses in each region also have relatively high HDIs. Based on this fact, a decision to analyse CE services by (binned) HDIs was rejected; regional and hospital profile variables were instead selected to present the sample within this chapter.

\subsubsection{Hospital Profile}

\subsubsection{Hospital Type}

Teaching or university-based hospitals tend to offer a wider variety of clinical services and to have significantly larger equipment bases; Frize reported that teaching hospitals invested roughly six times as much annually in capital equipment expenditures as non-teaching hospitals [13]. Private hospitals and non-govermental hospitals also offer a significant amount of health care services in some developing countries [22], 
Table 5.1: Regional Response Distribution: Africa and Latin America

\begin{tabular}{|l|l|c|c|}
\hline Region & Country & HDI & Responses \\
\hline Africa & Ghana & 0.553 & 15 \\
& South Africa & 0.674 & 13 \\
& Uganda & 0.505 & 6 \\
& Morocco & 0.646 & 5 \\
& Madagascar & 0.533 & 4 \\
& Cameroon & 0.532 & 2 \\
& Mozambique & 0.384 & 1 \\
& Nigeria & 0.470 & 1 \\
& Rwanda & 0.452 & 1 \\
& The Gambia & 0.502 & 1 \\
& Guinea-Bissau & 0.374 & 1 \\
& Kenya & 0.521 & 1 \\
& Benin & 0.437 & 1 \\
\cline { 2 - 4 } & Total & & $\mathbf{5 2}$ \\
\hline \hline Latin America & Brazil & 0.800 & 29 \\
& Mexico & 0.829 & 25 \\
& Colombia & 0.791 & 13 \\
& Honduras & 0.700 & 9 \\
& Peru & 0.773 & 7 \\
& Venezuela & 0.792 & 6 \\
& Argentina & 0.869 & 3 \\
& Costa Rica & 0.846 & 3 \\
& Ecuador & 0.772 & 3 \\
& Chile & 0.867 & 2 \\
& Barbados & 0.892 & 1 \\
& Bolivia & 0.695 & 1 \\
& Cuba & 0.838 & 1 \\
& Guatemala & 0.689 & 1 \\
& Paraguay & 0.755 & 1 \\
\cline { 2 - 4 } & Total & & $\mathbf{1 0 4}$ \\
\hline
\end{tabular}


Table 5.2: Regional Response Distribution: Asia, Middle East and Eastern Europe

\begin{tabular}{|l|l|c|c|}
\hline Region & Country & HDI & Responses \\
\hline Asia & Malaysia & 0.811 & 14 \\
& Taiwan & 0.932 & 8 \\
& Philippines & 0.771 & 6 \\
& Cambodia & 0.598 & 2 \\
& Hong Kong & 0.937 & 2 \\
& India & 0.619 & 2 \\
& Thailand & 0.781 & 2 \\
& Indonesia & 0.728 & 1 \\
& Vietnam & 0.733 & 1 \\
\cline { 2 - 4 } & Total & & $\mathbf{3 8}$ \\
\hline \hline \multirow{5}{*}{ Middle East } & Iran & 0.759 & 4 \\
& Saudi Arabia & 0.812 & 3 \\
& Bahrain & 0.866 & 1 \\
& Bhutan & 0.579 & 1 \\
\cline { 2 - 4 } & Total & & $\mathbf{9}$ \\
\hline \hline Eastern Europe & Bulgaria & 0.824 & 1 \\
& Croatia & 0.850 & 1 \\
& Estonia & 0.860 & 1 \\
\cline { 2 - 4 } & Total & & $\mathbf{3}$ \\
\hline
\end{tabular}


[24].

Respondents were asked to select all types of hospitals they worked at (i.e. multiple responses were permitted) from the following list: university/teaching $(\mathrm{U} / \mathrm{T})$; general/non-teaching $(\mathrm{G} / \mathrm{N})$; government-funded (GV); private (PR); philanthropic/nongovernmental organisation $(\mathrm{PH})$; community (CM) and other (OT). The majority of those who selected 'other' indicated hospital specialties, such as rehabilitation, maternal and child health, and laboratory services. The category of military hospital (MI) was added because 4 'other' respondents indicated this hospital type. The results are shown in Table 5.3.

Table 5.3: Hospital Type $(\mathrm{n}=202)$

\begin{tabular}{|c|c|c|c|c|c|c|c|c|}
\hline & U/T & G/N & GV & PR & PH & CM & MI & OT \\
\hline U/T & $\mathbf{5 6}$ & - & 20 & 8 & 6 & 5 & - & 7 \\
\hline G/N & - & $\mathbf{1 2}$ & 5 & 6 & 3 & 1 & - & 1 \\
\hline GV & 20 & 5 & $\mathbf{9 6}$ & 3 & 3 & 7 & 2 & 18 \\
\hline PR & 8 & 6 & 3 & $\mathbf{4 8}$ & 2 & 2 & - & 2 \\
\hline PH & 6 & 3 & 3 & 2 & $\mathbf{1 7}$ & 2 & - & 3 \\
\hline CO & 5 & 1 & 7 & 2 & 2 & $\mathbf{1 3}$ & - & 2 \\
\hline MI & - & - & 2 & - & - & - & $\mathbf{4}$ & 4 \\
\hline OT & 7 & 1 & 18 & 2 & 3 & 2 & 4 & $\mathbf{3 8}$ \\
\hline
\end{tabular}

This sample differs from that of Cao and Frize, who reported $55.7 \%$ of respondents being from teaching hospitals with the remaining respondents being from general hospitals (they did not collect data on the other categories). In this sample, only $27.7 \%$ of respondents come from teaching hospitals. Government-funded hospitals account for nearly half of all respondents (47.5\%) and private hospitals close to another quarter $(23.8 \%)$. Almost one tenth of respondents work at philanthropic hospitals (17/202). It is interesting to note the substantial number of respondents who reported multi- 
ple hospital funding sources (for example, government and private) and that mixed service delivery is more common in the developing world ${ }^{2}$.

\subsubsection{Hospital Size}

The distribution of hospital sizes is presented in Figure 5.3. The most common size is between 50 and 250 beds for one third of respondents (62/186). However hospital sizes of $250-500$ beds and $>500$ beds are also significantly represented with $42 / 186$ and 50/186 responses respectively. Regional trends are presented in Table 5.5. They are relatively similar in the overall distribution, with the exception of Asia which has a majority of hospitals with over 500 beds $(21 / 37)$. Government-funded hospitals generally reflect the overall trend, while almost half of all private hospitals have between 50 and 250 beds (47.9\%).

Table 5.4: Hospital Size by Region $(n=186)$

\begin{tabular}{|lr|c|c|c|c|c|}
\hline \multirow{2}{*}{ Region } & \multicolumn{5}{|c|}{ Number of Beds } \\
\cline { 3 - 7 } & & $<50$ & $\mathrm{f} 50-250$ & $250-500$ & $>500$ & don't know \\
\hline Africa (n=48) & Regional & $10.4 \%$ & $31.3 \%$ & $12.5 \%$ & $29.2 \%$ & $16.7 \%$ \\
& Overall & $2.4 \%$ & $7.2 \%$ & $2.9 \%$ & $6.8 \%$ & $3.9 \%$ \\
\hline Latin America (n=89) & Regional & $12.4 \%$ & $42.7 \%$ & $30.3 \%$ & $11.2 \%$ & $3.4 \%$ \\
& Overall & $5.3 \%$ & $18.4 \%$ & $13.0 \%$ & $4.8 \%$ & $1.4 \%$ \\
\hline Asia (n=37) & Regional & $5.4 \%$ & $18.9 \%$ & $13.5 \%$ & $56.8 \%$ & $5.4 \%$ \\
& Overall & $1.0 \%$ & $3.4 \%$ & $2.4 \%$ & $10.1 \%$ & $1.0 \%$ \\
\hline Middle East (n=8) & Regional & $12.5 \%$ & $.0 \%$ & $50.0 \%$ & $37.5 \%$ & $.0 \%$ \\
& Overall & $.5 \%$ & $.0 \%$ & $1.9 \%$ & $1.4 \%$ & $.0 \%$ \\
\hline Eastern Europe (n=3) & Regional & $.0 \%$ & $33.3 \%$ & $.0 \%$ & $66.7 \%$ & $.0 \%$ \\
& Overall & $.0 \%$ & $.5 \%$ & $.0 \%$ & $1.0 \%$ & $.0 \%$ \\
\hline
\end{tabular}

\footnotetext{
${ }^{2}$ It is suggested that future researchers break this question into three sub-questions for type (teaching vs. non), funding (government, private or philanthropic) and specialisation(s).
} 


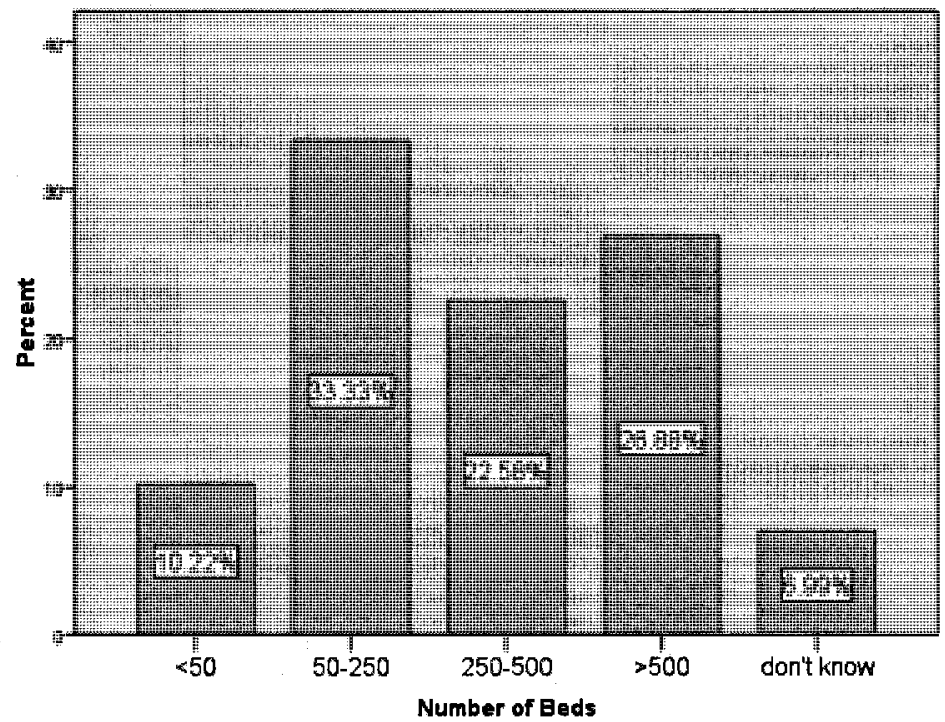

Figure 5.3: Hospital Size $(\mathrm{n}=186)$

\subsubsection{Average Occupancy}

Respondents reported their hospital's average occupancy as shown in Figure 5.4. The results are concurrent with previous findings of Cao and Frize [6], which found no occupancy rates below $50 \%$. The distribution of occupancy rates across regions was relatively similar. Africa was the only region in which a minority of respondents reported more than $75 \%$ occupancy $(42.6 \%)$.

\subsubsection{Proportion of ICU Beds}

Intensive care unit (ICU) beds are very technology-intensive; ICU wards tend to have the most sophisticated technologies that are intensely and comprehensively used [6]. Figure 5.5 shows that the distribution of proportion of ICU beds categories is somewhat normalised around $5-10 \%$ of hospital beds, with $36.0 \%$ of respondents reporting 


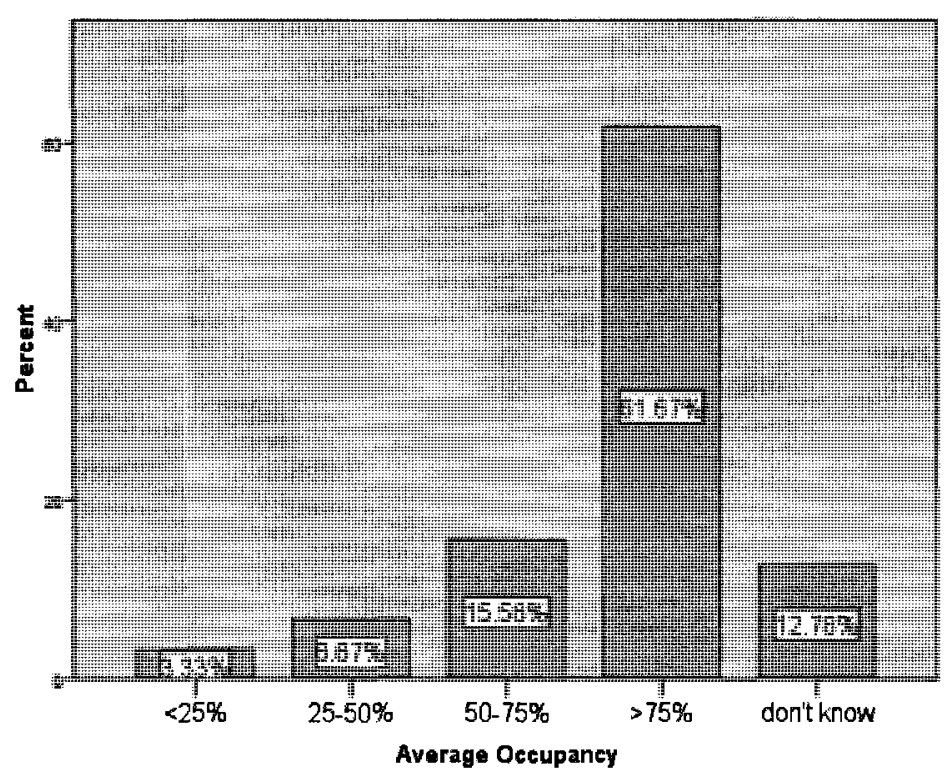

Figure 5.4: Average Occupancy $(\mathrm{n}=180)$

Table 5.5: Average Occupancy by Region $(n=180)$

\begin{tabular}{|lr|c|c|c|c|c|}
\hline \multirow{2}{*}{ Region } & \multicolumn{5}{|c|}{ Average Occupancy } \\
\cline { 3 - 7 } & & $<25 \%$ & $25-50 \%$ & $50-75 \%$ & $>75 \%$ & don't know \\
\hline Africa (n=47) & Regional & $4.3 \%$ & $10.6 \%$ & $25.5 \%$ & $42.6 \%$ & $17.0 \%$ \\
& Overall & $1.0 \%$ & $2.4 \%$ & $5.8 \%$ & $9.7 \%$ & $3.9 \%$ \\
\hline Latin America (n=89) & Regional & $2.2 \%$ & $6.7 \%$ & $13.5 \%$ & $67.4 \%$ & $10.1 \%$ \\
& Overall & $1.0 \%$ & $2.9 \%$ & $5.8 \%$ & $29.0 \%$ & $4.3 \%$ \\
\hline Asia (n=32) & Regional & $6.3 \%$ & $3.1 \%$ & $12.5 \%$ & $68.8 \%$ & $9.4 \%$ \\
& Overall & $1.0 \%$ & $.5 \%$ & $1.9 \%$ & $10.6 \%$ & $1.4 \%$ \\
\hline Middle East (n=8) & Regional & $.0 \%$ & $.0 \%$ & $.0 \%$ & $87.5 \%$ & $12.5 \%$ \\
& Overall & $.0 \%$ & $.0 \%$ & $.0 \%$ & $3.4 \%$ & $.5 \%$ \\
\hline Eastern Europe (n=3) & Regional & $.0 \%$ & $.0 \%$ & $.0 \%$ & $66.7 \%$ & $33.3 \%$ \\
& Overall & $.0 \%$ & $.0 \%$ & $.0 \%$ & $1.0 \%$ & $.5 \%$ \\
\hline
\end{tabular}

that proportion. Table 5.6 presents the breakdown by region. Proportionally, $<5 \%$ of ICU beds was most common in Asia and Africa, while in Latin America 5-10\% was 


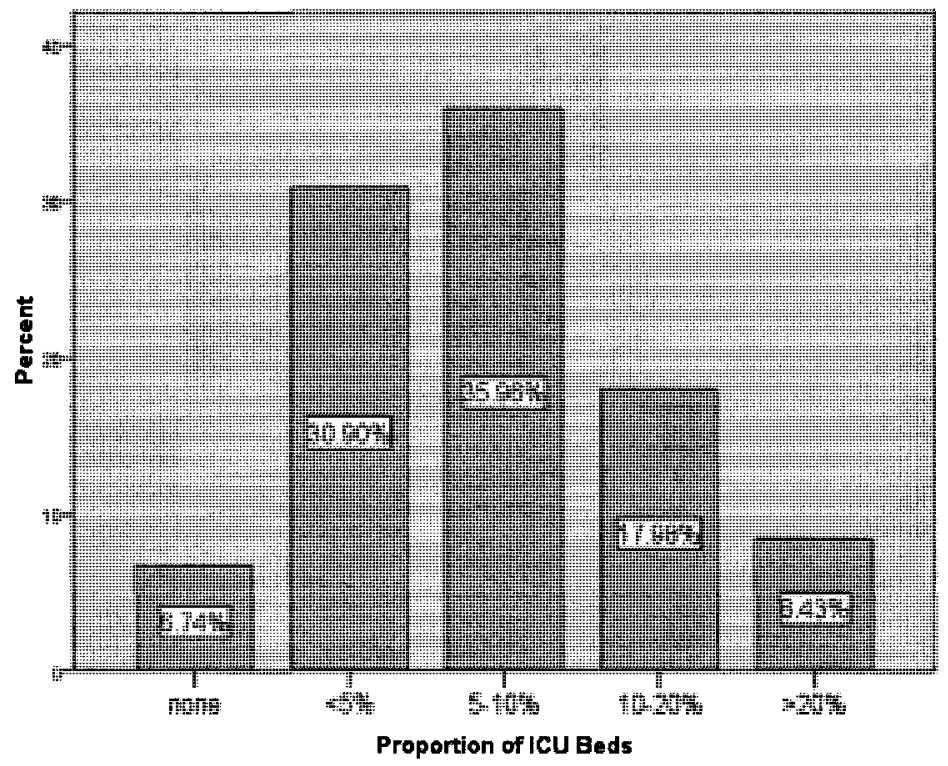

Figure 5.5: Proportion of ICU Beds $(\mathrm{n}=178)$

the most common proportion, with almost half of the 93 respondents. In [6], 36.1\% of respondents reported more than $10 \%$ ICU beds; $47 \%$ of teaching hospitals and only $22 \%$ of non-teaching hospitals had this proportion.

\subsubsection{Summary}

In summary, this sample represents a novel hospital type population when compared with previous research. The mix of sources of hospital funding and the lower proportion of teaching hospitals differentiate it from previous findings by Cao and Frize [6] and by Glouhova et al. [8]. 
Table 5.6: Proportion of ICU Beds by Region ( $\mathrm{n}=178$ )

\begin{tabular}{|lr|c|c|c|c|c|}
\hline \multicolumn{2}{|c|}{ Region } & \multicolumn{5}{|c|}{ Proportion of ICU Beds } \\
\cline { 3 - 7 } & & none & $<5 \%$ & $5-10 \%$ & $10-20 \%$ & $>20 \%$ \\
\hline Africa (n=48) & Regional & $14.6 \%$ & $43.8 \%$ & $22.9 \%$ & $10.4 \%$ & $8.3 \%$ \\
& Overall & $3.4 \%$ & $10.1 \%$ & $5.3 \%$ & $2.4 \%$ & $1.9 \%$ \\
\hline Latin America (n=93) & Regional & $2.4 \%$ & $20.2 \%$ & $46.4 \%$ & $21.4 \%$ & $9.5 \%$ \\
& Overall & $1.0 \%$ & $8.2 \%$ & $18.8 \%$ & $8.7 \%$ & $3.9 \%$ \\
\hline Asia (n=35) & Regional & $2.9 \%$ & $45.7 \%$ & $34.3 \%$ & $11.4 \%$ & $5.7 \%$ \\
& Overall & $.5 \%$ & $7.7 \%$ & $5.8 \%$ & $1.9 \%$ & $1.0 \%$ \\
\hline Middle East (n=8) & Regional & $25.0 \%$ & $12.5 \%$ & $.0 \%$ & $62.5 \%$ & $.0 \%$ \\
& Overall & $1.0 \%$ & $.5 \%$ & $.0 \%$ & $2.4 \%$ & $.0 \%$ \\
\hline Eastern Europe (n=2) & Regional & $.0 \%$ & $.0 \%$ & $50.0 \%$ & $.0 \%$ & $50.0 \%$ \\
& Overall & $.0 \%$ & $.0 \%$ & $.5 \%$ & $.0 \%$ & $.5 \%$ \\
\hline
\end{tabular}

\subsubsection{Equipment Maintenance Department Profile}

\subsubsection{Structure}

It was suggested during the consultation phase of questionnaire design that the name of this section be changed to 'equipment maintenance department' instead of 'clinical engineering department' to include respondents who may not exist as a separate unit within their hospital and may primarily be regarded as a repair shop. This was a wise decision, as many respondents reported varying names and a significant amount reported being named 'maintenance' departments. Overall, 59.4\% reported being separate departments, while $40.6 \%$ reporting being part of a larger department with other maintenance responsibilities $(\mathrm{n}=155)$. This denotes a different population than Cao and Frize's findings in which over $80 \%$ of respondents in both Latin America and Asia existed as a separate unit [71].

Regionally, existence as a separate unit is as follows: $63.4 \%$ in Africa (26/41), $57.7 \%$ in Latin America (45/78), $44.4 \%$ in Asia (12/27), and $100 \%$ in the Middle 
East and Eastern Europe (8/8). For those departments that are part of a larger department, the majority reported belonging to a 'maintenance', 'technical', 'engineering services' or 'facilities' department. Several also indicated that the department was part of a regional or national maintenance service team. Respondents were also asked for the names of their staff positions, in descending order of seniority. This was recommended by another consultant during questionnaire design, and can be used by future researchers to further assess CE development levels within hospitals.

\subsubsection{Reporting Authority}

Overall, reporting authorities were reported as: senior administrator ( $29 \%$ or $45 / 155)$; medical director $(36.8 \%$ or $57 / 155)$; plant/maintenance director $(18.1 \%$ or $28 / 155)$; and other $(16.1 \%$ or $25 / 155)$, with no major variation based on region. A total of $75.7 \%$ of respondents reported being satisfied with their reporting authority, which is similar to the findings of Cao and Frize [6] in which over $80 \%$ of respondents reported being satisfied. Satisfaction was highest in Asia, with $88.5 \%$ of respondents reporting satisfaction with their reporting authority $(n=23)$. Considering the political nature of employment hierarchies in developing world hospitals (and elsewhere), it is possible that this high rate of satisfaction is not entirely accurate. Satisfaction with reporting authority correlated with reporting authority is presented in Table 5.7. It shows that those who report to medical directors and 'other' report the highest satisfaction rates. For those who report to 'other', the most common answers were regional authorities; for example, 'district health officer' or 'deputy director, regional health services'. Interestingly, the only hospital type correlated with reporting authority and with satisfaction rates is university/teaching; respondents from these hospitals tend to report to administrators and to be satisfied with the arrangement. 
Table 5.7: Reporting Authority and Satisfaction Rates $(\mathrm{n}=150)$

\begin{tabular}{|l||c|c|}
\hline \multicolumn{1}{|l||}{ Reporting Authority } & \multicolumn{2}{c|}{ Satisfied } \\
\cline { 2 - 3 } & Yes & No \\
\hline Senior Administrator $(\mathrm{n}=42)$ & $69.0 \%$ & $31.0 \%$ \\
\hline Medical Director $(\mathrm{n}=56)$ & $78.6 \%$ & $21.4 \%$ \\
\hline Plant / Maintenance Director $(\mathrm{n}=28)$ & $75.0 \%$ & $25.0 \%$ \\
\hline Other $(\mathrm{n}=25)$ & $84.0 \%$ & $16.0 \%$ \\
\hline
\end{tabular}

\subsubsection{Shared Services}

Shared equipment services can be very cost and resource effective. Overall, a minority of respondents $(36.6 \%$ or $56 / 153)$ reporting sharing services with other hospitals and health centres. Regionally, the proportion of hospitals who share services differs significantly, as shown in Table 5.8, with three quarter of Latin American respondents not sharing services, while $57 . \%$ of African respondents and almost one half of Asian respondents do. The high rate among African respondents is explained partially by the fact that many of the South African respondents are from a network of public/private hospitals that share services. Only one respondent in the Middle East shared services, and neither of the Eastern European respondents did. There was little variation between government-funded and privates hospitals, of which $40.0 \%$ and $33.3 \%$ respectively reported sharing services.

Of those who did report sharing services, $64.4 \%$ were the main centre. The results for number of hospitals and number of health centres sharing the services of respondent hospitals are presented in Table 5.9; thirty-two respondents share services with both hospitals and health centres. The standard deviation is large for overall responses because there are a total of nine respondents who are responsible for 25 or more hospitals and health centres; they are the same sample that indicated reporting 
Table 5.8: Shared Services by Region $(\mathrm{n}=152)$

\begin{tabular}{|l||c|c|}
\hline \multicolumn{1}{|l||}{ Region } & \multicolumn{2}{c|}{ Shared Services } \\
\cline { 2 - 3 } & Yes & No \\
\hline Africa $(\mathrm{n}=42)$ & $57.1 \%$ & $42.9 \%$ \\
\hline Latin America $(\mathrm{n}=77)$ & $24.7 \%$ & $75.3 \%$ \\
\hline Asia $(\mathrm{n}=25)$ & $48.0 \%$ & $52.0 \%$ \\
\hline Middle East $(\mathrm{n}=6)$ & $16.7 \%$ & $83.3 \%$ \\
\hline Eastern Europe $(\mathrm{n}=2)$ & $.0 \%$ & $100.0 \%$ \\
\hline
\end{tabular}

to national health authorities. The average number of health centres supported is twice that of hospitals.

Table 5.9: Number of Shared Hospitals and Health Centres

\begin{tabular}{|c|c|c|}
\hline & Hospitals $(n=47)$ & Health Centres $(n=37)$ \\
\hline Mean & 12.69 & 27.97 \\
\hline Median & 7.00 & 15.00 \\
\hline Std. Deviation & 16.643 & 33.613 \\
\hline $\begin{array}{ll}\text { Percentiles } & 25 \\
& 50 \\
& 75\end{array}$ & $\begin{array}{l}2.00 \\
7.00 \\
7500\end{array}$ & $\begin{array}{c}5.00 \\
15.00 \\
45.00\end{array}$ \\
\hline
\end{tabular}

\subsubsection{Summary}

In summary, a higher proportion of EMDs that are not classified as 'clinical engineering departments' are present in the sample. Satisfaction with reporting authority is high, which is similar to prior findings of Cao and Frize [6]. However, it is only correlated with university/teaching hospitals. Over one third of respondents share equipment maintenance services, with a majority of African respondents reporting a shared service program. 


\subsubsection{Equipment Maintenance Department Personnel}

\subsubsection{Human Resources}

Respondents were asked to report the total number of engineers (ENG), technicians / technologists $(\mathrm{T} / \mathrm{T})$, students (STU) and clerical (CLE) staff working in their EMD. Results are presented in Table 5.10. The mean number of engineers and technicians/technologists is 3.39 and 5.69 respectively. Almost half of all respondents reported having 2 engineers in the department (47.2\%), followed by $3(16.2 \%)$ and 1 (9.9\%). Somewhat similarly, the majority of respondents reported having either 2, 3, or 4 technicians / technologists $(16.0 \%, 13.2 \%$, and $14.6 \%$ respectively).

Respondents also reported a mean of 3.05 students and 2.92 clerical staff. It must be noted, however, that the number of respondents for these staff was considerably lower, and it is assumed that those who did not respond had no students or clerical staff. The most common number of students in a department was 1,3 , and $2(35.4 \%$, $23.2 \%$, and $15.2 \%$ respectively). There were most commonly 2,3 , and 1 clerical staff reported $(40.6 \%, 26.7 \%$, and $11.9 \%$ respectively) when respondents did have clerical staff.

When asked if staffing was adequate, $61.4 \%$ of all respondents said it was not. This level did not vary greatly between government-funded and private hospitals $(67.6 \%(50 / 74)$ and $69.4 \%(25 / 36)$ respectively). Regional responses are presented in Table 5.11, which show that African respondents had the highest reporting of inadequate staff (76.2\%). The majority of Asian respondents reported adequate staffing, while slightly more than one third of Latin American respondents reported having adequate staffing.

Respondents were also asked whether it was difficult to find qualified engineers 
Table 5.10: Number of Staff

\begin{tabular}{|c|c|c|c|c|}
\hline & ENG $(n=142)$ & $\mathrm{T} / \mathrm{T}(\mathrm{n}=144)$ & STU $(n=99)$ & CLE $(n=101)$ \\
\hline Mean & 3.39 & 5.69 & 3.05 & 2.92 \\
\hline Median & 2.00 & 5.00 & 2.00 & 2.00 \\
\hline Std. Deviation & 2.609 & 3.308 & 2.557 & 2.564 \\
\hline $\begin{array}{ll}\text { Percentiles } & 25 \\
& 50 \\
& 75\end{array}$ & $\begin{array}{l}2.00 \\
2.00 \\
4.00\end{array}$ & $\begin{array}{l}3.00 \\
5.00 \\
8.00\end{array}$ & $\begin{array}{l}1.00 \\
2.00 \\
4.00\end{array}$ & $\begin{array}{l}1.00 \\
2.00 \\
3.00\end{array}$ \\
\hline
\end{tabular}

Table 5.11: Adequate Staff by Region $(\mathrm{n}=152)$

\begin{tabular}{|l||c|c|}
\hline \multicolumn{1}{|l||}{ Region } & \multicolumn{2}{c|}{ Adequate Staff } \\
\cline { 2 - 3 } & Yes & No \\
\hline Africa $(\mathrm{n}=42)$ & $23.8 \%$ & $76.2 \%$ \\
\hline Latin America $(\mathrm{n}=77)$ & $37.7 \%$ & $62.3 \%$ \\
\hline Asia $(\mathrm{n}=25)$ & $64.0 \%$ & $36.0 \%$ \\
\hline Middle East $(\mathrm{n}=6)$ & $33.3 \%$ & $66.7 \%$ \\
\hline Eastern Europe $(\mathrm{n}=2)$ & $100.0 \%$ & $.0 \%$ \\
\hline
\end{tabular}

and technicians/technologists locally, based on the reality that human resources are in short supply in the developing world, even when financial resources are not. Overall, $77.3 \%$ of respondents said it was difficult to find qualified engineers locally, and $68.0 \%$ reported difficulty finding technicians locally $(n=148)$. Responses are presented regionally in Table 5.12. Similar to reporting on adequate staff, Africa has the highest response rate for difficulty finding qualified engineers locally. Latin America has the highest proportion of respondents indicating that finding qualified technicians locally is a challenge, while Asia has lower levels of need for both engineers and technicians. 
Table 5.12: Difficulty Finding Qualified Engineers and Technicians Locally $(\mathrm{n}=148)$

\begin{tabular}{|l||c|c|c|c|}
\hline \multicolumn{1}{|l||}{ Region } & \multicolumn{2}{c|}{ Engineers } & \multicolumn{2}{c|}{ Technicians } \\
\cline { 2 - 5 } & Yes & No & Yes & No \\
\hline Africa $(\mathrm{n}=40)$ & $85.0 \%$ & $15.0 \%$ & $73.2 \%$ & $26.8 \%$ \\
\hline Latin America $(\mathrm{n}=75)$ & $77.6 \%$ & $22.4 \%$ & $78.9 \%$ & $21.1 \%$ \\
\hline Asia $(\mathrm{n}=25)$ & $60.0 \%$ & $40.0 \%$ & $64.7 \%$ & $35.3 \%$ \\
\hline Middle East $(\mathrm{n}=6)$ & $83.3 \%$ & $16.7 \%$ & $66.7 \%$ & $33.3 \%$ \\
\hline Eastern Europe $(\mathrm{n}=2)$ & $100.0 \%$ & $.0 \%$ & $100.0 \%$ & $.0 \%$ \\
\hline
\end{tabular}

\subsubsection{Training}

Respondents were asked how many of their staff were trained in biomedical and/or electronics technology before they started working in the EMD. Overall results are presented in Table 5.13, and regional responses are presented in Table 5.14. The majority of overall respondents report few to none of their staff being trained in biomedical technology prior to working in the EMD; however almost 50\% reported most to all of their staff being trained in electronics technology.

Regionally, Africa reported the lowest rate of biomedical technology training with $79 \%$ reporting little to no prior training. More than half of all Latin American respondents reported the same rates (i.e. few to no staff being trained prior). However, over a quarter of Latin American respondents also reported that all staff were trained in biomedical technology prior to being employed by the EMD (26.0\%). This is accounted for by the fact that $46.7 \%$ of all Mexican respondents $(n=15)$ reported all staff being trained prior to employment in the EMD. Brazil, on the other hand, reported only $11.8 \%$ for the same level of staff training $(n=17)$. The most common responses from Asian respondents were 'half' and 'few' staff being trained in biomedical technology prior, accounting for $74.2 \%$ of the regional total. 
For electronics technology, regional responses showed that more than half of African, Latin American and Asian respondents reported to 'most' to 'all' staff receiving prior training. Approximately one third of all African and Latin American respondents reported all of their staff being trained to EMD employment.

Table 5.13: Prior Staff Training

\begin{tabular}{|l|c|c|c|c|c|}
\hline Training & All & Most & Half & Few & None \\
\hline Biomedical Technology $(\mathrm{n}=150)$ & $14.0 \%$ & $15.3 \%$ & $12.7 \%$ & $32.7 \%$ & $25.3 \%$ \\
\hline Electronics $(\mathrm{n}=136)$ & $25.0 \%$ & $24.3 \%$ & $11.8 \%$ & $29.4 \%$ & $9.6 \%$ \\
\hline
\end{tabular}

Table 5.14: Prior Staff Training by Region

\begin{tabular}{|l||c|c|c|c|c|}
\hline \multicolumn{1}{|c||}{ Region } & \multicolumn{5}{|c|}{ Trained in Biomedical Technology } \\
\cline { 2 - 6 } & All & Most & Half & Few & None \\
\hline Africa $(\mathrm{n}=43)$ & $4.7 \%$ & $9.3 \%$ & $7.0 \%$ & $39.5 \%$ & $39.5 \%$ \\
\hline Latin America $(\mathrm{n}=73)$ & $26.0 \%$ & $16.4 \%$ & $8.2 \%$ & $26.0 \%$ & $23.3 \%$ \\
\hline Asia $(\mathrm{n}=26)$ & $.0 \%$ & $15.4 \%$ & $34.6 \%$ & $34.6 \%$ & $15.4 \%$ \\
\hline Middle East $(\mathrm{n}=5)$ & $.0 \%$ & $60.0 \%$ & $20.0 \%$ & $20.0 \%$ & $.0 \%$ \\
\hline Eastern Europe $(\mathrm{n}=2)$ & $.0 \%$ & $.0 \%$ & $.0 \%$ & $100.0 \%$ & $.0 \%$ \\
\hline \multirow{2}{*}{ Region } & \multicolumn{1}{|c|}{ Trained in Electronics Technology } \\
\cline { 2 - 6 } & All & Most & Half & Few & None \\
\hline Africa $(\mathrm{n}=39)$ & $33.3 \%$ & $25.6 \%$ & $7.7 \%$ & $28.2 \%$ & $5.1 \%$ \\
\hline Latin America $(\mathrm{n}=65)$ & $32.3 \%$ & $21.5 \%$ & $7.7 \%$ & $26.2 \%$ & $12.3 \%$ \\
\hline Asia $(\mathrm{n}=24)$ & $.0 \%$ & $25.0 \%$ & $25.0 \%$ & $41.7 \%$ & $8.3 \%$ \\
\hline Middle East $(\mathrm{n}=5)$ & $.0 \%$ & $60.0 \%$ & $20.0 \%$ & $20.0 \%$ & $.0 \%$ \\
\hline Eastern Europe $(\mathrm{n}=2)$ & $.0 \%$ & $.0 \%$ & $50.0 \%$ & $50.0 \%$ & $.0 \%$ \\
\hline
\end{tabular}

Respondents were also asked whether they provide 'on the job' training for their staff. This has been recognised by many authors in the literature as a benchmark of CED / EMD effectiveness and a retention tool; engineers and technicians are often lured away from hospitals to work for private companies when trained human 
resources are scarce. Results are presented regionally in Table 5.15, and show that the majority of respondents in all regions (except Eastern Europe with 50\% and only $\mathrm{n}=2$ ) perform training 'on the job'. Future researchers could further investigate what type of training EMDs offer.

Table 5.15: 'On the Job' Training by Region

\begin{tabular}{|l||c|c|}
\hline \multicolumn{1}{|l||}{ Region } & \multicolumn{2}{c|}{ Provide 'on the job' Training } \\
\cline { 2 - 3 } & Yes & No \\
\hline Africa $(\mathrm{n}=41)$ & $80.5 \%$ & $19.5 \%$ \\
\hline Latin America $(\mathrm{n}=76)$ & $69.7 \%$ & $30.3 \%$ \\
\hline Asia $(\mathrm{n}=26)$ & $73.1 \%$ & $26.9 \%$ \\
\hline Middle East $(\mathrm{n}=6)$ & $100.0 \%$ & $.0 \%$ \\
\hline Eastern Europe $(\mathrm{n}=2)$ & $50.0 \%$ & $50.0 \%$ \\
\hline
\end{tabular}

The highest education level of an EMD's engineer(s) and technicians/technologist(s) are presented in Figure 5.6 and Figure 5.7. Almost half (47.73\%) of respondents reported a university bachelor degree as the highest level of education for engineers, and another $34.09 \%$ reported engineers with university masters degrees. For technicians/technologists, almost half reported a 3-4 year technical school education $(47.86 \%)$.

Regional results are shown in Table 5.16, using the following codes: N/A (N/A), Under High School (U-HS), High School (HS), Technical School (1-2 yrs) (TS 12), Technical School (3-4 yrs) (TS 3-4), University (Bachelors) (U-B), University (Masters) (U-M), and University (Doctorate) (U-D). Latin America has the highest rate of university educated engineers $(94.1 \%)$, while Africa has the least $(72.3 \%)$; all regions have a majority of university-educated engineers. Regarding technologists, all regions have a minimum of $84 \%$ or more technicians with between a 1-2 year 
technical school education and a university bachelor degree (with the exception of Eastern Europe with a negligible sample size, and the possibility that the engineer with a university doctorate was also reported for the technician question).

Data collected by Cao and Frize [6] was similar. They reported that a majority of both Asian $(n=27)$ and Latin American $(n=34)$ engineers held bachelors degrees (55\% and $69 \%$ respectively). They also found that the highest level of technician education was more evenly distributed over the range of high school to a 4 year technical program. This differs from the current research presented in Figure 5.7. They also found that Asian respondents had a higher level of education than Latin American respondents in both categories. Education levels in the current sample also don't differ significantly from previous developed country research done by Frize [13] and Glouhova et al. [8], with the exception of the proportion of engineers who hold a doctorate, which is higher in the developed world.

Table 5.16: Highest Education by Region

\begin{tabular}{|l||c|c|c|c|c|c|c|c|}
\hline \multirow{2}{*}{ Region } & \multicolumn{7}{|c|}{ Highest Education Level of Engineer } \\
\cline { 2 - 10 } & N/A & U-HS & HS & TS 1-2 & TS 3-4 & U-B & U-M & U-D \\
\hline Africa (n=36) & $8.3 \%$ & $.0 \%$ & $.0 \%$ & $.0 \%$ & $19.4 \%$ & $25.0 \%$ & $30.6 \%$ & $16.7 \%$ \\
\hline Latin America (n=67) & $3.0 \%$ & $1.5 \%$ & $1.5 \%$ & $.0 \%$ & $.0 \%$ & $62.7 \%$ & $28.4 \%$ & $3.0 \%$ \\
\hline Asia (n=21) & $.0 \%$ & $.0 \%$ & $.0 \%$ & $.0 \%$ & $4.8 \%$ & $42.9 \%$ & $52.4 \%$ & $.0 \%$ \\
\hline Middle East (n=5) & $.0 \%$ & $.0 \%$ & $.0 \%$ & $.0 \%$ & $.0 \%$ & $40.0 \%$ & $60.0 \%$ & $.0 \%$ \\
\hline Eastern Europe (n=2) & $.0 \%$ & $.0 \%$ & $.0 \%$ & $.0 \%$ & $.0 \%$ & $.0 \%$ & $50.0 \%$ & $50.0 \%$ \\
\hline \multicolumn{1}{|c|}{ Region } & \multicolumn{3}{|c|}{ Highest Education Level of Technician/Technologist } \\
\cline { 2 - 10 } & N/A & U-HS & HS & TS 1-2 & TS 3-4 & U-B & U-M & U-D \\
\hline Africa (n=40) & $.0 \%$ & $.0 \%$ & $5.0 \%$ & $17.5 \%$ & $60.0 \%$ & $10.0 \%$ & $7.5 \%$ & $.0 \%$ \\
\hline Latin America (n=67) & $4.5 \%$ & $.0 \%$ & $7.5 \%$ & $17.9 \%$ & $46.3 \%$ & $20.9 \%$ & $3.0 \%$ & $.0 \%$ \\
\hline Asia (n=25) & $8.0 \%$ & $4.0 \%$ & $4.0 \%$ & $32.0 \%$ & $36.0 \%$ & $16.0 \%$ & $.0 \%$ & $.0 \%$ \\
\hline Middle East (n=5) & $.0 \%$ & $.0 \%$ & $.0 \%$ & $20.0 \%$ & $40.0 \%$ & $40.0 \%$ & $.0 \%$ & $.0 \%$ \\
\hline Eastern Europe (n=2) & $.0 \%$ & $.0 \%$ & $.0 \%$ & $.0 \%$ & $50.0 \%$ & $.0 \%$ & $.0 \%$ & $50.0 \%$ \\
\hline
\end{tabular}




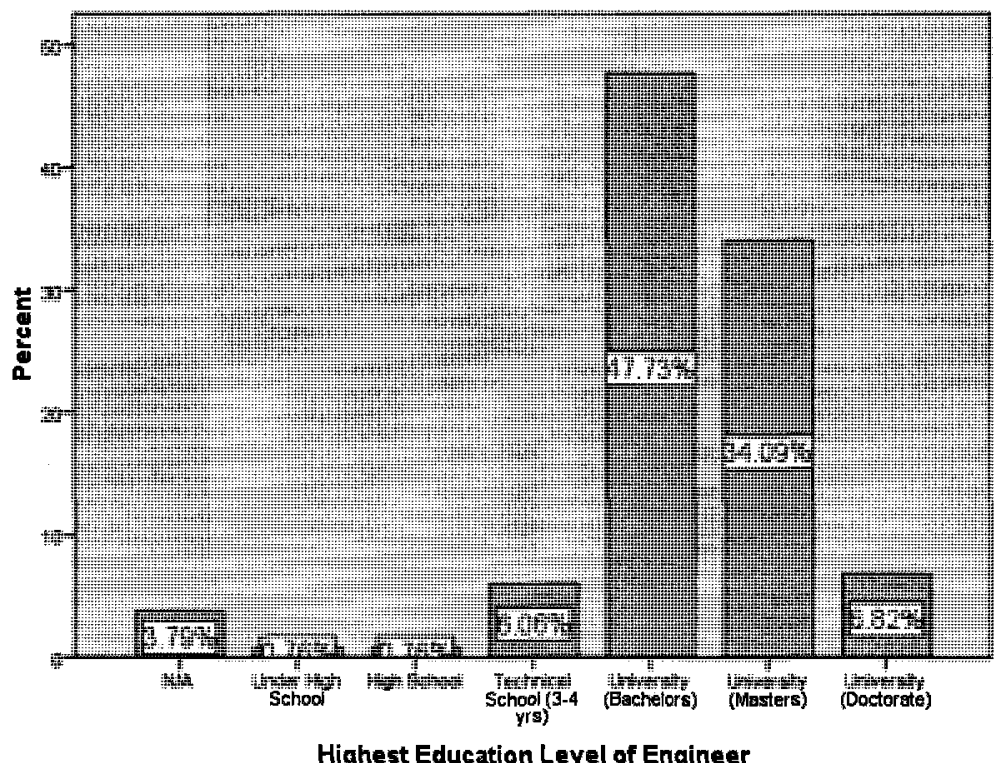

Figure 5.6: Highest Education Level of Engineer $(\mathrm{n}=132)$

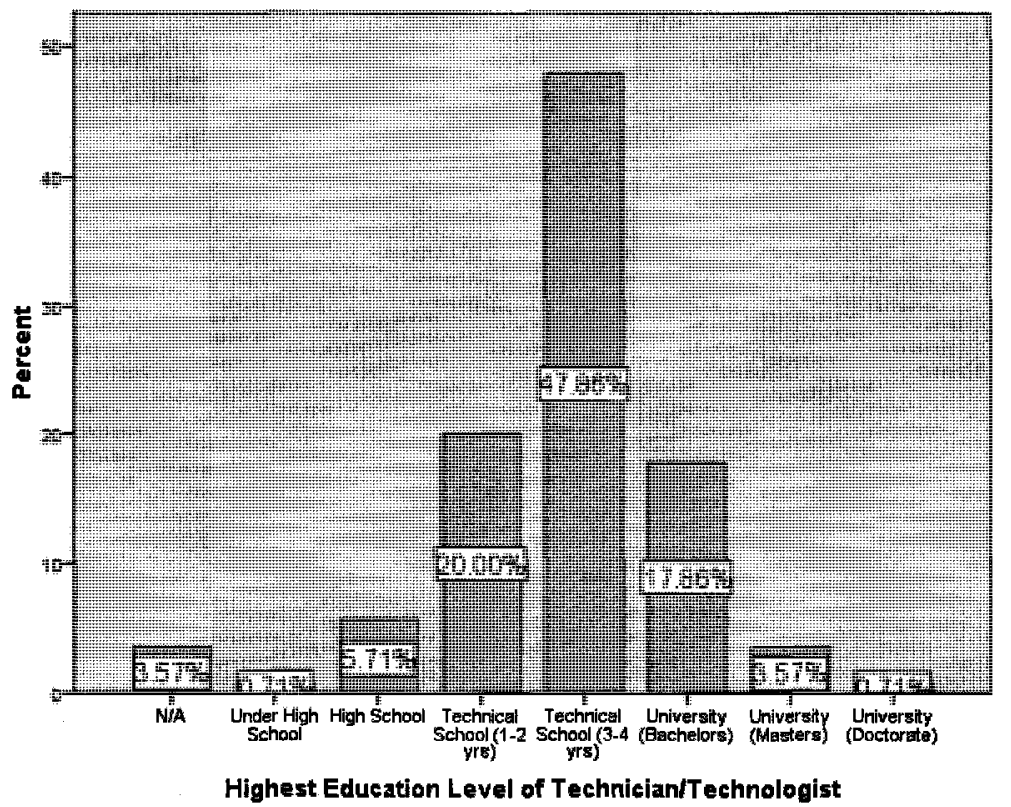

Figure 5.7: Highest Education Level of Technician/Technologist $(n=140)$ 
Finally, with regards to training, respondents were asked whether any of their staff had received training outside of the country, and if so, where. Overall, $44.4 \%$ replied 'yes', $53.6 \%$ replied 'no' and 2.0\% replied 'don't know' (n=151). The U.K., France, Germany, Japan and the U.S. were the most common countries staff had received additional training in.

\subsubsection{Responsibilities}

Respondents were asked to select which activities their engineers and technicians/technologists performed. Originally the question had asked respondents to rank which activities their staff performed in order of time spent on each activity. However, this question was found to be the most confusing by $4 / 5$ pre-test respondents, and was changed to only ask which activities engineers and technicians / technologists are responsible for. Possible choices were randomised with the online questionnaire to reduce response bias. Table 5.17 presents the results.

Table 5.17: Engineers and Technicians Responsibilities ( $\mathrm{n}=152)$

\begin{tabular}{|l||c|c|c|c|}
\hline \multicolumn{1}{|l||}{ Activity } & \multicolumn{2}{c|}{ Engineers } & \multicolumn{2}{c|}{ Technicians } \\
\cline { 2 - 5 } & N & Total & N & Total \\
\hline In-house Repair & 78 & $51.32 \%$ & 78 & $51.32 \%$ \\
\hline Incoming Inspection & 82 & $53.95 \%$ & 114 & $75.00 \%$ \\
\hline Preventive Maintenance & 65 & $42.76 \%$ & 128 & $84.21 \%$ \\
\hline User Education and Training & 102 & $67.11 \%$ & 74 & $48.68 \%$ \\
\hline Pre-purchase Consultation & 107 & $70.39 \%$ & 43 & $28.29 \%$ \\
\hline Research & 83 & $54.61 \%$ & 20 & $13.16 \%$ \\
\hline Clerical Work & 74 & $48.68 \%$ & 73 & $48.03 \%$ \\
\hline Other & 30 & $19.74 \%$ & 39 & $25.66 \%$ \\
\hline
\end{tabular}

Results show that the tasks technicians perform most often in descending or- 
der are: preventive maintenance (84.21\%), incoming inspection (75.0\%), in-house repair $(51.32 \%)$, user education and training $(48.68 \%)$, clerical work (48.03\%), prepurchase consultation (28.29\%), other (25.66\%) and research (13.16\%). The most common tasks performed by engineers in descending order are: pre-purchase consultation $(70.39 \%)$, user education and training $(67.11 \%)$, research $(54.61 \%)$, incoming inspection (53.95\%), in-house repair (51.32\%), clerical work (48.68\%), preventive maintenance $(42.76 \%)$ and other $(19.74 \%)$. Several findings are interesting. In the sample, engineers and technicians perform an equal amount of in-house repairs, with just over half of all respondents reporting this activity. They also perform almost equal rates of clerical work. There is, however, a general division of labour with engineers performing more managerial and consultative activities (such as pre-purchase consultation, user education and training, and research) while technicians perform more technical activities (such as preventive maintenance, incoming inspections and in-house repair). It would be interesting for future researchers to determine which equipment types engineers and technicians typically repair.

\subsubsection{Infrastructure Responsibilities}

Another indicator of level of sophistication of an equipment maintenance department $(E M D)^{3}$ is whether or not they are responsible for the maintenance of infrastructure systems within the hospital; more advanced CEDs will primarily be responsible for medical equipment, and occasionally for infrastructure systems which heavily affect equipment such as medical gas or sterilisation, but will not be responsible for more basic infrastructure systems such as power [72]. Table 5.18 presents which infrastructure systems respondents reported being responsible for within the EMD. Medical gas

\footnotetext{
${ }^{3} \mathrm{EMD}$ in this thesis is synonymous with CED in other literature.
} 
and sterilisation are most commonly maintained by EMDs, while computers and IT systems are least often maintained by EMDs in the sample. Regionally, variation was low; there was also little variation between government-funded and private hospitals.

Table 5.18: Infrastructure Responsibilities $(\mathrm{n}=153)$

\begin{tabular}{|l||c|}
\hline Infrastructure System & EMD Responsibility \\
\hline Power & $38.2 \%$ \\
\hline Medical Gas & $46.7 \%$ \\
\hline Sterilisation & $48.8 \%$ \\
\hline Water & $30.9 \%$ \\
\hline Computers and IT & $17.4 \%$ \\
\hline HVAC & $39.1 \%$ \\
\hline
\end{tabular}

\subsubsection{Summary}

In summary, African hospitals reported having the most challenges with EMD staffing and with finding qualified staff locally. They also reported the lowest education rates of EMD staff. Asia had the least difficulty finding human resources, and their staff had a higher level of education than other regions. Latin America tended to rate between Africa and Asia in many EMD personnel indicators. The small Middle East and Eastern Europe sample sizes were small, but reported higher levels of engineer education. There was a general division of labour between engineers and technicians, with two exceptions - in-house repair and clerical work.

\subsubsection{Equipment Inventory}

Another excellent indicator of a CED's effectiveness is the sophistication of its inventory system. Respondents were asked whether they had an inventory of their medical 
equipment, how it was managed, and which details it kept track of.

Almost all respondents (94/1\%) reported having an inventory of their medical equipment $(\mathrm{n}=153)$. Of these, $13.7 \%$ wrote their inventory by hand on paper, $45.2 \%$ used a computer and a generic spreadsheet software such as Microsoft Excel and $41.4 \%$ used a computer equipped with a specialised medical equipment management software, such as AIMS, VHTemp or Four Rivers $(n=146)$. Regionally, the most common system in both Africa and Latin America was using generic software (48.8\% and $53.6 \%$ respectively), while in Asia $64.0 \%$ of respondents used a specialised software. Table 5.19 presents the distribution of which equipment information respondents store in their inventory system, which were randomised to reduce response bias.

Table 5.19: Inventory Information $(\mathrm{n}=152)$

\begin{tabular}{|l|c|c|}
\hline \multirow{2}{*}{ Item } & \multicolumn{2}{|c|}{ Tracked in Inventory System } \\
\cline { 2 - 3 } & $\mathbf{N}$ & Total \\
\hline Serial Number & 125 & $82.24 \%$ \\
\hline Model Number & 114 & $75.00 \%$ \\
\hline Vendor, Manufacturer and Sales Support & 105 & $69.08 \%$ \\
\hline Age & 101 & $66.45 \%$ \\
\hline Purchase Information & 93 & $61.18 \%$ \\
\hline PM Schedule & 89 & $58.55 \%$ \\
\hline Original Cost & 89 & $58.55 \%$ \\
\hline History of Work Orders & 88 & $57.89 \%$ \\
\hline Main Service Technician & 86 & $56.58 \%$ \\
\hline Condition & 85 & $55.92 \%$ \\
\hline Warranty Duration for Parts and Labour & 85 & $55.92 \%$ \\
\hline Spare Parts & 75 & $49.34 \%$ \\
\hline Infrastructure Requirements & 67 & $44.08 \%$ \\
\hline Unique Asset Number & 64 & $42.11 \%$ \\
\hline Replacement Priority & 63 & $41.45 \%$ \\
\hline
\end{tabular}

Results show that the most common equipment attributes stored are serial num- 
ber $(82.2 \%)$, model number (75.0\%), vendor, manufacturer and sales support (69.1\%), age $(66.5 \%)$ and purchase information $(61.2 \%)$. The least stored attributes are replacement priority (41.5\%), unique asset number (42.1\%), infrastructure requirements (44.1\%) and spare parts (49.3\%). All other attributes (PM schedule, original cost, history of work orders, main service technician, condition and warranty duration for parts and labour) were recorded by more than $50 \%$ of respondents. Common responses for 'other' included location, manuals and risk categorisation. Many respondents used this open-ended question to indicate that they would like to, or are moving towards, including all attributes but that it is a challenge. Several also noted that inventory management is done in an 'ad hoc' manner.

\subsubsection{Medical Equipment}

Medical equipment in this research was categorised by complexity, as presented in Section 3.3.3. The four categories of complexity, based on sophistication of components, ease of repair and user training are:

1. Basic: very simple mechanical parts and no electrical parts, requires very minimal user training (less than 15 minutes), very simple to repair or disposable. Examples: needles, stethoscopes, and manual sphygmomanometers.

2. Simple: simple mechanical parts and electrical parts (no complex circuit boards or microchips), requires some user and maintenance training (less than 2 days). Examples: incubators, centrifuges, and nebulisers.

3. Complex: more complex mechanical and electrical parts (mircochips), requires substantial user and maintenance training (less than 1 week). Examples: ultra- 
sound, x-ray, electro-surgical equipment, monitors, and specialised lab equipment.

4. Highly Specialised: highly complex mechanical and electrical systems, requires extensive user and maintenance training (more than 1 week). Examples: MRI, CAT scanning, and nuclear medicine.

Respondents reported number of devices as a percentage of the total equipment base. Table 5.20 presents the results. An average of one third of a hospital's base is reported as basic, one third as simple and one third as complex equipment, while highly specialised equipment accounts for just over $10 \%$ of equipment. The complexity categories exhibited normalised distributions, while there was little variation regionally. Responses do not reflecte the suggested distribution of equipment complexity presented both by Cheng [62] and Roy [16]. Future researchers may use different metrics to assess complexity of equipment base, including cost of equipment.

Table 5.20: Equipment Complexity

\begin{tabular}{|c|c|c|c|c|}
\hline & Basic & Simple & Complex & Highly Specialised \\
\hline $\mathrm{n}$ & 112 & 116 & 116 & 107 \\
\hline Mean & 29.84 & 29.99 & 30.69 & 11.39 \\
\hline Std. Deviation & 16.485 & 11.098 & 16.168 & 11.846 \\
\hline Variance & 271.740 & 123.174 & 261.399 & 140.335 \\
\hline Percentiles & 15.00 & 20.00 & 20.00 & 5.00 \\
\hline 50 & 30.00 & 30.00 & 30.00 & 10.00 \\
\hline 75 & 40.00 & 37.25 & 40.00 & 10.00 \\
\hline
\end{tabular}




\subsubsection{Equipment Status}

Respondents were asked how much of their equipment base is out of use (OOS) or obsolete. Results presented in Table 5.21 show that the majority of all respondents reported less than $25 \%$ of their equipment base being OOS or obsolete, and that simple equipment was more commonly OOS than complex equipment, which was more commonly OOS than highly specialised equipment. Regionally, for all three complexity categories, Africa reported the highest rate of OOS equipment, followed by Latin America, followed by Asia with the lowest rates of OOS equipment. For example, $48.8 \%$ of African respondents reported $<25 \%$ of simple equipment OOS; $73.0 \%$ of Latin American respondents reported the same; and 76.5\% of Asian respondents reported the same.

Table 5.21: Proportion of OOS Equipment

\begin{tabular}{|l||c|c|c|c|}
\hline \multicolumn{1}{|c||}{ Complexity } & \multicolumn{4}{c|}{ Proportion of OOS Equipment (\%) } \\
\hline & $<\mathbf{2 5 \%}$ & $\mathbf{2 5 - 5 0 \%}$ & $\mathbf{5 0 - 7 5 \%}$ & $>\mathbf{7 5 \%}$ \\
\hline Simple $(\mathrm{n}=117)$ & 66.7 & 24.8 & 6.8 & 1.7 \\
\hline Complex $(\mathrm{n}=114)$ & 71.1 & 21.9 & 4.4 & 2.6 \\
\hline Highly Specialised $(\mathrm{n}=100)$ & 82.0 & 13.0 & 3.0 & 2.0 \\
\hline
\end{tabular}

Respondents were also asked to report the most common condition of their equipment base, based on reliability and frequency of repairs. Results presented in Table 5.22 show that approximately half of respondents reported equipment that was in 'good' condition for all three complexity levels. Regionally, Latin America reported the highest proportion of 'good' equipment for all three complexity levels, while Africa reported the largest proportion of 'fair' equipment. Asia responses varied more by complexity and proportion. It must be noted that the number of responses for both 
OOS and obsolete equipment and for common equipment condition had lower numbers of responses for highly specialised equipment. Cross-tabulation revealed that respondents who answered the question for simple and complex equipment, but skipped it for highly specialised equipment, are those who reported having no highly specialised equipment in their base.

Table 5.22: Proportion of Most Common Equipment Condition

\begin{tabular}{|l||c|c|c|c|c|}
\hline \multicolumn{1}{|c||}{ Complexity } & \multicolumn{5}{c|}{ Proportion of Most Common Condition (\%) } \\
\hline & Excellent & Good & Fair & Poor & Very Poor \\
\hline Simple $(\mathrm{n}=122)$ & 16.39 & 53.28 & 27.05 & 1.64 & 1.64 \\
\hline Complex $(\mathrm{n}=123)$ & 17.1 & 53.7 & 24.4 & 4.9 & .0 \\
\hline Highly Specialised $(\mathrm{n}=114)$ & 28.07 & 49.12 & 18.42 & 3.51 & 0.88 \\
\hline
\end{tabular}

Equipment standardisation is another good indicator of the sophistication of $\mathrm{CE}$ services within a hospital. Respondents reported the proportion of their equipment base that was standardised as presented in Table 5.23. The majority of respondents reported less than $50 \%$ of their simple and complex equipment being standardised (highly specialised equipment was not included because there are typically far fewer devices per equipment type). Regional variation was not significant.

Table 5.23: Proportion of Standardised Equipment

\begin{tabular}{|l||c|c|c|c|c|c|}
\hline \multicolumn{1}{|c|}{ Complexity } & \multicolumn{5}{|c|}{ Proportion of Standardised Equipment (\%) } \\
\hline & None & $<\mathbf{2 5 \%}$ & $\mathbf{2 5 - 5 0 \%}$ & $\mathbf{5 0 - 7 5 \%}$ & $\mathbf{7 5 \%}$ & All \\
\hline Simple $(\mathrm{n}=120)$ & 11.67 & 28.33 & 24.17 & 14.17 & 18.33 & 3.33 \\
\hline Complex $(\mathrm{n}=119)$ & 12.61 & 25.21 & 15.13 & 16.81 & 21.01 & 9.24 \\
\hline
\end{tabular}




\subsubsection{Resources}

It has been widely documented that equipment resources are scarce in many developing world hospitals. Respondents were asked for what proportion of their equipment base they currently the following resources: spare parts, user and maintenance manuals, test equipment, and trained users and maintenance technicians. Results are presented in Table 5.24; they show that the majority of respondents reported less than $25 \%$ of equipment having spare parts and test equipment. More than half also reported trained maintenance technicians being available for less than $50 \%$ of their base, with $10 \%$ reporting no trained maintenance technicians for their equipment base. User manuals were the most available resource, with $67.5 \%$ of respondents reporting this resource for more than half of their equipment base, and $23.3 \%$ reporting having user manuals for all equipment. Trained users were also reported for more $50 \%$ of the equipment by more than half of respondents $(53.7 \%)$. These results show an emphasis imbalance between equipment users and equipment maintenance staff; it appears that user training and user manuals have been prioritised over maintenance training and maintenance manuals.

Table 5.24: Proportion of Equipment with In-hospital Resources

\begin{tabular}{|l||c|c|c|c|c|c|}
\hline \multicolumn{1}{|c||}{ Resource } & \multicolumn{6}{c|}{ Proportion of Equipment with Resources (\%) } \\
\hline & None & $<\mathbf{2 5 \%}$ & $\mathbf{2 5 - 5 0 \%}$ & $\mathbf{5 0 - 7 5 \%}$ & $\mathbf{7 5 \%}$ & All \\
\hline Spare Parts (n=121) & 9.92 & 46.28 & 15.70 & 9.09 & 10.74 & 8.26 \\
\hline User Manuals $(\mathrm{n}=120)$ & 1.67 & 18.33 & 12.50 & 23.33 & 20.83 & 23.33 \\
\hline Maintenance Manuals $(\mathrm{n}=119)$ & 5.88 & 30.25 & 17.65 & 17.65 & 15.13 & 13.45 \\
\hline Test Equipment $(\mathrm{n}=121)$ & 19.01 & 37.19 & 14.88 & 12.40 & 10.74 & 5.79 \\
\hline Trained Users $(\mathrm{n}=121)$ & 3.31 & 28.10 & 14.88 & 19.01 & 23.97 & 10.74 \\
\hline Trained Maintenance Tech $(\mathrm{n}=120)$ & 10.00 & 32.50 & 16.67 & 14.17 & 20.00 & 6.67 \\
\hline
\end{tabular}


The WHO considers equipment obsolete when spare parts, accessories and reagents and/or manufacturer sales support ${ }^{4}$ are no longer available for equipment because they have been discontinued or are not under warranty. The reality is that a high proportion of equipment in the developing world is obsolete. Table 5.25 presents how often respondents reported the following resources being unavailable when needed: spare parts, accessories and reagents (Access \& Reag), manufacturer sales support (Manu Sales Supp) and troubleshooting and repair assistance (TSing \& Rep Assis). Results show that spare parts are the resource that are most often unavailable when needed, while troubleshooting and repair assistance are most often available, quite possibly from sources other than the manufacturer. Over a quarter or more of accessories and reagents and both types of support are rarely to never available when needed ${ }^{5}$.

Table 5.25: Rate of Discontinued Equipment Resources

\begin{tabular}{|l|c|c|c|c|c|}
\hline \multicolumn{1}{|c|}{ Resource } & \multicolumn{5}{c|}{ Rate of Discontinued Equipment Resources (\%) } \\
\hline & Always & Often & Sometimes & Rarely & Never \\
\hline Spare Parts (n=119) & 4.20 & 31.09 & 42.02 & 18.49 & 4.20 \\
\hline Access \& Reag (n=119) & 1.68 & 18.49 & 42.02 & 31.09 & 6.72 \\
\hline Manu Sales Supp (n=120) & 6.67 & 16.67 & 44.17 & 25.00 & 7.50 \\
\hline TSing \& Rep Assis (n=118) & 4.24 & 13.56 & 50.85 & 24.58 & 6.78 \\
\hline
\end{tabular}

\footnotetext{
${ }^{4}$ Preferably, a minimum of 2-4 years of manufacturer support is available.

${ }^{5}$ These results do exhibit central mean (i.e. a minimum of $42.0 \%$ of respondents chose 'sometimes' for each category); future researchers are encouraged to use an even numbered Likert scale to avoid this.
} 


\subsubsection{Additional Information}

Many respondents elaborated on problems with equipment in the open-ended question at the end of the equipment section of the questionnaire. Lack of spare parts in the local market, lack of budget for equipment resources (only capital costs considered), and unreliable voltage were commonly mentioned, and four African respondents reported that the majority of their equipment was donated and obsolete, or very hard to manage, while others reported that their hospital was currently defining procurement policies.

\subsubsection{Summary}

In summary, less than half of a hospital's equipment base tends to be out of use or obsolete, and the average condition of equipment was inversely proportional to complexity. Resources are shown to be a challenge, both having them within the hospital available to be used when needed, and available to order or seek elsewhere when needed. Maintenance resources were less available than user resources, signifying an imbalance.

\subsubsection{Repairs}

\subsubsection{Resources}

Respondents were asked whether they had an adequate budget for spare parts. Results are presented regionally in Table 5.26. African respondents most often reported not having an adequate budget for spare parts ( $55.2 \%$ for $n=29)$, followed by Latin American respondents ( $45.0 \%$ for $\mathrm{n}=60)$. Asian respondents reported a much higher rate of having an adequate budget for spare parts (70.6\%). 
Table 5.26: Adequate Budget for Spare Parts by Region ( $\mathrm{n}=112)$

\begin{tabular}{|c|c|c|c|}
\hline \multirow{2}{*}{ Region } & \multicolumn{3}{|c|}{ Adequate Budget for Spare Parts } \\
\hline & Yes & No & Don't know \\
\hline Africa $(n=29)$ & $37.9 \%$ & $55.2 \%$ & $6.9 \%$ \\
\hline Latin America $(n=60)$ & $51.7 \%$ & $45.0 \%$ & $3.3 \%$ \\
\hline Asia $(n=17)$ & $70.6 \%$ & $17.6 \%$ & $11.8 \%$ \\
\hline Middle East $(\mathrm{n}=3)$ & $100.0 \%$ & $.0 \%$ & $.0 \%$ \\
\hline Eastern Europe $(\mathrm{n}=2)$ & $50.0 \%$ & $50.0 \%$ & $.0 \%$ \\
\hline
\end{tabular}

EMDs in developing countries often have to be resourceful in finding spare parts. Table 5.27 presents where respondents find spare parts. A higher proportion of African respondents reported both scavenging parts and making them from locally available supplies than other regions ( $65.5 \%$ and $44.8 \%$ respectively), while a similar proportion in all regions reported ordering them from the manufacturer. Additionally, more than half of all respondents reported 'other' sources, including local contractors, centralised health ministry distribution services and manufacturing simple pieces themselves. For respondents who order spare parts from manufacturers (the great majority), they were asked how long, on average, the parts take to arrive (in number of months). The average time delay between the ordering of spare parts and their arrival was 2.53 months $(\mathrm{n}=103$, s.d. $=8.76)$.

Table 5.27: Sources of Spare Parts $(n=112)$

\begin{tabular}{|l|c|c|}
\hline Source & N & Total \\
\hline Order from Manufacturer & 95 & $84.8 \%$ \\
\hline Make from Locally Available Supplies & 65 & $58.0 \%$ \\
\hline Scavenge from Obsolete Equipment & 58 & $51.8 \%$ \\
\hline Other & 74 & $48.68 \%$ \\
\hline
\end{tabular}




\subsubsection{Effectiveness of In-house Repairs}

Frize defined substantial involvement as the CED being responsible for the repair of $75 \%$ or more of the hospital's equipment base [11]. Respondents were asked what proportion of their simple, complex and highly specialised equipment they repaired in house. Results are presented in Table 5.28.

Table 5.28: Proportion of In-house Repairs

\begin{tabular}{|l||c|c|c|c|c|c|}
\hline \multicolumn{1}{|c||}{ Equipment } & \multicolumn{5}{c|}{ Proportion of In-House Repairs (\%) } \\
\cline { 2 - 7 } & None & $<\mathbf{2 5 \%}$ & $\mathbf{2 5 - 5 0 \%}$ & $\mathbf{5 0 - 7 5 \%}$ & $\mathbf{7 5 \%}$ & All \\
\hline Simple $(\mathrm{n}=111)$ & 3.6 & 9.0 & 6.3 & 10.8 & 34.2 & 36.0 \\
\hline Complex $(\mathrm{n}=110)$ & 9.1 & 17.3 & 13.6 & 25.5 & 29.1 & 5.5 \\
\hline Highly Specialised $(\mathrm{n}=101)$ & 35.6 & 37.6 & 7.9 & 5.0 & 10.9 & 3.0 \\
\hline
\end{tabular}

A high proportion of EMDs perform more than $75 \%$ of repairs on simple equipment (70.2\%), and more than half performed $50 \%$ or more of complex equipment repairs. More than one third reported performing no in-house repairs in highly specialised equipment. In addition to repairs, $87.2 \%$ of overall respondents reported performing preventive maintenance on equipment $(\mathrm{n}=109)$; this figure did not vary significantly by region.

An inversely proportional relationship between equipment complexity and the proportion of in-house repairs exists, which reflects the fact that in-house repairs are more cost-effective for simple equipment, but can be less cost-effective for highly specialised equipment. This was validated by the responses to the open-ended question 'If most of your repairs are either in-house or external, why? Please explain.'. Other responses to this question indicated that in-house repairs were most often limited by the cost of training technicians, test equipment and general lack of expertise in the 
area.

Table 5.29 presents the average repair time, in hours, for in-house repairs of simple and complex equipment. Simple equipment repairs take on average 3.91 hours $(\mathrm{n}=104$, s.d. $=3.492)$, while complex equipment repairs take on average 11.53 hours ( $\mathrm{n}=100, \mathrm{s.d}=9.613$ ). The average time a device is out of service due to in-house repairs is presented in Table 5.30. Simple equipment spends an average of 7.96 days out of service $(n=100$, s.d. $=19.205)$ and complex equipment is out of service for on average 16.71 days $(\mathrm{n}=99$, s.d. $=28.912)$.

Table 5.29: Average In-house Repair Time (Hours)

\begin{tabular}{|c|c|c|}
\hline & Simple $(n=104)$ & Complex $(n=100)$ \\
\hline Mean & 3.91 & 11.53 \\
\hline Std. Error of Mean & .342 & .961 \\
\hline Median & 2.00 & 7.00 \\
\hline Std. Deviation & 3.492 & 9.613 \\
\hline Variance & 12.196 & 92.413 \\
\hline $\begin{array}{cc}\text { Percentiles } & 25 \\
& 50 \\
& 75\end{array}$ & $\begin{array}{l}1.00 \\
2.00 \\
7.50\end{array}$ & $\begin{array}{c}3.00 \\
7.00 \\
24.00\end{array}$ \\
\hline
\end{tabular}

\subsubsection{External Repairs}

Respondents were asked how long on average devices were out of service due to external repairs, and what the average cost of an external repairs was, as a percentage of the capital cost of the device. Table 5.30 presents the average time out of service, with an average of 11.22 days for simple equipment $(n=95$, s.d. $=17.308)$ and 21.95 days for complex equipment $(\mathrm{n}=100$, s.d.=25.396). Simple equipment is out of service on average 1.41 times longer (or 3.26 days) when repaired externally than when 
repaired in-house. Complex equipment is out of service on average 1.31 times longer (or 5.24 days) when repaired externally vs. in-house.

Table 5.30: Average Time OOS Due to Repair (Days)

\begin{tabular}{|c|c|c|c|c|}
\hline & \multicolumn{2}{|c|}{ In House } & \multicolumn{2}{|c|}{ External } \\
\hline & Simple & Complex & Simple & Complex \\
\hline $\mathrm{N}$ & 100 & 99 & 95 & 100 \\
\hline Mean & 7.96 & 16.71 & 11.22 & 21.95 \\
\hline Std. Error of Mean & 1.920 & 2.906 & 1.776 & 2.540 \\
\hline Median & 2.00 & 5.00 & 5.00 & 15.00 \\
\hline Std. Deviation & 19.205 & 28.912 & 17.308 & 25.396 \\
\hline Variance & 368.827 & 835.883 & 299.578 & 644.977 \\
\hline $\begin{array}{l}\text { Percentiles } 25 \\
25\end{array}$ & 1.00 & 2.00 & 1.00 & 5.00 \\
\hline 50 & 2.00 & 5.00 & 5.00 & 15.00 \\
\hline 75 & 5.00 & 15.00 & 15.00 & 30.00 \\
\hline
\end{tabular}

The average cost of external repairs, as a percentage of the total capital cost of the equipment is presented in Table 5.31. The relationship between complexity and average cost is proportional (19.37\% for simple equipment; $22.80 \%$ for complex equipment and $25.79 \%$ for highly specialised). However, there is very large variation in the data, and many respondents indicated that they did not have enough knowledge of financial equipment data to answer the question properly ${ }^{6}$.

\subsubsection{Additional Information}

In the final open-ended question of the section, many respondents shared more information about repairs. Many indicated that both in-house and external repairs were made more expensive by the fact that the vast majority of equipment is imported

\footnotetext{
${ }^{6}$ While data collected with this question are somewhat unreliable, the responses and variation reinforce the earlier design decision to avoid financial questions.
} 
Table 5.31: Average Cost of External Repair

\begin{tabular}{|l|c|c|c|}
\hline \multirow{2}{*}{} & \multicolumn{3}{|c|}{ Average Cost (\% of Capital Cost) } \\
\cline { 2 - 4 } & Simple & Complex & Highly Spec. \\
\hline $\mathrm{N}$ & 84 & 87 & 80 \\
\hline Mean & 19.37 & 22.80 & 25.79 \\
\hline Std. Error of Mean & 2.788 & 2.248 & 2.880 \\
\hline Median & 10.00 & 15.00 & 15.00 \\
\hline Std. Deviation & 25.552 & 20.965 & 25.760 \\
\hline Variance & 652.886 & 439.531 & 663.562 \\
\hline Percentiles 25 & 5.00 & 10.00 & 8.50 \\
& 10.00 & 15.00 & 15.00 \\
& 50 & 30.00 & 38.75 \\
\hline
\end{tabular}

from other countries; spare parts take longer to arrive and are subject to import fees, and sending equipment away for external repair can be prohibitively expensive.

\subsubsection{Summary}

In summary, African respondents reported the most challenges with affording and spare parts for in-house repairs and most often reported scavenging them from obsolete equipment, or making them from locally available supplies. EMDs reported repairing more simple than complex equipment in-house, and both the length of time spent on in-house repairs, and the cost of having them done externally, was proportional to complexity.

\subsubsection{Procurement}

Eighty-five percent of respondents indicated that their hospital has a formal policy or procedure for equipment procurement $(n=107)$. A total of $12 \%$ said they did not, and the remaining $10 \%$ indicated that they did not know, which may indicate that their 
hospital doesn't, or that the EMD manager is not involved in the process. Having a formal policy for equipment acquisition was fairly consistent across regions, with Africa reporting 80.8\%, Latin America $78.0 \%$ and Asia 75.0\%. All respondents in the small sample of the Middle East and Eastern Europe also reported having a formal policy or procedure.

For those who do have a formal policy, Table 5.32 shows who most often leads the team that decides which equipment to procure, and who is involved in the decision. Results may be inaccurate because the proportion of responses for who leads the equipment procurement team totals $122.9 \%$ (it is also possible that a combination of individuals co-lead the team). However, results show the equipment users are most often involved in the decision, while administrators and EMD staff are the least involved. Administrators most often lead the team that decides (for $45.7 \%$ of respondents), followed by the manager of the EMD (30.5\% of respondents). On average, $77.98 \%$ of the equipment base of hospitals surveyed is procured $(n=105$, s.d. $=24.771)$, as opposed to donated or leased, rented, or loaned $(L / R / L)$. Table 5.33 presents these results.

Table 5.32: Personnel Involved in Equipment Acquisition Decision Making ( $\mathrm{n}=105)$

\begin{tabular}{|l||c|c|}
\hline Personnel & Leads & Is Involved \\
\hline Administrator & $45.7 \%$ & $53.3 \%$ \\
\hline Equipment User & $27.6 \%$ & $71.4 \%$ \\
\hline Consultant & $8.6 \%$ & $36.2 \%$ \\
\hline EMD Manager & $30.5 \%$ & $67.6 \%$ \\
\hline EMD Staff & $10.5 \%$ & $53.3 \%$ \\
\hline
\end{tabular}

Figure 5.8 shows the level of involvement of EMDs in equipment procurement at their hospitals. Asia respondents reported the least proportional involvement in the 
Table 5.33: Equipment Base Sources

\begin{tabular}{|c|c|c|c|c|}
\hline & Procurement & Donation & $\mathrm{L} / \mathbf{R} / \mathrm{L}$ & Other \\
\hline $\mathrm{N}$ & 105 & 82 & 88 & 24 \\
\hline Mean & 77.98 & 17.52 & 10.18 & 2.13 \\
\hline Std. Error of Mean & 2.417 & 2.941 & 1.298 & .969 \\
\hline Median & 90.00 & 5.00 & 5.00 & .00 \\
\hline Std. Deviation & 24.771 & 26.635 & 12.179 & 4.749 \\
\hline Variance & 613.615 & 709.438 & 148.334 & 22.549 \\
\hline $\begin{array}{ll}\text { Percentiles } & 25 \\
& 50 \\
& 75\end{array}$ & $\begin{array}{l}70.00 \\
90.00 \\
95.00\end{array}$ & $\begin{array}{c}1.00 \\
5.00 \\
20.00\end{array}$ & $\begin{array}{c}2.00 \\
5.00 \\
10.00\end{array}$ & $\begin{array}{c}.00 \\
.00 \\
1.75\end{array}$ \\
\hline
\end{tabular}

decision. Africa respondents reported slightly more than Latin American respondents. Many of those reporting very little involvement indicated in the open-ended procurement question that their hospital was part of a centralised equipment acquisition program (either at a regional or national level).

Table 5.34 presents how often WHO-recommended equipment requirements are considered before equipment is procured, as well as how often recipient hospitals are consulted on the requirements prior to donation. Categories were randomised during online collection to reduce response biase. All requirements are considered during procurement by more than half of the respondents, which is very telling. Clinical needs and benefits are the most frequently considered criterion, in $81.0 \%$ of the cases. Requirements considered in descending order of frequency are: available maintenance support (75.2\%); approved source of operating budget (73.3\%); availability of qualified users $(70.5 \%)$; regulatory compliance $(67.6 \%)$; standardisation with other equipment (66.7\%); and adequate infrastructure support (59.0\%). 


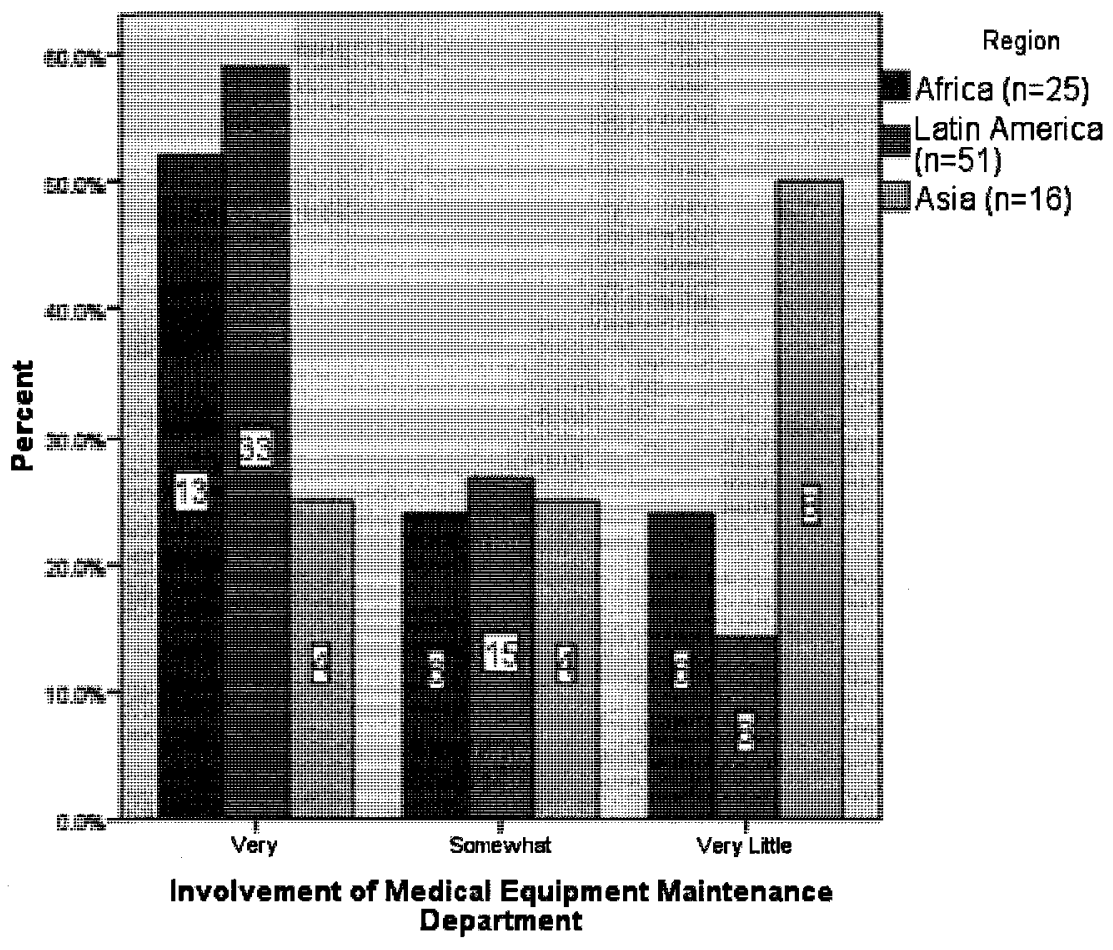

Figure 5.8: EMD's Level of Involvement in Procurement by Region 
Table 5.34: Requirements Considered/Consulted on for Procurement/Donation

\begin{tabular}{|l||c|c|c|c|}
\hline \multicolumn{1}{|c||}{ Requirements } & \multicolumn{2}{c|}{ Procurement $(\mathbf{n = 1 0 5})$} & \multicolumn{2}{c|}{ Donation (n=82) } \\
\cline { 2 - 5 } & $\mathbf{N}$ & Total & $\mathbf{N}$ & Total \\
\hline Clinical Needs and Benefits & 85 & $81.0 \%$ & 30 & $36.6 \%$ \\
\hline Standarisation with Other Equipment & 70 & $66.7 \%$ & 24 & $29.3 \%$ \\
\hline Availability of Qualified Users & 74 & $70.5 \%$ & 17 & $20.7 \%$ \\
\hline Approved Source of Operating Budget & 77 & $73.3 \%$ & 17 & $20.7 \%$ \\
\hline Available Maintenance Support & 79 & $75.2 \%$ & 26 & $31.7 \%$ \\
\hline Adeqaute Infrastructure Support & 62 & $59.0 \%$ & 17 & $20.7 \%$ \\
\hline Regulatory Compliance & 71 & $67.6 \%$ & 17 & $20.7 \%$ \\
\hline
\end{tabular}

\subsubsection{Summary}

The great majority of the sample reports having a formal procurement policy at their hospital. Practices for who leads and who in involved in the team that makes procurement decisions varies widely. The percentage of respondents who indicated considering requirements when procuring equipment themselves, vs. what considerations they are consulted on pre-donation is quite telling.

\subsubsection{Donations}

Donated equipment typically arrives at hospitals from three main sources:

1. Equipment donation organisations co-ordinate donations between source and recipient organisations. Examples are: REMEDY, MedShare and ECHO.

2. Hospitals in other countries often donate equipment directly to developing world hospitals. 
3. Large aid agencies often include equipment donation in their global health programming. Examples include: bilateral agencies such as CIDA (Canada), JICA (Japan) and GTZ (Germany) and global organisations such as the WHO and the various U.N. agencies.

On average, a total of $17.52 \%$ of the equipment base of hospitals surveyed was donated $(\mathrm{n}=82$, s.d. $=24.771)$, as opposed to donated or leased, rented, or loaned (see Table 5.33). Table 5.35 presents the proportion of donated equipment that was received from the three categories of donating organisations.

Table 5.35: Donated Equipment Base Sources

\begin{tabular}{|c|c|c|c|c|}
\hline & Equip Don Org & Hosp Other Count & Large Aid Agen & Other \\
\hline $\mathrm{N}$ & 62 & 49 & 59 & 47 \\
\hline Mean & 33.85 & 17.76 & 28.20 & 67.38 \\
\hline Std. Error of Mean & 4.812 & 3.823 & 4.581 & 6.187 \\
\hline Median & 12.50 & 5.00 & 10.00 & 100.00 \\
\hline Std. Deviation & 37.894 & 26.762 & 35.186 & 42.416 \\
\hline Variance & 1435.929 & 716.230 & 1238.061 & 1799.154 \\
\hline $\begin{array}{ll}\text { Percentiles } & 25 \\
& 50 \\
& 75\end{array}$ & $\begin{array}{c}.00 \\
12.50 \\
76.25\end{array}$ & $\begin{array}{c}.00 \\
5.00 \\
30.00\end{array}$ & $\begin{array}{c}.00 \\
10.00 \\
70.00\end{array}$ & $\begin{array}{c}10.00 \\
100.00 \\
100.00\end{array}$ \\
\hline
\end{tabular}

\subsubsection{Equipment Status}

Respondents reported their proportion of donated equipment based on complexity levels. Results, which are presented in Table 5.36, show that equipment complexity is fairly distributed between donations, with all four categories commonly being reported as less than $25 \%$ of donated equipment. 
Table 5.36: Proportion of Donated Equipment by Complexity

\begin{tabular}{|l||c|c|c|c|c|c|}
\hline \multicolumn{1}{|c||}{ Complexity } & \multicolumn{5}{c|}{ Proportion of Donated Equipment (\%) } \\
\cline { 2 - 7 } & None & $<\mathbf{2 5 \%}$ & $\mathbf{2 5 - 5 0 \%}$ & $\mathbf{5 0 - 7 5 \%}$ & $>\mathbf{7 5 \%}$ & All \\
\hline Basic $(\mathrm{n}=124)$ & 44.6 & 31.3 & 9.6 & 6.0 & 7.2 & 1.2 \\
\hline Simple $(\mathrm{n}=82)$ & 34.1 & 41.5 & 17.1 & 4.9 & 2.4 & 0.0 \\
\hline Complex $(\mathrm{n}=81)$ & 40.7 & 35.8 & 7.4 & 8.6 & 7.4 & 0.0 \\
\hline Highly Specialised $(\mathrm{n}=74)$ & 75.7 & 17.6 & 1.4 & 0.0 & 4.1 & 1.4 \\
\hline
\end{tabular}

\subsubsection{Resources}

The state of donated equipment is presented in Table 5.37. Table 5.38 presents how often the following resources accompany donations: spare parts, user manuals, maintenance manuals, user training and maintenance training and support. The most common resource sent with donated equipment is user manuals (with $15.9 \%$ of respondents indicating that they always receive user manuals). However, a majority of respondents reported all five resources being sent either rarely or never.

Table 5.37: Proportion of Donated Equipment by State

\begin{tabular}{|l||c|c|c|c|c|c|}
\hline \multicolumn{1}{|c||}{ State } & \multicolumn{5}{c|}{ Proportion of Donated Equipment (\%) } \\
\cline { 2 - 7 } & None & $<\mathbf{2 5 \%}$ & $\mathbf{2 5 - 5 0 \%}$ & $\mathbf{5 0 - 7 5 \%}$ & $\mathbf{7 5 \%}$ & All \\
\hline New $(\mathrm{n}=82)$ & 36.6 & 19.5 & 4.9 & 4.9 & 12.2 & 22.0 \\
\hline Used $(\mathrm{n}=76)$ & 40.8 & 18.4 & 14.5 & 10.5 & 11.8 & 3.9 \\
\hline Refurbished $(\mathrm{n}=74)$ & 56.8 & 18.9 & 13.5 & 4.1 & 6.8 & 0.0 \\
\hline Obsolete $(\mathrm{n}=70)$ & 64.3 & 21.4 & 4.3 & 7.1 & 2.9 & 0.0 \\
\hline
\end{tabular}

\subsubsection{Consultation}

Many hospitals report little to no consultation prior to receiving equipment shipments.

Figure 5.9 shows that $32.89 \%$ of respondents reported no consultation whatsoever. 
Table 5.38: Rate of Resource-accompanied Donation

\begin{tabular}{|l||c|c|c|c|c|}
\hline \multicolumn{1}{|c||}{ Resource } & \multicolumn{5}{c|}{ Rate of Resource-accompanied Donation (\%) } \\
\hline & Always & Often & Sometimes & Rarely & Never \\
\hline Spare Parts $(\mathrm{n}=81)$ & 4.9 & 2.5 & 11.1 & 22.2 & 59.3 \\
\hline User Manuals $(\mathrm{n}=82)$ & 15.9 & 12.2 & 23.2 & 19.5 & 29.3 \\
\hline Maintenance Manuals ( $\mathrm{n}=81)$ & 9.9 & 1.2 & 21.0 & 21.0 & 46.9 \\
\hline User Training (n=81) & 11.1 & 6.2 & 13.6 & 25.9 & 43.2 \\
\hline Maintenance Training ( $\mathrm{n}=80)$ & 7.5 & 0.0 & 10.0 & 26.3 & 56.3 \\
\hline
\end{tabular}

For those who were consulted, the level as rated by the respondent is somewhat normalised around 'fair' 7 . The equipment requirements about which hospitals are consulted prior to donation are presented above in Table 5.34, which shows that only one fifth of respondents are consulted on the majority of requirements (regulatory compliance, adequate infrastructure, availability of qualified users, and approved source of operating budget). Approximately one third of respondents reported being consulted on clinical needs and benefits, standardisation with other equipment and available maintenance support $(\mathrm{n}=82)$.

\subsubsection{Additional Information}

The open-ended donation question reinforced the wide range of levels of $\mathrm{CE}$ advancement represented in this research. Several reported that they rejected obsolete equipment, and/or had strong relationships with donors; the majority of these were Asian respondents. Others reported no consultation and receiving exclusively obsolete equipment. Perhaps even more telling, three African respondents said "please send us any donated equipment you have".

\footnotetext{
${ }^{7}$ This is potentially another example of central tendency in response.
} 


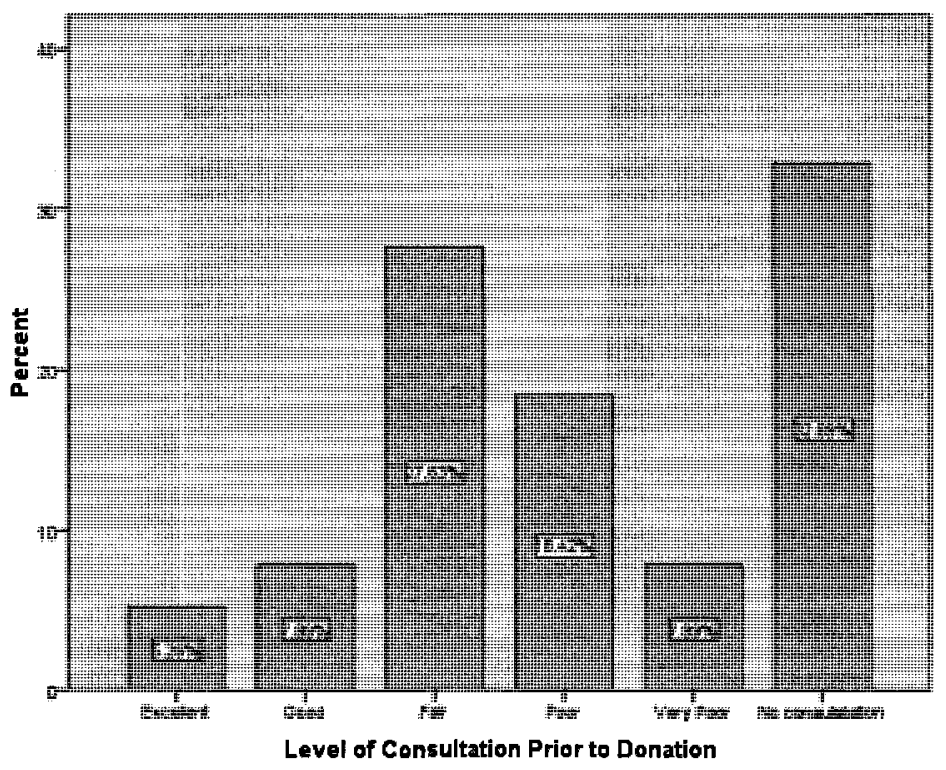

Figure 5.9: Level of Consultation Prior to Donation $(n=76)$

\subsection{Discussion}

This sample is decidedly different from Cao and Frize's sample; Africa is adequately profiled for the first time in this type of international investigation of $\mathrm{CE}$ effectiveness. Different hospital and EMD profiles (i.e. private and philanthropic hospitals, more EMDs that do not exist as a separate unit or self-identify as a 'clinical engineering department') further differentiate it from Cao and Frize's sample. The response rate and number of overall responses are also higher.

This sample reveals several dimensions of $\mathrm{CE}$ services, medical equipment and equipment procurement and donation practices in developing countries worldwide. Overall, African hospitals are the least effective and most resource-poor; they report the least human and technical resources, and the highest rates of out of service equipment. Asian hospitals profiled are the most effective, reporting the lowest need 
for additional resources and lowest rates of out of service equipment, while Latin American hospitals profiled tend to fall between the Africa and Asia groups for most metrics covered. The small sample from the Middle East and Eastern Europe suggests relatively effective CE services in those regions. 


\section{Chapter 6}

\section{Quantitative Analysis}

This chapter presents the quantitative analyses used to test the two hypotheses of this thesis; Spearman correlation tests are used to test the CE effectiveness model for developed countries in the developing world and to develop a preliminary model for the relationship between $\mathrm{CE}$ effectiveness metrics and the state/functionality of medical equipment. A discussion of the limitations of the data collection is also presented.

\subsection{Clinical Engineering Effectiveness Model}

The first hypothesis of this thesis is that Frize's model (Figure 3.1) for CE effectiveness in developed world hospitals can be applied, with modification, to developing world hospitals. Frize's model presents four concepts that characterise the climate of the institution, and were found to have consistent association with $\mathrm{CE}$ effectiveness: organisational structure, managerial policies and practices, employee characteristics 
and external environment ${ }^{1}$.

\subsubsection{Variable Selection}

Input variables (IVs) in the original model characterise the organisational climate of the institution, while output variables (DVs) are metrics for CE effectiveness. In order to test the model in the context of developing world hospitals, the majority variables from the original model were retained and several were removed, added or modified to reflect the new context. Figure 6.1 presents the list of potential input variables for this analysis and Figure 6.2 presents the new list of DVs, which are categorised as indicators of resources, functional involvement of the EMD and miscellaneous. Retention, deletion, addition and modification of new variables is denoted in italics.

Note that throughout this chapter, $\rho$ signifies the Spearman correlation coefficient and the p-value signifies the significance level: '*) denotes correlation significance at the 0.05 (two-tailed) level, while ${ }^{\text {'**' }}$ denotes significance at the 0.01 (two-tailed) level. A significance level of 0.01 represents a strong correlation, with a confidence level of $99 \%$, while a significance level of 0.05 has a confidence level of $95 \%$. A positive correlation coefficient means that as variable 1 increases, so does variable 2; a negative correlation means that as variable 1 increases, variable 2 decreases.

A Spearman correlation was run on all potential input variables to determine which were truly independent (IVs) and which were confounding (CVs) or moderating (MVs). A large number of variables were correlated, and each was tested individually against the model's DVs to determine which had the most significant impact on the outputs.

\footnotetext{
${ }^{1}$ The external environment - defined by the economy; government policy; technology proliferation; and environment type - is not included in this analysis, nor was it in Frize's original analysis, because data collection would be very difficult.
} 


\section{Organisational Structure}

(a) Hospital type - removed due to lack of confidence in data

(b) Hospital size - retained

(c) Existence as a separate department - retained

(d) Reporting authority - retained

(e) Work unit size - number of engineers and technicians - retained

(f) Adequate staffing - retained

(g) Shared services - added to reflect the studied context

(h) Main service centre (shared services) - added to reflect the studied context

2. Employee Characteristics

(a) Presence of qualified engineers - retained, $M V$ in original model

3. Managerial Policies and Practices

(a) Adequate staffing - retained

(b) Formal equipment procurement policy - added to reflect the studied context

(c) Recognition within the hospital - removed because it was deemed too politically sensitive a question that was unlikely to yield accurate responses

Figure 6.1: CE Effectiveness Model - Potential IVs 


\section{Resources}

(a) Number of engineers - moved from IVs

(b) Number of technicians - moved from IVs

(c) Inventory system (level of sophistication - modified from original model

(d) Adequate budget for spare parts - retained

(e) Proportion of equipment with user manuals - added

(f) Proportion of equipment with maintenance manuals - added

(g) Proportion of equipment with test equipment - retained, modified

\section{Functional Involvement}

(a) Level of consultation pre-donation - added to reflect the studied context

(b) In-house repairs (eng/tech) - retained, simplifed

(c) Incoming inspections (eng/tech) - retained, simplifed

(d) Preventive maintenance (eng/tech) - retained, simplifed

(e) User training and education (eng/tech) - retained, simplifed

(f) Pre-purchase consultation (eng/tech) - retained, simplifed

(g) Research (eng/tech) - retained, simplifed

(h) Recognition within the hospital - retained, simplifed

(i) Formal equipment procurement policy - retained, simplifed

\section{Miscellaneous}

(a) Satisfied with reporting authority - retained

(b) Provide 'on the job 'training for EMD staff - retained

Figure 6.2: CE Effectiveness Model - DVs 
Based on these results, two variables were moved to the list of outputs ('number of engineers' and 'number of technicians'). The variable 'shared services' was retained despite being weakly correlated with 'hospital size' $\left(\rho=0.185^{*}, \mathrm{p}=.027\right)$ because it had a significant effect on six of the model's DVs; it was classified as an MV. The 'main service centre' variable was removed entirely; it was found to be a CV strongly correlated with 'shared services' $\left(\rho=0.795^{* *}, \mathrm{p}=.000\right)$ but with less of an effect on the DVs.

\subsubsection{Correlation Analysis}

Spearman correlation analysis was run for all model IVs and DVs. Results are presented by input variable, with each IV-DV correlation at both the 0.05 and 0.01 significance level below.

\subsubsection{Hospital size}

Hospital size is correlated with the following $\mathrm{CE}$ effectiveness outcomes:

1. number of engineers $\left(\rho=0.405^{* *}, \mathrm{p}=.000\right)$

2. number of technicians $\left(\rho=0.394^{* *}, \mathrm{p}=.000\right)$

3. inventory management system $\left(\rho=0.239^{* *}, \mathrm{p}=.005\right)$

4. satisfied with reporting authority $\left(\rho=0.189^{*}, \mathrm{p}=.024\right)$

5. preventive maintenance (engineers) $\left(\rho=-0.149^{*}, \mathrm{p}=.042\right)$

Hospital size is strongly correlated (significant at the 0.01 level) with both the number of engineers and the number of technicians. It is also strongly correlated 
with the sophistication level of the inventory management system, signifying that larger hospitals are more likely to use specialised biomedical equipment management software. Hospital size is also correlated (significant at the 0.05 level) with satisfaction with the EMD's reporting authority (i.e. more satisfaction at larger hospitals), and it is negatively correlated with the proportion of engineers who perform preventive maintenance, which suggests that at larger hospitals this technical task is more often performed by technicians. Based on these five results, larger hospitals comprise an organisational climate that encourages $\mathrm{CE}$ effectiveness.

\subsubsection{Existence as a Separate Department}

Existence as a separate department is correlated with the following CE effectiveness outcomes:

1. provide 'on the job 'training $\left(\rho=0.167^{*}, \mathrm{p}=.044\right)$

2. proportion of equipment with user manuals $\left(\rho=0.185^{*}, \mathrm{p}=.045\right)$

Existence as a separate unit is positively correlated (significant at the 0.05 level) with both providing 'on the job' training for EMD staff and the proportion of equipment for which user manuals exist. Thus, existence as a separate unit influences employee training and one resource.

\subsubsection{Reporting Authority}

Reporting authority is correlated with the following CE effectiveness outcomes:

1. incoming inspections (engineers) $\left(\rho=-0.221^{* *}, \mathrm{p}=.006\right)$

2. user education and training (technicians) $\left(\rho=-0.180^{*}, \mathrm{p}=.025\right)$ 
3. proportion of equipment with maintenance manuals $\left(\rho=0.207^{*}, \mathrm{p}=.026\right)$

4. proportion of equipment with user manuals $\left(\rho=0.193^{*}, \mathrm{p}=.037\right)$

Reporting authority ${ }^{2}$ is strongly negatively correlated (significant at the 0.01 level) with the proportion of engineers who perform incoming inspections, which suggests engineers in EMDs who report to lower seniority levels perform this technical task more often. It was also negatively correlated with the proportion of technicians who perform user education and training, suggesting that this task is performed more often by technicians in EMDs who report to a lower seniority level. Reporting authority is also positively correlated with the proportion of equipment which has maintenance and user manuals; EMDs who report to more senior administrators tend to have more manual resources. Thus, reporting authority influences both functional involvement and resource indicators of effectiveness.

\subsubsection{Shared Services}

Shared services is strongly correlated with the MV 'main service centre' $\left(\rho=0.795^{* *}\right.$, $\mathrm{p}=.000$ ), which is to be expected. It is also correlated with the following CE effectiveness outcomes:

1. user education and training (technicians) $\left(\rho=.300^{* *}, \mathrm{p}=.000\right)$

2. proportion of equipment with test equipment $\left(\rho=0.213^{*}, \mathrm{p}=.021\right)$

3. involvement of the EMD in pre-donation consultation $\left(\rho=-0.220^{*}, \mathrm{p}=.026\right)$

4. incoming inspections (technicians) $\left(\rho=0.173^{*}, \mathrm{p}=.033\right)$

\footnotetext{
${ }^{2}$ Reporting authority was coded in SPSS in descending level of authority as follows: $0=$ hospital administrator, $1=$ medical director, $2=$ plant/facilities director, and $3=$ other.
} 
5. number of technicians $\left(\rho=0.170^{*}, \mathrm{p}=.048\right)$

Shared services are correlated with the number of technicians (significant at the 0.05 level) and with the proportion of technicians who both perform user training and education (significant at the 0.05 level) and user education and training (significant at the 0.01 level). The level of test equipment is also higher in hospitals which share services. The majority of respondents who reported sharing services also reported being the main service centre, thus the correlation with technicians and their level of involvement seems appropriate. Shared services is negatively correlated with the involvement of the EMD in pre-donation consultation. This may be as a result of many respondents who share services reporting that donations were managed centrally. It may also indicate that those with shared services, which is an indicator of $\mathrm{CE}$ advancement, do not receive donations. Based on these results, hospitals that share services tend to have more technician-related $\mathrm{CE}$ effectiveness indicators and be less involved in donation consultations.

\subsubsection{Adequate Staff}

Adequate staff is correlated with the following CE effectiveness outcomes:

1. proportion of equipment with maintenance manuals $\left(\rho=0.282^{* *}, \mathrm{p}=.002\right)$

2. adequate budget for spare parts $\left(\rho=0.234^{*}, \mathrm{p}=.013\right)$

3. proportion of equipment with user manuals $\left(\rho=0.200^{*}, \mathrm{p}=.029\right)$

4. number of engineers $\left(\rho=0.172^{*}, \mathrm{p}=.042\right)$

5. number of technicians $\left(\rho=0.173^{*}, \mathrm{p}=.048\right)$ 
Interestingly, adequate staff is correlated with an adequate budget for spare parts and the proportion of equipment with user manuals (significant at the 0.05 level) and it is highly correlated (significant at the 0.01 level) with the proportion of equipment with maintenance manuals. This indicates that EMDs that are adequately staffed are more able to lobby for equipment resources within the hospital. Adequate staff is also correlated with the number of engineers and technicians (significant at the 0.05 level), which is to be expected. Thus, adequate staff appears to significantly influence the amount of equipment resources within the hospital.

\subsubsection{Presence of Qualified Engineers}

Presence of qualified engineers (minimum of B. Sc./B. Eng) is correlated with the following $\mathrm{CE}$ effectiveness outcomes:

1. pre-purchase consultation (engineers) $\left(\rho=0.351^{* *}, \mathrm{p}=.000\right)$

2. pre-purchase consultation (technicians) $\left(\rho=-0.340^{* *}, \mathrm{p}=.000\right)$

3. user training and education (engineers) $\left(\rho=0.299^{* *}, \mathrm{p}=.001\right)$

4. research (technicians) $\left(\rho=-0.282^{* *}, \mathrm{p}=.001\right)$

5. number of engineers $\left(\rho=0.270^{* *}, \mathrm{p}=.002\right)$

6. in-house repairs (engineers) $\left(\rho=0.182^{*}, \mathrm{p}=.037\right)$

The presence of qualified engineers in an EMD is highly correlated (significant at the 0.01 level) with five functional involvement indicators: positively with engineers performing pre-purchase consultation and user training and education, and negatively with technicians performing pre-purchase consultation and research. This suggests a 
division of labour with EMDs staffed by qualified engineers; engineers tend to perform more managerial and consultative activities, while technicians tend to perform less of this type of activity. It is also correlated (significant at the 0.05 level) with the proportion of engineers who perform in-house repairs, and highly correlated with the number of engineers, which is to be expected. Presence of qualified engineers has a significant impact on functional involvement indicators of $\mathrm{CE}$ effectiveness.

\subsubsection{Formal Procurement Policy}

The existence of a formal equipment procurement policy at the hospital is correlated with the following $\mathrm{CE}$ effectiveness outcomes:

1. inventory management system $\left(\rho=0.434^{* *}, \mathrm{p}=.000\right)$

2. adequate budget for spare parts $\left(\rho=0.374^{* *}, \mathrm{p}=.000\right)$

3. proportion of equipment with user manuals $\left(\rho=0.364^{* *}, \mathrm{p}=.000\right)$

4. proportion of equipment with maintenance manuals $\left(\rho=0.419^{* *}, \mathrm{p}=.000\right)$

5. involvement of the EMD in pre-donation consultation $\left(\rho=0.287^{* *}, \mathrm{p}=.003\right)$

6. proportion of equipment with test equipment $\left(\rho=0.263^{* *}, \mathrm{p}=.007\right)$

Having a formal procurement policy is strongly correlated (significant at the 0.01 level) with all four resource outputs (adequate budget for spare parts, user manuals, maintenance manuals and test equipment), and with the sophistication of the equipment management system and the level of EMD involvement in pre-donation consultation. A formal procurement policy is, therefore, a very significant indicator of CE effectiveness. 


\subsubsection{Discussion}

Hospital size, the presence of qualified engineers and having a formal procurement policy had the most significant impact on CE effectiveness indicators. Existing as a separate department, shared services, adequate staff also each impacted five $\mathrm{CE}$ effectiveness indicators, while reporting authority had the least significant impact on outputs (but was still correlated with four outputs). The presence of engineers was the strongest determinant of functional involvement indicators, while a formal procurement policy was correlated with all resource indicators in the model. Hospital size influenced more varied effectiveness indicators. The three DVs that were not correlated with any IVs were: in-house repairs and preventive maintenance done by technicians and research done by engineers.

\subsubsection{Refined Model}

Figure 6.3 presents the refined model based on this analysis. All organisational climate variables (i.e. inputs) from Frize's original model were retained and shown to be statistically independent. They were all also shown to be correlated with $\mathrm{CE}$ effectiveness indicators (i.e. DVs) in the analysis. Based on this analysis, the null hypothesis that Frize's original model is applicable, with some modification, to the developing world is accepted.

\subsection{Medical Equipment Functionality Model}

The second hypothesis of this thesis is that CE effectiveness metrics influence the state/functionality of medical equipment in a hospital. It is known that a high proportion of medical equipment in the developing world is out of service (OOS), yet no 

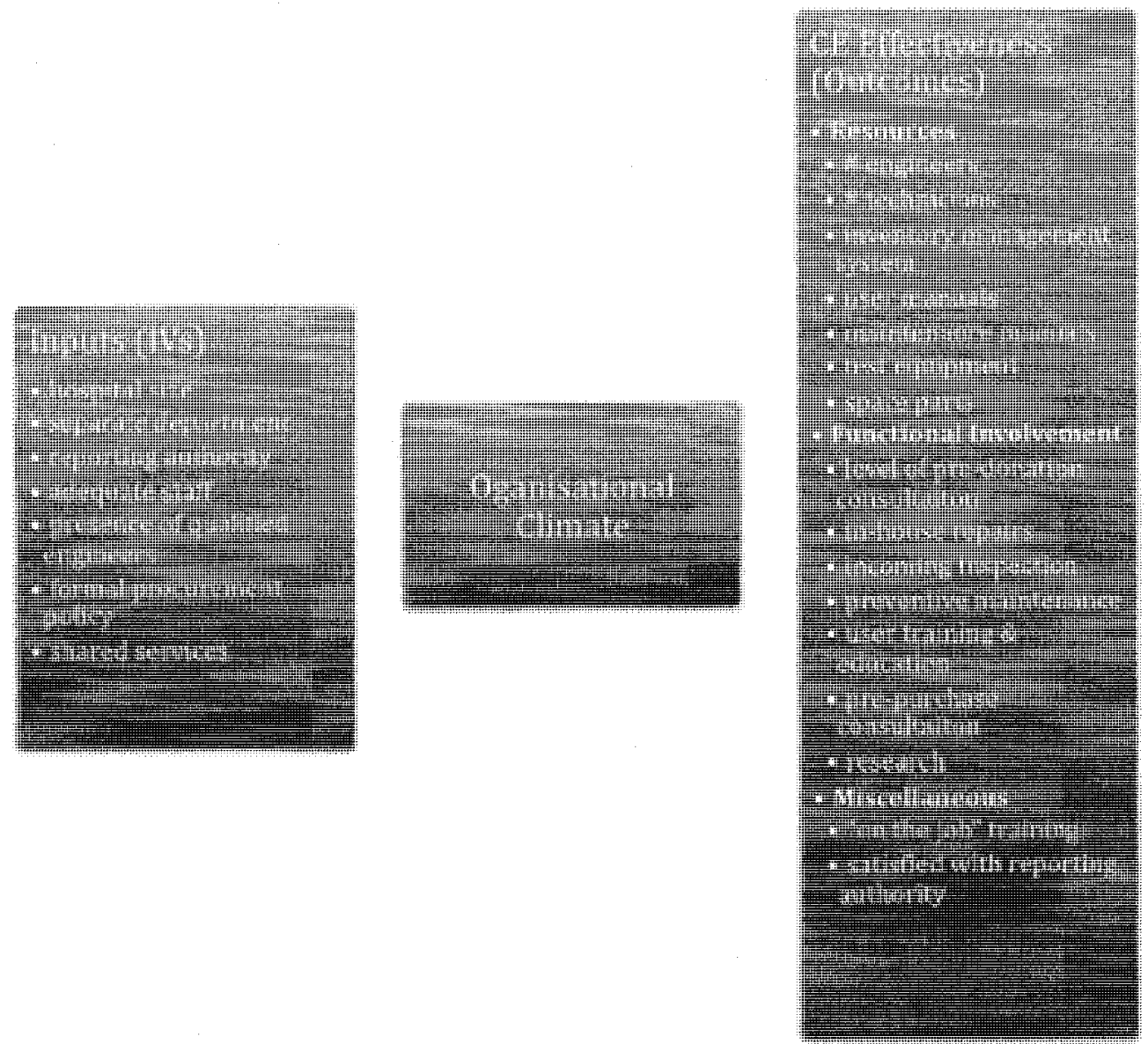

Figure 6.3: Refined CE Effectiveness Model

models exist to describe the relationship between $\mathrm{CE}$ effectiveness metrics and the state/functionality of medical equipment. Several variables in the data set reflect the state/functionality of equipment; most are stratified by equipment complexity level. These include: proportion of OOS equipment, most common condition of equipment and obsolescence which was determined by availability of spare parts to order, accessories and reagents, manufacturer sales support and troubleshooting and repair assistance $^{3}$.

\footnotetext{
${ }^{3}$ Metrics are based on the WHO's definition of obsolescence that was presented in Section 3.3.2.
} 


\subsubsection{Variable Selection}

The proportion of OOS equipment was selected as the output for a new model based on its objectivity (compared with the subjective 'common condition' variable) and its simplicity (compared with the multi-variable obsolescence metric). Both the 'simple' and 'complex' OOS variables were selected while the 'highly specialised' one was not. Highly specialised equipment tends to be maintained externally and its state is therefore not as reflective of an EMD's effectiveness.

All CE effectiveness metrics from the model in Figure 6.3 were originally considered as potential IVs for the new model, however a Spearman correlation of them revealed the presence of a large number of confounding variables. This is not surprising; it can be assumed that the relationship between CE effectiveness metrics is highly complex and confounding. In order to expose potential trends, the two OOS output metrics were correlated with every other variable in the data set.

The next two sections present the findings of this correlation tests, for the 'simple OOS' variable and the 'complex OOS' variable. The correlation coefficients and significance levels are presented in Table 6.1 and Table 6.2. Correlated variables are grouped into the following categories: (1) IVs, MVs and DVs from the CE effectiveness model, (2) other equipment state/functionality metrics, (3) equipment base and donation metrics, and (4) regional metrics. The findings which are based on these results expose relationships between the simple and complex OOS variables and these four groups of metrics. 
Table 6.1: OOS Simple Equipment - All Correlated Variables

\begin{tabular}{|l|c|c|l|c|c|}
\hline CE Effect. DVs & $\rho$ & $\mathbf{p}$ & Equipment State & $\rho$ & $\mathbf{p}$ \\
\hline \hline Satisfied with Rep Auth & $.235^{*}$ & .014 & Condition (S) & $.355^{* *}$ & .000 \\
\hline Spare Parts & $-.227^{*}$ & .015 & Condition (C) & $.427^{* *}$ & .000 \\
\hline User Manuals & $-.261^{* *}$ & .006 & Condition (HS) & $.327^{* *}$ & .001 \\
\hline Maintenance Manuals & $-.263^{* *}$ & .006 & Standardised (S) & $-.268^{* *}$ & .005 \\
\hline User Edu \& Train-Eng & $-.234^{*}$ & .010 & Standardised (C) & $-.228^{*}$ & .014 \\
\hline User Edu \& Train-Tech & $.236^{*}$ & .009 & Trained Users & $-.347^{* *}$ & .000 \\
\hline Pre-purchase Consult-Eng & $-.257^{* *}$ & .023 & Obs-Spare Parts & $-.187^{*}$ & .046 \\
\hline Pre-purchase Consult-Tech & $.207^{*}$ & .023 & Obs-Access \& Reag & $-.209^{*}$ & .027 \\
\hline Research - Eng & $-.208^{*}$ & .026 & Obs-Manu Sales Supp & $-.223^{*}$ & .017 \\
\hline CE Effect. IVs \& CVs & $\rho$ & $\mathbf{p}$ & Avg. Cost Ext Rep (S) & $.394^{* *}$ & .000 \\
\hline Adequate Staff (IV) & $.260^{* *}$ & .005 & Avg. Cost Ext Rep (C) & $.243^{*}$ & .000 \\
\hline Main Service Centre (CV) & $.268^{*}$ & .014 & Avg. Cost Ext Rep (HS) & $.240^{*}$ & .032 \\
\hline \hline Equipment Base (\%) & $\rho$ & $\mathbf{p}$ & Donations (\% of base) & $\rho$ & $\mathbf{p}$ \\
\hline \hline Procurement & $-.214^{*}$ & .034 & Other Hospitals & $.365^{*}$ & .014 \\
\hline Donation & $.269^{*}$ & .019 & Large Aid Agencies & $.448^{* *}$ & .001 \\
\hline Basic & $.236^{*}$ & .013 & Other & $-.413^{* *}$ & .004 \\
\hline & & & Basic & $.258^{*}$ & .018 \\
\hline Other & $\rho$ & $\mathbf{p}$ & Simple & $.373^{* *}$ & .001 \\
\hline HDI & $-.235^{*}$ & .011 & Refurbished & $.260^{*}$ & .028 \\
\hline Region & $-.227^{*}$ & .014 & Obsolete & $.297^{*}$ & .015 \\
\hline
\end{tabular}

\subsubsection{Simple Equipment}

\subsubsection{CE Effectiveness Model Metrics}

Table 6.1 shows that nine DVs, one IV and the MV from the CE effectiveness model (Figure 6.3) are correlated with the proportion of simple equipment that is OOS. Five of these DVs are functional involvement metrics (user education and training performed by both engineers and technicians, pre-purchase consultation performed by both engineers and technicians and research performed by engineers). The OOS 
Table 6.2: OOS Complex Equipment - All Correlated Variables

\begin{tabular}{|l|c|c|l|c|c|}
\hline CE Effect. DVs & $\rho$ & $\mathbf{p}$ & Equipment State & $\rho$ & p \\
\hline \hline Satisfied with Rep Auth & $.260^{* *}$ & .006 & Condition (S) & $.282^{* *}$ & .009 \\
\hline Spare Parts & $-.265^{* *}$ & .005 & Condition (C) & $.524^{* *}$ & .000 \\
\hline User Manuals & $-.220^{*}$ & .021 & Condition (HS) & $.328^{* *}$ & .001 \\
\hline Maintenance Manuals & $-.295^{* *}$ & .002 & Standardised (S) & $-.393^{* *}$ & .000 \\
\hline Adeq Budg Spare Parts & $-.196^{*}$ & .044 & Standardised (C) & $-.282^{* *}$ & .003 \\
\hline CE Effect. IVs \& CVs & $\rho$ & $\mathbf{p}$ & Trained Users & $-.237^{*}$ & .013 \\
\hline Adequate Staff (IV) & $.219^{*}$ & .022 & Trained Maint Techs & $-.247^{* *}$ & .009 \\
\hline Equipment Base(\%) & $\rho$ & $\mathbf{p}$ & Obs-Manu Sales Supp & $-.243^{*}$ & .012 \\
\hline Procurement & $-.235^{*}$ & .019 & Perform PM & $-.294^{* *}$ & .003 \\
\hline
\end{tabular}

variable is negatively correlated with the engineers' tasks and positively correlated with the technicians' tasks, signifying that EMDs whose engineers perform these more consultative tasks tend to have less equipment OOS, while those whose technicians perform them tend to have more. Three resource effectiveness metrics are strongly correlated with the OOS variable (significant at the 0.01 level): spare parts, user manuals and maintenance manuals. The OOS variable is also correlated with adequate staff, being the main service centre and being satisfied with the EMD reporting authority. The higher number of DVs from the model than IVs and MVs supports the hypothesis, and the causality between $\mathrm{CE}$ effectiveness metrics and equipment state/functionality presented in Figure 6.4 (replication of Figure 1.1).

\subsubsection{Other State/Functionality Metrics}

Table 6.1 shows that the OOS variable is correlated with most other state/functionality metrics. It is strongly correlated (significant at the 0.01 level) with all three condition variables and negatively correlated (significant at the 0.05 level) with three of 


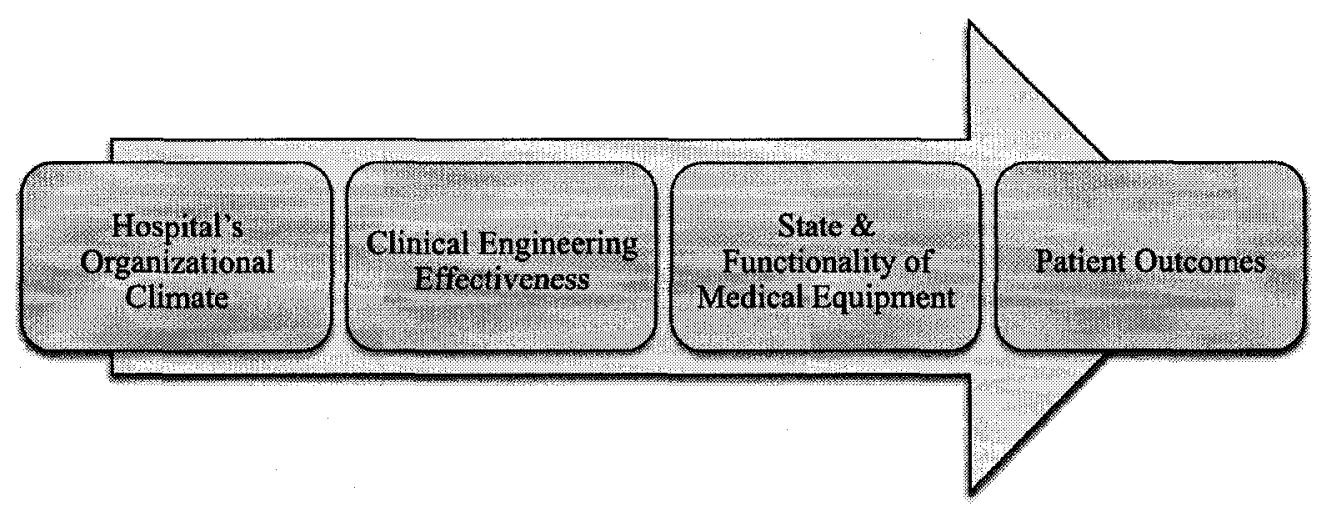

Figure 6.4: Relationship between CE Effectiveness and Patient Outcomes (replication of Figure 1.1)

the four obsolescence metrics - (1) spare parts, (2) accessories and reagents and (3) manufacturer sales support. It is also negatively correlated with the standardisation variables, i.e. hospitals with a higher proportion of standardised equipment have a lower proportion of OOS equipment. Finally, the OOS variable is correlated with all three variables representing the average cost of equipment repair (for simple, complex and highly specialised equipment); this suggests that those hospitals with higher proportions of OOS simple equipment also pay the most for external equipment repairs.

\subsubsection{Procurement and Donation Metrics}

Results in Table 6.1 indicate that hospitals with a higher proportion of procured equipment have lower rates of OOS equipment and those with a higher proportion of donated equipment have higher rates. Those with more donated equipment arriving from other hospitals and aid agencies tend to have more OOS equipment, while those with donated equipment coming from 'other' sources have lower rates (many respondents reported 'other' sources as their own government, or local NGOs). Rates of simple OOS equipment are also positively correlated with the proportion of donated 
equipment that is refurbished or obsolete on arrival, and highly correlated (significant at the 0.01 level) with the proportion of simple donated equipment.

Finally, both HDI and region are correlated with the proportion of simple OOS equipment; respondents from countries with lower HDIs tend to have more OOS equipment. Regions were coded in order of ascending average HDI of the countries represented in the sample ${ }^{4}$, so is is expected that this is also correlated.

\subsubsection{Complex Equipment}

\subsubsection{CE Effectiveness Model Metrics}

Table 6.2 shows the complex OOS variable was correlated with fewer variables in the set, and fewer variables from the CE effectiveness model as well. It is highly correlated (significant at the 0.01 level) with satisfaction with reporting authority, and also correlated with four resource metrics: spare parts, user manuals, maintenance manuals and (unlike simple equipment) an adequate budget for spare parts. The same IV from the CE effectiveness model is correlated with both complex and simple equipment: adequate staff.

\subsubsection{Other State/Functionality Metrics}

The proportion of complex equipment, like simple equipment, is strongly correlated with all three common condition variables, and negatively correlated with the rate of standardisation (i.e. the less standardisation, the more complex equipment is OOS). Only one of the obsolescence metrics is correlated - the availability of manufacturer sales support; this is the only metric not correlated with the simple OOS variable.

\footnotetext{
${ }^{4}$ Regions are coded as: Africa $=1$, Latin America $=2$, Asia $=3$, Middle East $=4$ and Eastern Europe $=5$ to reflect increasing average HDIs of the countries represented.
} 
Trained users are again negatively correlated, while trained maintenance technicians are strongly negatively correlated (significant at the 0.01 level). Performing PMs is also strongly negatively correlated (significant at the 0.01 level) with the rate of OOS complex equipment. These results suggest that maintenance resources (spare parts, manuals, trained technicians, manufacturer support and performing PMs) have a more significant impact on the OOS rate of complex equipment than simple equipment. Although no donation metrics are correlated with rates of OOS complex equipment, the higher the procured proportion of a total equipment base, the lower the rate of OOS equipment.

\subsubsection{Discussion}

These results present a starting point for evaluating the impact of CE effectiveness indicators on equipment state/functionality metrics. Resources such as spare parts, user and maintenance manuals appear to influence the amount of equipment that is out of service. Frize's approach for measuring functional involvement (with ordinal measurements representing the proportion of the hospital's equipment base the CED/EMD is responsible for) may provide more useful inputs to the model than the dichotomous metrics used in this research (i.e. for each task, respondents reported 'yes' or 'no' for whether both engineers and technicians performed them $)^{5}$. It is suggested future researchers use this approach to enable a deeper analysis of the relationship between FI metrics and state of equipment metrics.

The level of standardisation could become an input to a model as it is correlated with overall highly functional EMDs. Adequate staff could also become a poten-

\footnotetext{
${ }^{5}$ The original question that collected information about tasks asked respondents to rank them in order of decreasing time spent on them by engineers and technicians, but it was identified by 4 of 5 pre-test respondents as the most confusing question and was therefore simplified.
} 
tial input, as human resources are also listed as effectiveness metrics in the form of number of engineers and number of technicians. The strong correlation between the OOS metric and other state/functionality metrics (condition and obsolescence) indicates data accuracy, and also suggests that in future modelling work they should be considered as outputs along with OOS rates.

While these results are preliminary, the higher number of DVs from the effectiveness model than IVs and MVs do support the theoretical causality between (a) organisational factors and $\mathrm{CE}$ effectiveness and (b) CE effectiveness and the state of medical equipment presented in Figure 1.1. This is further validated by the solitary input variable from the effectiveness model that is present and correlated for both simple and complex equipment that is OOS (adequate staff, which could itself be considered an effectiveness metric in the place of number of engineers and technicians). Based on these results, the null hypothesis is excepted.

\subsection{Limitations}

How valid are the results of this research? The questionnaire was long, and included some possible sources of error. Some questions tested the perceptions of respondents; responses cannot be interpreted as absolute answers. Respondents may have also not known a particular answer and may have provided a guess instead of skipping the question. Results indicate that wording in some questions was ambiguous, despite rigourous pre-testing. Finally, rating scales were widely used in the questionnaire, and can introduce three types of bias into the data [70]:

1. Leniency occurs when respondents tend to be 'easy raters 'or 'hard raters 'for subjective questions with scale categories such as 'excellent', 'good', 'fair', poor', 
and 'very poor'. An example of this type of question in the instrument is: 'What is the most common condition of your simple equipment?".

2. Central tendency occurs when raters are reluctant to give a strong judgement and choose the central answer on a symmetrical scale. This is evident in several responses in the data with normal distributions around the central response category.

3. Halo effect occurs when raters apply a similar impression to all questions with the same response categories. Two strategies attempted to reduce the halo effect in the questionnaire: separating rating scale questions with other types when possible, and varying response categories for rating scales (for example, with Q.2 to Q.5 in the Donations section).

\subsubsection{Validity}

Internal validity refers to the ability of an instrument to measure what it is purported to measure [70]. It can be classified into three major forms:

1. Content validity is the extent to which the instrument provides average coverage of the topic under study. This questionnaire was very long (perhaps too long) and thus is not at high risk of being content invalid.

2. Criterion-related validity reflects the success of measures used for empirical estimating purposes to predict an outcome or estimation of the existence of some current behaviour or condition [70]. Many relationships studied in this analysis suggest strong criterion-related validity. For example, strong correlation between adequate staffing and number of engineers and technicians; correlation 
between many variables accepted to be characteristics of advanced CE services (formal procurement policy, specialised inventory management software, existence as a separate department, etc. There are definite exceptions, and they have been noted as potentially erroneous results in Chapter 5 .

3. Construct validity measures or infers the presence of abstract characteristics for which no empirical validation seems possible. This applies mainly to attitude and aptitude tests, and does not apply to this research.

\subsubsection{Reliability}

An instrument is reliable to the extent that it supplies consistent results. Frequently used methods to determine reliability are stability and equivalence [70].

1. Stability is present when consistent results are secured with repeated measurements of the same respondent with the same instrument. Several questions were planted in the questionnaire during the design phase to test stability; they were presented in Section 4.2.0.2 and indicate a high rate of stability.

2. Equivalence concerns errors that may be introduced by different investigators or different samples being studied. This is not an issue for this research.

\subsubsection{Conclusions}

In addition to these criteria, correlation results presented in this chapter that support empirical observation (for example, that the rate of OOS equipment increases when maintenance resources are in short supply, etc.) also suggest a level of validity. Thus, one can have a reasonable amount of confidence in the data. 


\subsection{Discussion}

This chapter provides results that demonstrate both that Frize's model for CE effectiveness $i s$ applicable to developing countries with modification and that a relationship does exist between $\mathrm{CE}$ effectiveness metrics and the state/functionality of medical equipment in developing world hospitals. This preliminary investigation provides a basis for further study by future researchers. It has also discussed measures of validity with which the data set can be tested. 


\section{Chapter 7}

\section{Conclusions}

This chapter presents a brief summary of the work, highlights contributions to knowledge, and discusses future work.

\subsection{Summary}

This work built on previous studies of both clinical engineering effectiveness and clinical engineering services worldwide. The 207 valid responses that were collected with a novel research instrument exposed regional trends in $\mathrm{CE}$ effectiveness and resources, the state of medical equipment, and equipment procurement and donation practices across Africa, Latin America and Asia. Generally, African hospitals profiled are the most resource-poor and least effective, followed by Latin American hospitals. Asian hospitals profiled reported the highest rates of effectiveness and least need for additional health technology management resources.

Frize's original model for $\mathrm{CE}$ effectiveness in developed world hospitals was validated in the developing world, with modification of the model variables to reflect the 
studied context, and a refined model for $\mathrm{CE}$ effectiveness within secondary and tertiary care hospitals was presented. It demonstrated that hospitals that have a formal equipment procurement policy tend to have more effectiveness resources, including user and maintenance manuals, test equipment, spare parts, and a sophisticated inventory management system. It also determined that the presence of qualified engineers (which was a moderating variable in Frize's original model but an independent variable in the refined model created by this work) was the strongest determinant of functional involvement effectiveness indicators, including a more clear division of labour between engineers and technicians, with engineers performing more managerial and consultative functions (pre-purchase consultation, user training and education) and technicians performing more technical tasks (equipment repair, incoming inspections and preventive maintenance).

A preliminary model for the relationship between $\mathrm{CE}$ effectiveness and the state or functionality of medical equipment in developing world hospitals was also developed. It determined that four outputs of the refined $\mathrm{CE}$ effectiveness model (satisfaction with reporting authority, spare parts and user and maintenance manuals) were correlated with the proportion of both simple and complex equipment that is out of service. An additional five functional involvement outputs were correlated with the simple equipment that is out of service, suggesting that hospitals again who have a more clear division of labour between engineers and technicians tend to have less OOS simple equipment. An adequate budget for spare parts was strongly correlated with the proportion of complex equipment that is OOS, and additionally more maintenance-related variables from the overall data set (trained maintenance technicians, etc.) affected the OOS rate of complex equipment. Only one input variable to the effectiveness model (adequate staff) was correlated with either outcome of this 
model, further validating the original hypothesis that the organisational climate of a hospital affects its $\mathrm{CE}$ effectiveness, which in turn affects the state and functionality of medical equipment within the hospital.

\subsection{Contributions}

Many valuable contributions arise from the work. It is the largest study of $\mathrm{CE}$ effectiveness in the developing world ever performed, both in terms of number of responses (207) and the size of the data set (184 variables). It was also the first study ever to adequately profile $\mathrm{CE}$ services in African hospitals, with a regional total of 53 responses; previously one African response was received in a similar study and was categorised as Asian. The most comprehensive profile of CE services, equipment and procurement and donation in the developing world to date was also presented in this thesis. In fact, the profile is more comprehensive than previous international studies that studied the developed world as well.

This study collected and presented the most information to date on CE services within developed world hospitals, and was the first to collect any information at all about the state and functionality of medical equipment, and equipment procurement and donation practices in the studied context. Results validated what had been previously explained empirically; that procurement is strongly linked with overall $\mathrm{CE}$ effectiveness, and that the consultation surrounding equipment donations, and the resources and support sent with donations, is incredibly poor.

This research was the first to validate Frize's effectiveness model in the developing world, with a statistically significant amount of data, thus proving the relationship between the organisational climate of a hospital and the effectiveness of its $\mathrm{CE}$ services 
and in the developing world as well as the developed world. This produced the first model for $\mathrm{CE}$ effectiveness in the developed world, using metrics appropriate to the context.

This research was also the first to study the relationship between CE effectiveness and the state and functionality of medical equipment. It was proven that a relationship does exist, and a preliminary model for the relationship was developed. The model is the first to be developed to examine this relationship and validated in an international study, either in the developed or developing world.

Finally, the comprehensive, appropriate data collection tool (questionnaire) that was developed and used collects more information than any previous international study of CE effectiveness. It, and the resulting database, are additional contributions that will be of great use to future researchers.

\subsection{Future Work}

Many opportunities for future work were highlighted throughout this thesis.

\subsubsection{Model Refinement}

Within the framework of the theoretical construct that links CE effectiveness with patient outcomes, the novel research instrument itself can be used to collect more data on $\mathrm{CE}$ effectiveness, medical equipment and procurement and donation practices; suggestions for question modification were also presented throughout the thesis. The infrastructure section that was removed is an additional valuable resource to future researchers. The large database of developing world $\mathrm{CE}$ metrics is of use for future researchers to perform additional modelling of the relationships between organisational 
climate variables, $\mathrm{CE}$ effectiveness variables, and equipment state variables in developing world hospitals. Finally future researchers can investigate the integration of other $\mathrm{CE}$ effectiveness output metrics into modelling, including both the qualitative and quantitative $\mathrm{CE}$ effectiveness benchmarks presented in this thesis.

The preliminary model for the relationship between CE effectiveness and medical equipment state can be refined and validated, both through further research using a similar methodology and from first hand study within the developing world health systems setting. Finally, within the construct, much research can be done, both in the developed and the developing world, to determine the effect of medical equipment state and functionality on patient outcomes within the hospital setting. This area of study provides many avenues for research.

\subsubsection{Qualitative Research and Modelling}

Qualitative research on the topics presented in this thesis would greatly enrich the study of HTM challenges in the developing world. It is strongly recommended that future researchers entertain the possibility. Qualitative study of this topic would permit greater detailed study of the areas covered in this thesis, and would also permit data collection on topics deemed too sensitive or complex for the research instrument used for this work.

Moving beyond the theoretical construct that guided this work, there are vast opportunities for research that expands upon the work presented in this thesis. An ecosystems approach can be used to examine the relationships between actors in the health technology management process in developing world hospitals. It would also be of great value to study the role of culture and local learning practices and integrate them into $\mathrm{CE}$ effectiveness modelling. A different approach to modelling, based on 
the ecosystems approach or a similar social networking framework that accommodates "softer" variables, would yield fascinating results.

In conclusion, this work added to the literature and body of knowledge surrounding $\mathrm{CE}$ services and challenges in the developing world. It also led to more opportunities for research in the area based on the findings of this thesis. The health challenges faced by those living in the developing world are immense, and more research must be done into all service-delivery aspects of health care in the developing world. Those living in extreme poverty around the world deserve no less. 


\section{References}

[1] A. Issakov, "Addressing global health technology management challenges: Who integrated healthcare infrastructure and technology management toolkit," in Pan American Health Care Exchange, February 2007.

[2] (2008, March). [Online]. Available: http://hdr.undp.org/en/statistics/

[3] D. of Essential Health Technologies (WHO), "Towards a who model list of essential medical device," http://www.who.int/eht/en/MedicalDevices.pdf, 2007.

[4] T. Judd, J. Dyro, and J. Wear, "Advanced health technology management workshop," in Clinical Engineering Handbook, J. Dyro, Ed. Elsevier, 2004.

[5] (2008, January). [Online]. Available: http://www.un.org/millenniumgoals/

[6] X. Cao, "Assessment of clinical engineering departments in developing countries," Master's thesis, University of Ottawa, December 2003.

[7] J. Bronzino, "Clinical engineering: Evolution of a discipline," in Clinical Engineering Handbook, J. Dyro, Ed. Elsevier, 2004.

[8] M. Glouhova, Z. Kolitsi, and N. Pallikarakis, "International survey on the practice of clinical engineering: Mission, structure, personnel, and resources." Journal of Clinical Engineering, vol. 25, no. 5, pp. p269 -276, 2000. 
REFERENCES

[9] M. Frize, "The clinical engineer: A full member of the health care team?" Medical and Biological Engineering and Computing, pp. 461-465, 1988.

[10] M. Ridgway, G. Johnson, and J. McClain, "History of engineering and technology in health care," in Clinical Engineering Handbook, J. Dyro, Ed. Elsevier, 2004.

[11] M. Frize, "Results of an international survey of clinical engineering departments: part 1," Medical and Biological Engineering and Computing, vol. 28, no. 2, pp. 153-159, 1990.

[12] C. Campbell, "A model clinical engineering department," in Clinical Engineering Handbook, J. Dyro, Ed. Elsevier, 2004.

[13] M. Frize, "Evaluating the effectiveness of clinical engineering departments in canadian hospitals," Ph.D. dissertation, Erasmus University, 1989.

[14] T. Judd, "Health technology management," in Clinical Engineering Handbook, J. Dyro, Ed. Elsevier, 2004.

[15] M. Cheng and J. Dyro, "Good management practice for medical equipment," in Clinical Engineering Handbook, J. Dyro, Ed. Elsevier, 2004.

[16] I. Roy, "The medical technology assessment model," Master's thesis, Carleton University, 2004.

[17] WHO, "Informal consultation on physical infrastructure, technology and sustainable health systems for developing countries," WHO, December 1998.

[18] (2008, March). [Online]. Available: http://www.who.int/eht/en/

[19] (2008, March). [Online]. Available: http://www.theglobalfund.org/EN/ 
[20] F. Bekele, "Malnutrition: the 'silent emergency' unicef urges massive action to stem millions of preventable deaths," Africa Recovery, vol. 11, no. 3, p. 3, 2007.

[21] CIDA, "Icts in sub-saharan africa," Canadian International Development Agency, Tech. Rep., 2006.

[22] W. H. Organization. (2008, January) Who statistic information system. [Online]. Available: http://www.who.int/whosis/en/

[23] R. Quaye, "Assessment of medical technology and the challenge for health reform in africa," International Journal of Health Care Quality Assurance, vol. 9, no. 1, pp. 38-43, 1996.

[24] K. Buse, K. Lee, and S. Fustukian, Health Policy in a Globalising World. Cambridge University Press, 2002.

[25] J. Dyro, "Donation of medical device technologies," in Clinical Engineering Handbook, J. Dyro, Ed. Elsevier, 2004.

[26] W. Bjorn Falghren, Department of Essential Health Technologies. (2007) Access to effective medical technology in developing countries -what role for who?

[27] Bill and M. G. Foundation, "Determining the global health impact of improved diagnostic technologies for the developing world," Nature Publishing Group, 2006.

[28] A. Issakov, "Framework for a national healthcare technology policy," in Pan American Health Care Exchange, 2007.

[29] P. Heimann, A. Issakov, and T. Judd, "Ehtp: Improving health quality through health technology," Engineering in Medicine and Biology Society, 2006. EMBS 
'06. 28th Annual International Conference of the IEEE, vol. Supplement, pp. 6610-6613, Aug. 30 2006-Sept. 32006.

[30] (2008, March). [Online]. Available: www.ifmbe.org/

[31] (2008, March). [Online]. Available: http://www.global-medical-equipment.org/

[32] (2008, March). [Online]. Available: http://www.htm-matters.com/

[33] D. Yadin and D. Rohe, "Clinical engineering program productivity and measurements," Journal of Clinical Engineering, vol. 11, no. 6, pp. 435-443, NovemberDecember 1986.

[34] M. Frize, "Results of an international survey of clinical engineering departments: part 2," Medical and Biological Engineering and Computing, vol. 28, no. 2, pp. 160-165, 1990.

[35] T. Cohen, C. Bakuzonis, and S. Friedman, "Benchmark indicators for medical equipment repair and maintenance," Biomedical Instrumentation and Technology, vol. 29, no. 308-321, 1995.

[36] T. Cohen, "Validating medical equipment repair and maintenance metrics: a progress report," Biomedical Instrumentation and Technology, vol. 31, pp. 23$32,1997$.

[37] B. Wang, R. W. Eliason, and S. C. Vanderzee, "Global failure: Rate a promising medical equipment management outcome benchmark." Journal of Clinical Engineering, vol. 31, no. 3, pp. p145 - 151, 2006.

[38] A. Mahachek, "Benchmarking is for benchwarmers," Biomedical Instrumentation and Technology, vol. 30, pp. 372-373, 1996. 
[39] R. Stiefel, "Clinical engineering cannt do benchmarking," Biomedical Instrumentation and Technology, vol. 31, pp. 408-409, 1997.

[40] T. Cohen, "Validating medical equipment repair and maintenance metrics, part ii: Results of the 1997 survey," Biomedical Instrumentation and Technology, vol. 31, pp. 136-144, 1997.

[41] B. Wang, R. W. Eliason, S. M. Richards, L. W. Hertzler, and S. Koenigshof, "Clinical engineering benchmarking: An analysis of american acute care hospitals." Journal of Clinical Engineering, vol. 33, no. 1, pp. p24 - 37, 2008.

[42] K. Harris, R. Baumann, T. Cohen, J. Huerta, J. McGill, F. R. Painter, and C. Ward, "Body of knowledge survey results," American College of Clinical Engineers, Tech. Rep., 2006.

[43] S. J. Calil, L. N. Nascimento, and F. R. Painter, "Findings of the worldwide clinical engineering survey conducted by the clinical engineering division of the international federation for medicine and biological engineering," 11th Mediterranean Conference on Medical and Biomedical Engineering and Computing 2007, pp. 1085-1088, 2007.

[44] L. F. de Magalhaes Brito, "Clinical engineering in brazil," in Clinical Engineering Handbook, J. Dyro, Ed. Elsevier, 2004.

[45] A. Velasquez, "Clinical engineering in mexico," in Clinical Engineering Handbook, J. Dyro, Ed. Elsevier, 2004.

[46] J. E. V. Gutierrez, "Clinical engineering in colombia," in Clinical Engineering Handbook, J. Dyro, Ed. Elsevier, 2004. 
[47] J. Gomez, "Clinical engineering in ecuador," in Clinical Engineering Handbook, J. Dyro, Ed. Elsevier, 2004.

[48] P. Galvan, "Clinical engineering in paraguay," in Clinical Engineering Handbook, J. Dyro, Ed. Elsevier, 2004.

[49] L. Vilcahuaman and J. Brandan, "Clinical engineering in peru," in Clinical Engineering Handbook, J. Dyro, Ed. Elsevier, 2004.

[50] R. Silva and L. Lara-Estrella, "Clinical engineering in venezuela," in Clinical Engineering Handbook, J. Dyro, Ed. Elsevier, 2004.

[51] E. Nunziata and M. Sumalgy, "Clinical engineering in mozambique," in Clinical Engineering Handbook, J. Dyro, Ed. Elsevier, 2004.

[52] A. Khalaf, "Maintenance model for minimizing risk and optimizing cost effectiveness in palestine," Journal of Clinical Engineering, vol. 29, no. 4, pp. 210-217, October/December 2004.

[53] M. Mridha, "The developing countries' need for appropriate medical technology," Engineering in Medicine and Biology Society, 1992. Vol.14. Proceedings of the Annual International Conference of the IEEE, vol. 3, pp. 1186-1187, 29 Oct-1 Nov 1992.

[54] H. O. Al-Fadel, "Clinical engineering in the middle east," in Clinical Engineering Handbook, J. Dyro, Ed. Elsevier, 2004.

[55] K. Taylor, M. Frize, N. Iverson, and C. Paponnet-Cantat, "The need for the integration of clinical engineering and sociological perspectives in the manage- 
ment of medical equipment within developing countries," Journal of Clinical Engineering, vol. 19, no. 4, pp. 291-296, July/August 1994.

[56] S. Mullally, "What are the sociocultural implications of western technology transfer in traditional birthing systems in the developing world?" April 2007, for PADM5703: Health Policy in Developing Countries at Carleton University.

[57] H. N. et al., "Delivering the goods - medical equipment procurement study," World Bank HNPFlash, no. 39, December 282000.

[58] Evidence and I. for Policy Cluster, "Consultation on the role of physical infrastructure and technology in the development of sustainable health systems," Department of Organization of Health Services Delivery, WHO, Geneva, Tech. Rep., December 1998.

[59] W. H. Organization, "Guidelines for healthcare equipment donation," WHO, Tech. Rep., 2000.

[60] A. C. of Clinical Engineers, "Guidelines for the acquisition of technology," ACCE, Tech. Rep., 2007.

[61] K. Taylor, "Donation evaluation and donation support plan for the ministry of health, the gambia," Medical Research Council, UK, Tech. Rep., 2005.

[62] M. Cheng, "A strategy to maintain essential medical equipment in developing countries," in Clinical Engineering Handbook, J. Dyro, Ed. Elsevier, 2004.

[63] M. Frize and M. Cheng, "Technical services for healthcare facilities: a model for developing countries," Medical and Biological Engineering and Computing, vol. 32, no. 3, pp. 335-337, 1994. 
[64] (2008, April) Mrc website. [Online]. Available: http://www.mrc.gm/

[65] S. Mullally, "Research ethics in developing countries: Applying global frameworks to local contexts," Canadian Medical and Biomedical Engineering Society, 2008. 31st Annual Conference of the CMBEC., 2008.

[66] J. Dyro, Ed., Clinical Engineering Handbook. Elsevier, 2004.

[67] P. M. Nardi, Doing Survey Research: A Guide to Quantitative Methods. A. B. Longman, 2006.

[68] F. J. Fowler, Survey Research Methods. Sage Publications Inc., 2002.

[69] (2008, April). [Online]. Available: www.surveymonkey.com/

[70] W. Emory, Business Research Methods, R. Fetter and C. McMillan, Eds. Washington Press, 1980.

[71] M. Frize, X. Cao, and I. Roy, "Survey of clinical engineering in developing countries and model for technology acquisition and diffusion," Engineering in Medicine and Biology Society, 2005. IEEE-EMBS 2005. 27th Annual International Conference of the, pp. 170-173, 2005.

[72] B. Hyndman, "Engineering the clinical environment," in Clinical Engineering Handbook, J. Dyro, Ed. Elsevier, 2004. 
Appendix A

A.1 Ethics Approval Certificate and Letter of Information 
Carleton

Candedes coptual Unwersty
Carleton Uniwersity Research ofwe 5th Floos Tor whe dine 1125 corong or orw

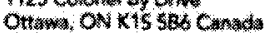
Tet 16135202516 Fax 18202521

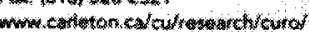

\section{Ethics Approval Form}

This is to certify that the Carleton University Research Ethics Committee has examined the application for ethlcal approval. The committee found the research project to meet appropriate ethical standards as outined in the Tri-Councit Policy Statement: Ethical Conduct for Research Involving Humans and, the Calleton University Policies and Procedures for the Ethical Conduct of Research.

\section{$x$ New approval}

a Renewal of original approval original date of approval:

Date of renewal 20 September 2007

Researcher Shauna Mullally

Status. M. Sc. candidate

Department Systems and Computer Engineering (OCrECE)

supervisor Prof Monique Frize

Tite of project Studylng the Effect of Health Technology Resources on Health

Technology Management Effectiveness in Tertiary Care Hospitats in Developing Countries:

Ethics approval expires on: 20 september 2008

\section{All researchers are governed by the following conditions:}

Annual status Reports ethics dearance ls valid for one year from date of approval. You are required to submit an Annual Status Report to either renewal approval or close the file. Falure to submit the Annual Status Regort will result in the immediate suspension of the project Funded projects will have accounts suspended until the report is submitted and approved.

Chenges to the project. Any changes to the project must be submitted to the Carleton Untversity Research Ethics Committee tor approval, All changes must be aporoved prior to the continuance of the research

Adverse eventes should any participant suffer adversely from their participation in the project you are required to report the matter to the Carleton University Research Ethics Commitee. You must submit a wrtten record of the ovent and indicate what steps you have taken to resolve the situation.

Suspendan or temmaton of upproval, falure to conduct the research in accordence wht the princlptes of

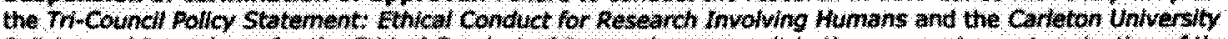
Policies and procedures for the ftheal Conduct of Research may resut in the suspension or termination of the research project

Letle I, Wo Sonald-Hicks Research Ethics Committee Coordinator: For tha Chair of the Carleton Unversity Research Ethics Committee Prof. Antonto Gualtien 


\section{Carleton}

Conadas cajital uniwasity

\section{Letter of Information}

\section{International Study of Medical Equipment (Maintenance, Resources and Procurement)}

Shauna Mullally, a Masters of Applied Science (M. A. Sc.) candidate in the Department of Systems and Computer Engineering (SCE) at Carleton University, is conducting an international research study on the state of medical equipment in secondary and tertiary care hospitals, and how it is related to (1) the equipment maintenance department, (2) available resources, and (3) equipment procurement. Ms. Mullally is conducting this research under the supervision of Dr. Monique Frize, also of the Department of SCE at Carleton University. Their research group is the Medical Informatics Research Group (MIRG), and the Natural Science and Engineering Research Council (NSERC) has provided a grant for this research.

The purpose of this study is to analyse how medical equipment is affected by the three areas listed above. The research aims to examine current challenges faced by you at your hospital - not to judge current practices. We understand you may work in a very resource-poor setting, and have little control over these challenges. A questionnaire is used to gather this information. It will ask you questions about the areas listed above, and will take approximately 20 minutes to complete. You are under no obligation to participate, you may decline to answer any questions, and you may withdraw from this study at any time and request your data be destroyed.

MIRG will benefit from this research. You will benefit if you indicate that you wish to know the results of the research; the recommendations may be of use to you and your hospital! You will also benefit by being entered into a draw for one 'Handbook of Clinical Engineering' textbook, edited by Joseph Dyro, which is valued at $\$ 130 \mathrm{CDN}$. If you are the winner, communication will take place either via email or via mail in March 2008. The odds of you winning will depend on how many other participants enter the draw; currently, we are aiming for 50 responses. If you feel that your workplace security is at risk, you should not participate in this study.

Your responses will be kept confidential in the publication of research. There will not be full anonymity in the publication of research. Personal data, such as name and email address, will not be published, but other identifiable data, such as country and hospital type, may be. Data from this study will be kept secure on a MIRG computer at Carleton University, and will be stored indefinitely. If you complete the online version of this study using SurveyMonkey.com, the information you submit will be stored on SurveyMonkey's server and may be accessed by the U.S. legal and government officials, in accordance with the U.S. Patriot's Act.

This project was reviewed and received ethics clearance by the Carleton University Research Ethics Committee. If you have any questions or concerns about your involvement in the study, please contact the ethics committee chair, Prof. Antonio Gualtieri. Contact information is:

Ethics Committee Chair

Carleton University Research Ethics Committee

Carleton University 1125 Colonel By Drive

Ottawa, Ontario, CANADA K1S 5B6

Phone: 0016135202517

Email: ethics@carleton.ca

Researcher

Shauna Mullally, M. A. Sc. Candidate

Dept. Systems and Computer Engineering Carleton University 1125 Colonel By Drive Ottawa, Ontario, CANADA K1S 5B6

Phone:

Fax: 1

Email:

\author{
Supervisor \\ Dr. Monique Frize \\ 7084 Minto Centre \\ Carleton University 1125 Colonel By Drive \\ Ottawa, Ontario, CANADA K1S 5B6 \\ Phone: $0016135202600 \times 8229$ \\ Fax: 0016135205727 \\ Email: mfrize@connect.carleton.ca
}


Appendix B

B.1 Research Instrument 


\section{Introduction}

This survey should be filled out by the main health technology (medical equipment) manager in your hospital. If your hospital has a separate clinical/biomedical engineering department, the manager of that department should fill it out. Please ensure that you have read the Letter of Information about the survey that was sent with this survey link. As a reminder, you are under no obligation to participate in this survey, you may skip any questions you wish, and your data is only collected at the end of the survey when you click the 'Submit' button. All responses are strictly confidential.

The results of the research will be shared with you if you indicate interest; it is possible that the results will benefit your health technology management practices! You will also be entered into a draw for the 'Clinical Engineering Handbook', edited by Joseph Dyro (2004). This Handbook, valued at $\$ 130.00$ Canadian, is a great resource for health technology managers with contributions from 170 of the profession's leaders. According to the Journal of Clinical Engineering, it "provides a good background to the wide array of tasks, programs, innovations, and challenges to the clinical engineering profession".

Thanks in advance for your participation!

\section{Hospital Information}

This section gathers basic information about your hospital.

\section{What type of hospital do you work at? Check all that apply:}

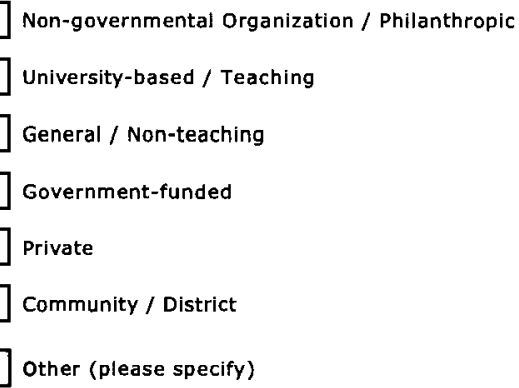

2. How many beds are in your hospital?
$0<50$
50-250
250.500
$\bigcirc>500$
Don't Know

3. What is the average occupancy of beds in the last year?
$\bigcirc<25 \%$
$25-50 \%$
50-75\%
$\bigcirc>75 \%$
Don't know

4. Intensive Care Unit (ICU) means intensive care for patients with acute, lifethreatening illness or injury accompanied by monitoring and emergency services. What proportion of beds in your hospital are ICU beds?
Onone
O $<5 \%$
- $5.10 \%$
${ }_{10-20 \%}$
$>20 \%$

5. Country: 


\section{Equpment Maintenance Department}

This section examines the department responsible for medical equipment maintenance. Sometimes this department is called the clinical or biomedical engineering department.

1. What is the name of your department that is responsible for medical equipment maintenance?

2. Is this department a separate department, or is it part of a larger department that has extra maintenance responsibilities?

Separate

Part of a larger department

If it's part of a larger department, which department does it belong to?

3. What are the names of the staff titles for this department? An example of a staff title is 'senior electronics technician'. Please write them in descending order of seniority, i.e. from the manager down.

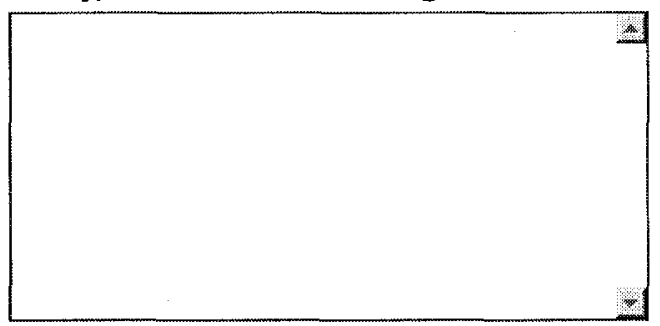

4. Who does the manager of this department report to?
Senior Administrator
Medical Director
Plant / Maintenance Director
other (please specify)

5. Are you satisfied with this reporting arrangement?

Yes

No 


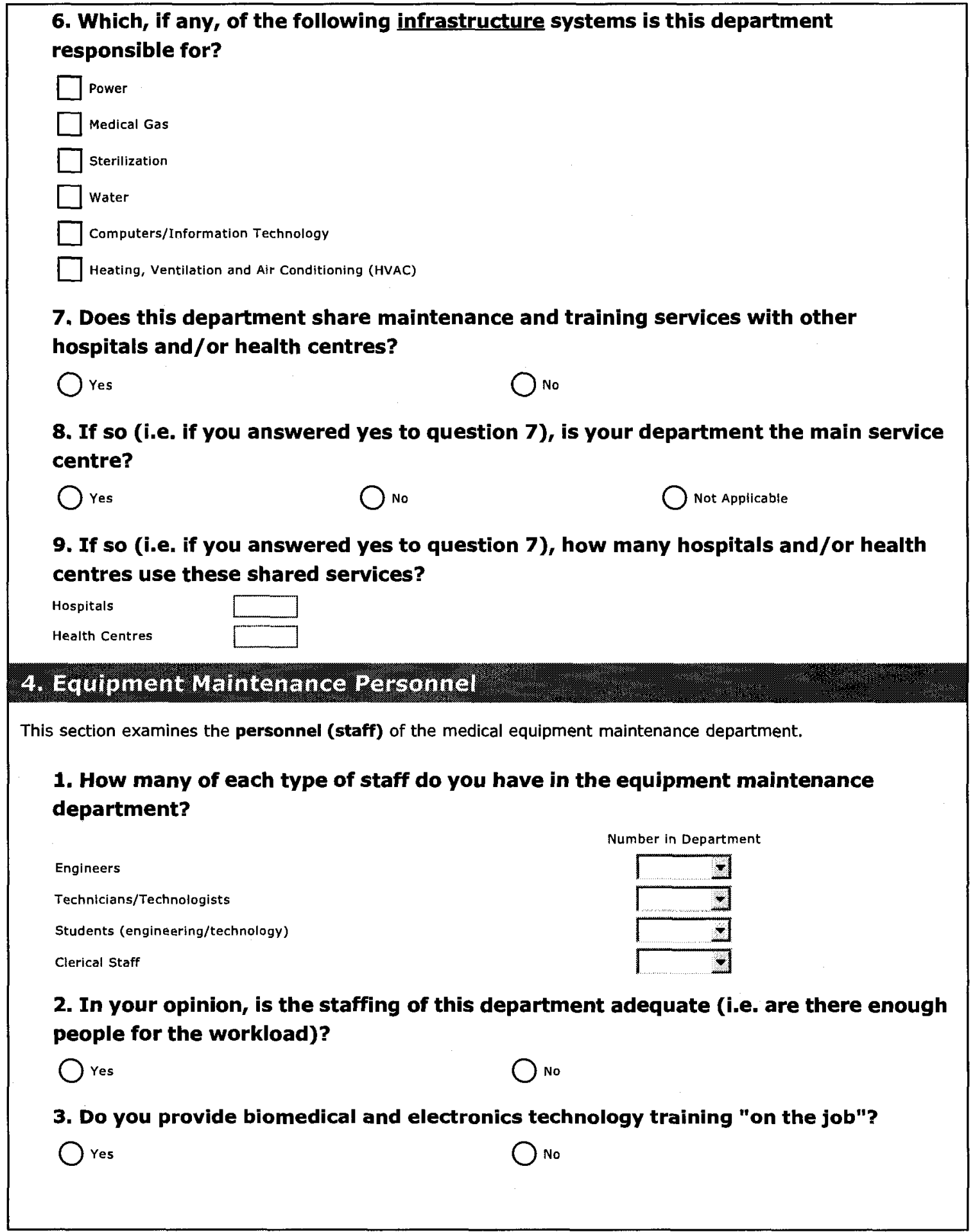




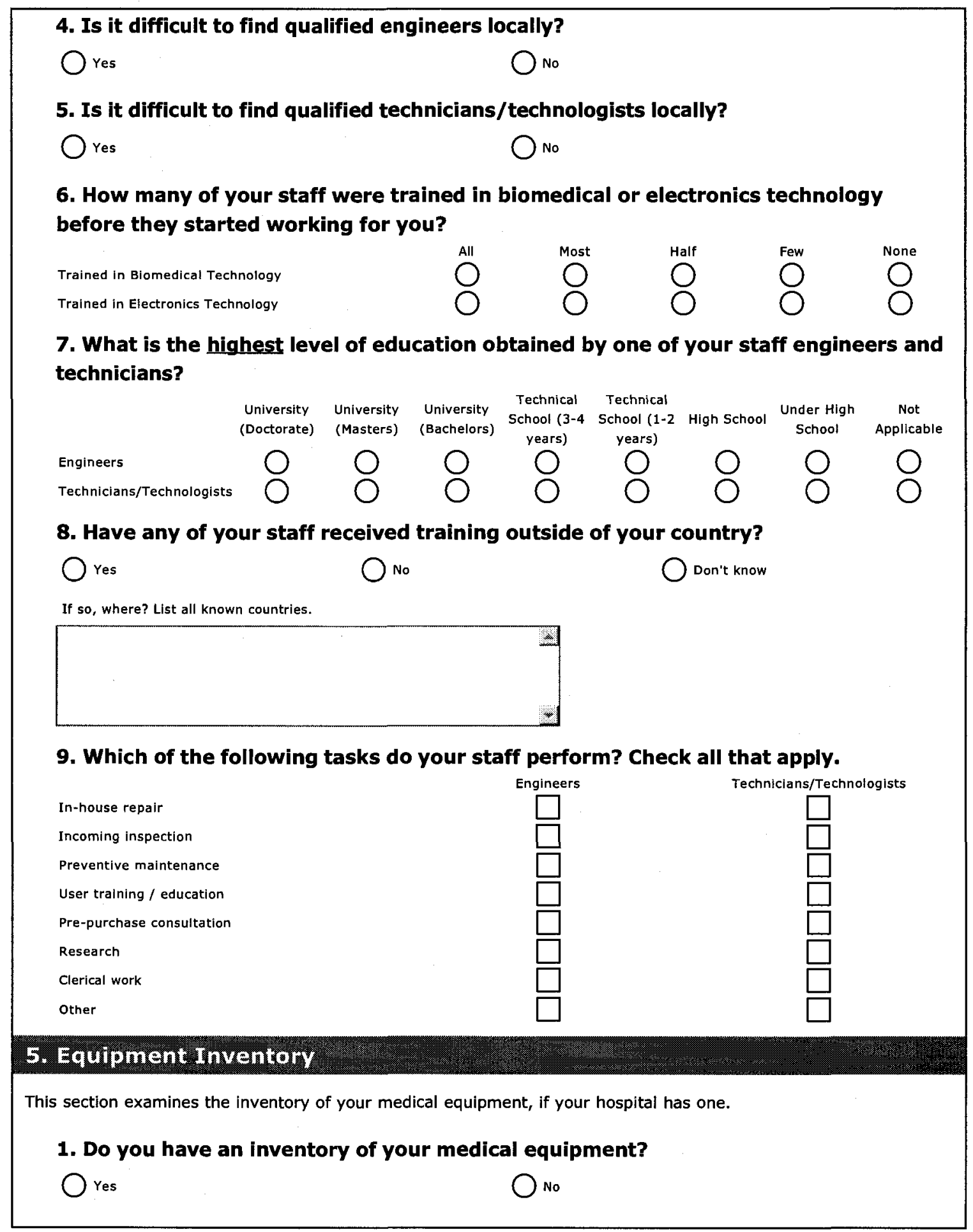




\section{If so (i.e. if you answered yes to question 1), how is this inventory information} stored?

Written by hand, tracked on paper

Done on a computer with generic spreadsheet software (MS Excel, etc.)

Done on a computer with a specialized software designed for medical equipment inventorles (AIMS, VHTemp, Four Rivers, HECS, etc.)

3. If so (i.e. if you answered yes to question 1), what information is included in the inventory? Check all that apply:

$\square$ History of Work Orders

$\square$ Spare Parts

$\square$ Preventive Maintenance Schedule

$\square$ Warranty Duration for Parts and Labour

$\square$ Original Cost

$\square$ Purchase Information

$\square$ Model Number

$\square$ Unique Asset Number

Condition

Vendor, Manufacturer and Support Information

Replacement Priority

Age

Main Service Technician

Serial Number

Infrastructure Requirements (physical space, power, gas, etc.)

Other (please specify)

\section{Medical Equipment}

This section examines what medical equipment your hospital has, and what resources you have for this equipment. If you do not have an inventory of your equipment, please provide your best guesses for the following questions. An estimate is fine! 


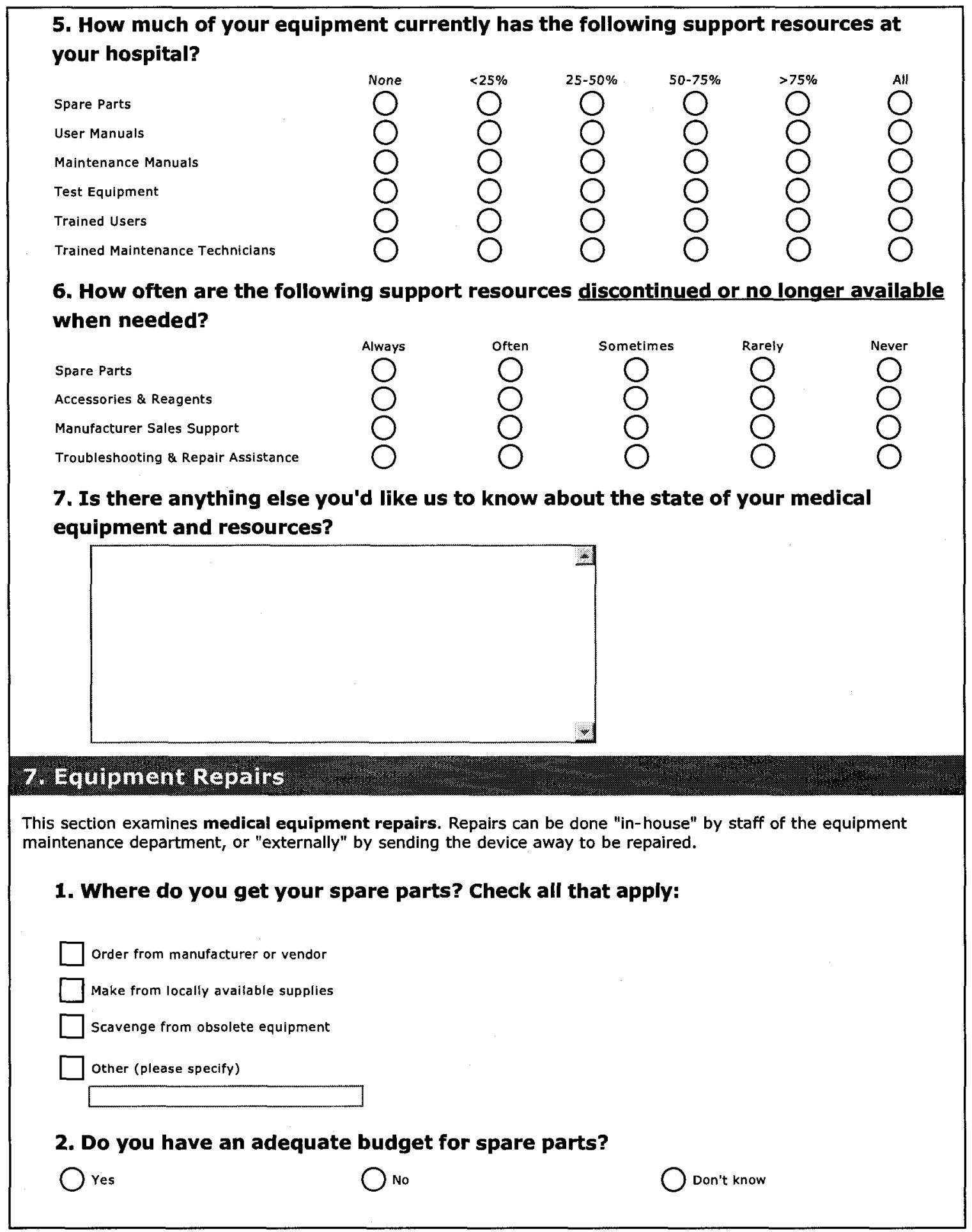


3. When you order spare parts from a manufacturer or vendor, how long on average do they take to arrive (in number of months)?

4. How much of your equipment is repaired in-house (as opposed to externally)?

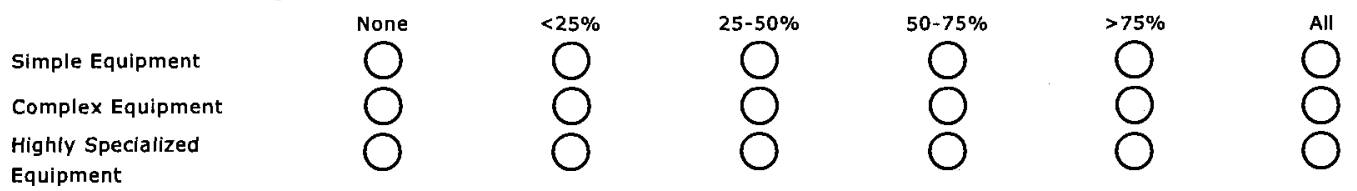

5. If most of your repairs for an equipment type are either in-house or external, why? Please explain.

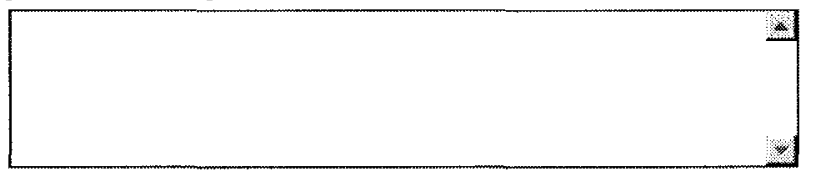

6. What is the average repair time per device for in-house repairs (in number of hours)?

Simple Equipment

Complex Equipment

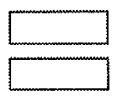

7. What is the average time a device is out of service due to an in-house repair (in number of days)?

Simple Equipment

Complex Equipment

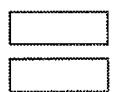

8. If you do send equipment away for repairs, what is the average time a device is out of service due to an external repair (in number of days)?

Simple Equipment

Complex Equipment

Highly Specialized

Equipment

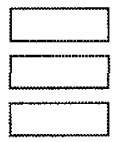

9. If you do send equipment away for repairs, what is the average cost of the external repair (as a percentage of the total cost of the equipment)?

Simple Equipment

Complex Equipment

Highly Specialized

Equipment

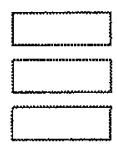

10. Do you perform preventive maintenance on your equipment?
Ores
No
Don't know 
11. Is there anything else you'd like us to know about your equipment repairs?

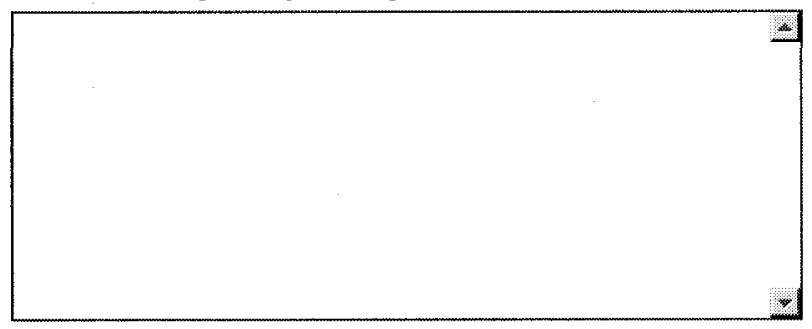

\section{Equipment Acquisition}

This section examines where your medical equipment comes from. It can be (1) procured (selected and bought by your hospital), (2) donated by an organization, or (3) leased, rented or loaned to your hospital.

1. Where has your medical equipment come from? Please enter an estimated percentage value of how much was acquired through procurement, donation and lease/rental/loan. NOTE; your answer should total 100\%. Remember than an estimate is fine!

Procurement

Donation

Lease/Rental/Loan

other

2. Does your hospital have a formal policy or procedure for equipment procurement? Yes No Don't know

3. Who helps decide which equipment the hospital procures? Who most often leads the team that decides? Check all that apply:

Hospital administrator

Doctor / other equipment user

Consultant

Medical equipment maintenance department manager

Medical equipment maintenance department staff

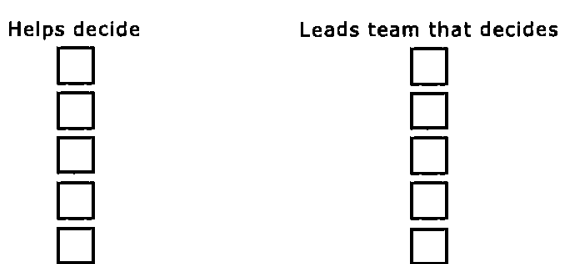

4. How involved are the medical equipment maintenance department manager and personnel in this decision?
Very
Somewhat
Very little
Don't know 


\section{Which requirements are considered before equipment is procured?}

Available maintenance support and services

Availability of qualified users

Demonstrated clinical needs and benefits

Adequate infrastructure support

Regulatory compliance (if applicable)

Approved source of operating budget

Standardization with other equipment

6. Is there anything else you would like us to know about equipment procurement at your hospital?

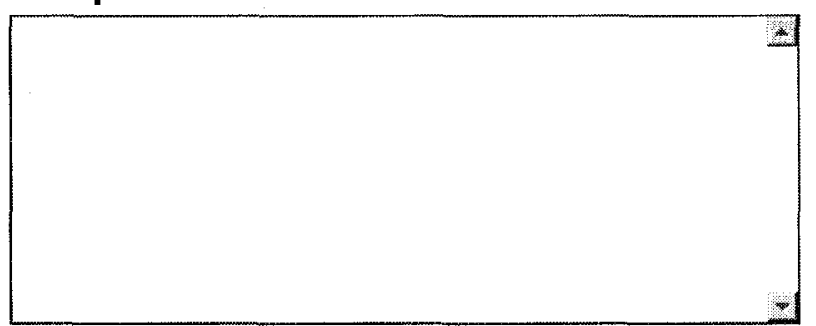

\section{Equipment Donation}

This section examines equipment donations, which can come from many different types of organizations: (1) equipment donation organizations, (2) hospitals in other countries, and (3) large aid agencies and global health programs.

(1) Equipment donatlon organizations connect equipment donors (hospitals, equipment and drug companies) with recipient hospitals. Examples: IMED (the International Medical Equipment Distribution program), IMEC (the International Medical Equipment Collaborative program), MedShare International and REMEDY.

(2) Hospitals in other countries often donate their used equipment directly to recipient hospitals.

(3) Large aid agencies and global health programs often donate equipment to hospitals and health centres as part of their technical assistance, or for a specific global health program. Examples: CIDA, DFID, SIDA, USAID, UNAIDS, The Gates Foundation, and the World Bank.

1. Where has your donated medical equipment come from? Please enter an estimated percentage value of how much was donated by the following types of organizations. NOTE: your answer should total $100 \%$. Remember that an estimate is fine!

Equipment donation organizations

Hospltals in other countries

Large aid agencies and global health programs

other

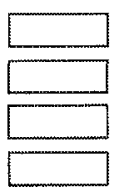


2. If you have received equipment donations from other sources, i.e. if you have an amount for 'Other' in $\mathbf{Q 1}$ above, what are they?

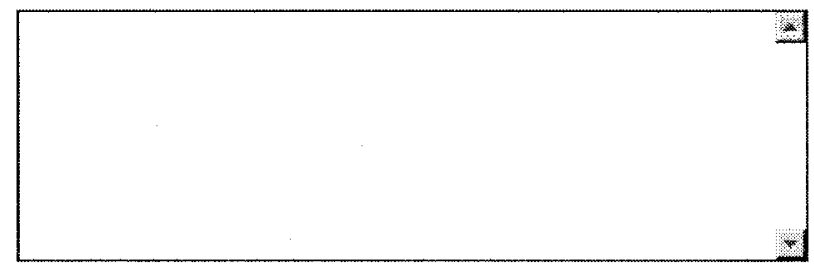

3. How much of your hospital's donated equipment (based on number of devices) is very basic, simple, complex and highly specialized equipment?

Very Basic Equipment
Complex Equipment
Highly Specialized Equipment

4. How much of your donated equipment was in the following state when it arrived at your hospital?

New
Used
Obsolete

5. How often do donation shipments arrive with the following resources?

Spare Parts
User Manuals

6. How often are donation shipments accompanied by the following support resources?

Mainten training

7. Do you ever receive donation shipments with equipment tagged "for parts only"?
Yes
No
Don't know

8. How would you rate the level of consultation with your hospital prior to the shipment, if any?
Excellent
Good
Fair
Poor
Very Poor
No consultation 
9. If your hospital was consulted prior to the shipment, what were you consulted on? Check all that apply:

Approved source of operating budget

$\square$ Standardization with other equipment

$\square$ Demonstrated clinical needs and benefits

Availability of qualified users

$\square$ Available maintenance support and services

$\square$ Regulatory compliance (if applicable)

Adequate infrastructure support

10. Is there anything else you would like us to know about equipment donations to your hospital?

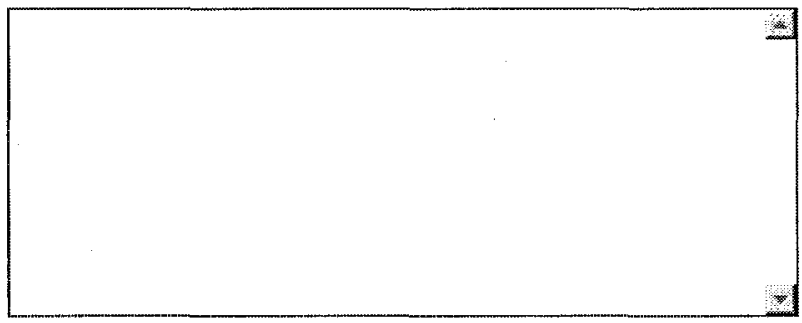

\section{Contact information}

Please enter in your contact information. Remember that your answers are confidential.

1. Would you like to know the results of this research?

Yyes

No

2. Would you like to be entered into the draw for the 'Clinical Engineering Handbook'?

For more information about the Handbook, visit: http://www.amazon.ca/ClinicalEngineering-Handbook-Joseph-Dyro/dp/012226570X/ref=sr_1_12? ie $=$ UTF8\&s $=$ books\&qid $=1197297135 \& s r=8-12$

Yes

No 


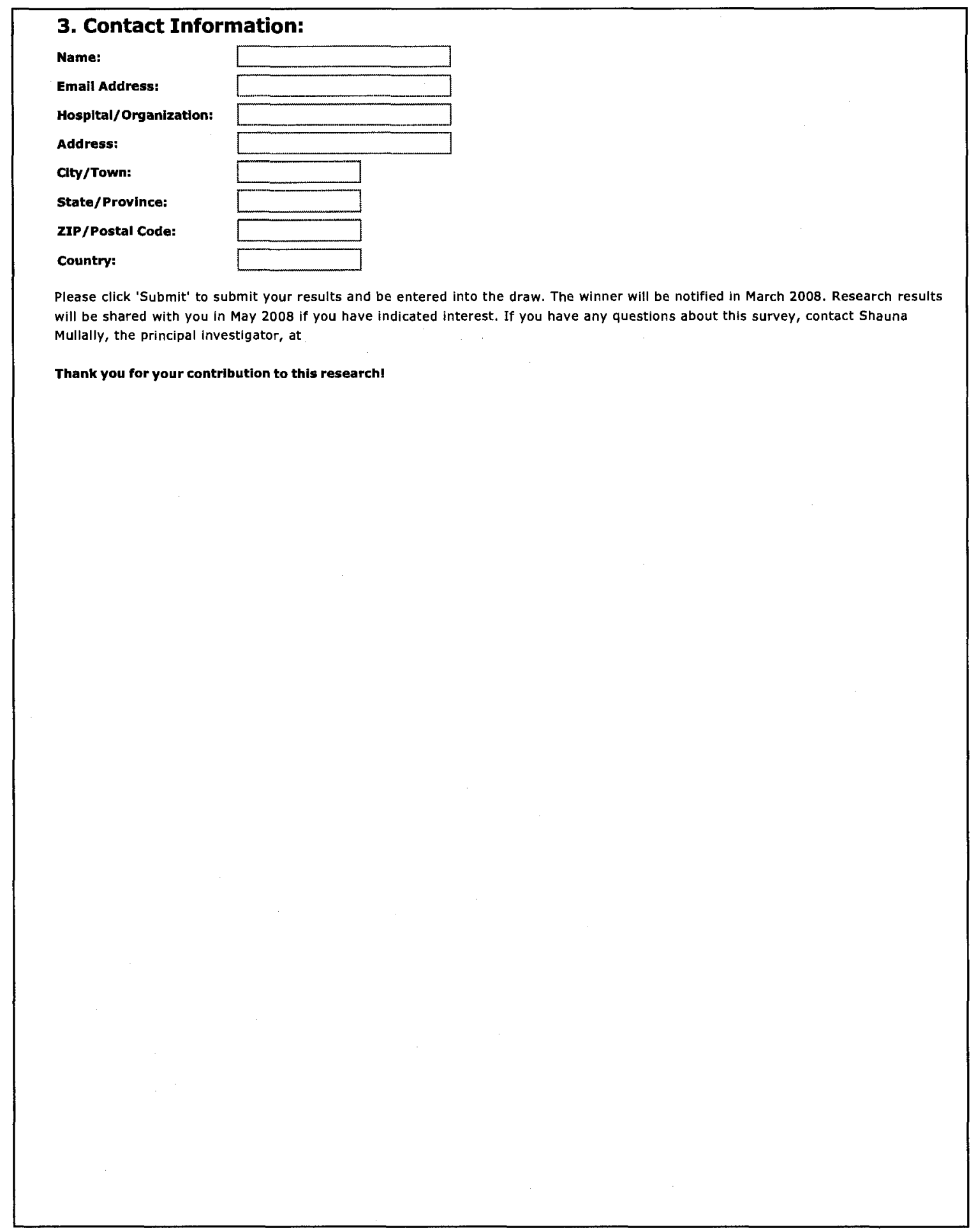

Page 13

Figure B-13: Page 13 - Research Instrument 


\section{Appendix C}

\section{C.1 Variables in Data Set}

Table C-1: General, Hospital Info and Equipment Maintenance Department Variables

\begin{tabular}{|l|l|c|c|}
\hline Section & Variable Name & Type & Value \\
\hline General & country & str-n & \\
& country.hdi & $\mathrm{s}$ & \\
& region & $\mathrm{o}$ & $0-3$ \\
& language & str-n & \\
\hline Hospital Info & hosp.type & $\mathrm{n}(\mathrm{mr})$ & 7 total \\
& num.beds & $\mathrm{o}$ & $0-3$ \\
& occupancy & $\mathrm{o}$ & $0-3$ \\
& prop.ICU & $\mathrm{o}$ & $0-3$ \\
\hline Equipment Maintenance Department & dept.name & str-n & \\
& separate.dept & o & 0,1 \\
& staff.titles & str-n & \\
& report.auth & o & $0-3$ \\
& other.report.auth & str-n & \\
& satisified & $\mathrm{n}(\mathrm{di})$ & 0,1 \\
& infra.systems & $\mathrm{n}(\mathrm{mr})$ & 5 total \\
& shared.service & $\mathrm{n}(\mathrm{di})$ & 0,1 \\
& main.centre & $\mathrm{n} \mathrm{(di)}$ & 0,1 \\
& shared.num.hosp & $\mathrm{s}$ & \\
& shared.num.hc & $\mathrm{s}$ & \\
\hline
\end{tabular}


Table C-2: Equipment Maintenance Personnel and Medical Equipment Variables

\begin{tabular}{|c|c|c|c|}
\hline Section & Variable Name & Type & Value \\
\hline \multirow[t]{15}{*}{ Equip Maintenance Personnel } & num.eng & $\mathrm{s}$ & \\
\hline & num.tech & $\mathrm{s}$ & \\
\hline & num.student & $\mathrm{s}$ & \\
\hline & num.clerical & $\mathrm{s}$ & \\
\hline & adequate.staff & $\mathrm{n}(\mathrm{di})$ & 0,1 \\
\hline & train.on.job & $\mathrm{n}(\mathrm{di})$ & 0,1 \\
\hline & difficult.find.eng & $n(\mathrm{di})$ & 0,1 \\
\hline & difficult.find.tech & $n(d i)$ & 0,1 \\
\hline & trained.in.biomed.before & o & $0-5$ \\
\hline & highest.edu.level.eng & o & \\
\hline & highest.edu.level.tech & o & $0-8$ \\
\hline & trained.outside.country & n (di) & 0,1 \\
\hline & trained.where & str-n & \\
\hline & tasks.eng & $\mathrm{n}(\mathrm{mr})$ & 8 total \\
\hline & tasks.tech & $\mathrm{n}(\mathrm{mr})$ & 8 total \\
\hline \multirow[t]{23}{*}{ Medical Equipment } & percent.basic & $\mathrm{s}$ & \\
\hline & percent.simple & $\mathrm{s}$ & \\
\hline & percent.complex & $\mathrm{s}$ & \\
\hline & percent.high.spec & $\mathrm{s}$ & \\
\hline & oos.simple & $\mathrm{o}$ & $0-3$ \\
\hline & oos.comlex & $\mathrm{o}$ & $0-3$ \\
\hline & oos.high.spec & o & $0-3$ \\
\hline & common.condition.simple & o & $0-4$ \\
\hline & common.condition.comlpex & $\mathrm{o}$ & $0-4$ \\
\hline & common.condition.high.spec & o & $0-4$ \\
\hline & standardized.simple & o & $0-4$ \\
\hline & standardized.complex & o & $0-5$ \\
\hline & how.much.spare.parts & o & $0-5$ \\
\hline & how.much.user.man & o & $0-5$ \\
\hline & how.much.maint.man & $\mathrm{o}$ & $0-5$ \\
\hline & how.much.test.equip & o & $0-5$ \\
\hline & how.much.trained.user & o & $0-5$ \\
\hline & how.much.trained.maint.tech & $\mathrm{o}$ & $0-5$ \\
\hline & not.avail.spare.parts & o & $0-5$ \\
\hline & not.avail.access.reage & o & $0-5$ \\
\hline & not.avail.manu.sales.supp & o & $0-5$ \\
\hline & not.avail.troubleshoot.repair.assist & o & $0-5$ \\
\hline & other.equip.info & str-n & \\
\hline
\end{tabular}


Table C-3: Equipment Inventory and Repair Variables

\begin{tabular}{|c|c|c|c|}
\hline Section & Variable Name & Туре & Value \\
\hline Equip Inventory & $\begin{array}{l}\text { have.inventory } \\
\text { how.inventory.stored } \\
\text { inventory.info.stored }\end{array}$ & $\begin{array}{l}\mathrm{n}(\mathrm{di}) \\
\mathrm{o} \\
\mathrm{n}(\mathrm{mr})\end{array}$ & $\begin{array}{c}0,1 \\
0=2 \\
15 \text { total }\end{array}$ \\
\hline Equip Repairs & $\begin{array}{l}\text { source.spare.parts } \\
\text { adequate.budget.spare.parts } \\
\text { num.months.parts.arrive } \\
\text { amount.in.house.simple } \\
\text { amount.in.house.complex } \\
\text { amount.in.house.high.spec } \\
\text { most.in.house.or.external.info } \\
\text { avg.repair.time.in.house.simple.hours } \\
\text { avg.repair.time.in.house.complex.hours } \\
\text { avg.time.oos.in.house.simple.days } \\
\text { avg.time.oos.in.house.complex.days } \\
\text { avg.time.oos.external.simple.days } \\
\text { avg.time.oos.external.complex.days } \\
\text { avg.time.oos.external.high.spec.days } \\
\text { avg.cost.external.simple } \\
\text { avg.cost.external.complex } \\
\text { avg.cost.external.high.spec } \\
\text { perform.pm } \\
\text { more.repair.info }\end{array}$ & $\begin{array}{l}\text { (mr) } \\
\mathrm{n}(\mathrm{di}) \\
\mathrm{s} \\
0 \\
0 \\
\mathrm{o} \\
\text { str-n } \\
\mathrm{s} \\
\mathrm{s} \\
\mathrm{s} \\
\mathrm{s} \\
\mathrm{s} \\
\mathrm{s} \\
\mathrm{s} \\
\mathrm{s} \\
\mathrm{s} \\
\mathrm{s} \\
\mathrm{n}(\mathrm{di}) \\
\mathrm{str}-\mathrm{n}\end{array}$ & $\begin{array}{c}4 \text { total } \\
0,1 \\
0-5 \\
0-5 \\
0-5\end{array}$ \\
\hline
\end{tabular}


Table C-4: Equipment Procurement and Donation Variables

\begin{tabular}{|c|c|c|c|}
\hline Section & Variable Name & Type & Value \\
\hline Equip Procurement & $\begin{array}{l}\text { percent.proc } \\
\text { percent.don } \\
\text { percent.Irl } \\
\text { percent.other.proc } \\
\text { helps.decide.proc } \\
\text { leads.decide.proc } \\
\text { how.involved.dept.manager } \\
\text { requirements.considered.proc } \\
\text { more.proc.info }\end{array}$ & $\begin{array}{c}\mathrm{s} \\
\mathrm{s} \\
\mathrm{s} \\
\mathrm{s} \\
\mathrm{n}(\mathrm{mr}) \\
\mathrm{n}(\mathrm{mr}) \\
\mathrm{o} \\
\mathrm{n}(\mathrm{mr}) \\
\text { str-n }\end{array}$ & $\begin{array}{c}5 \text { total } \\
5 \text { total } \\
0-2 \\
7 \text { total }\end{array}$ \\
\hline Equip Donations & $\begin{array}{l}\text { percent.don.orgs.don } \\
\text { percent.hosps.don } \\
\text { percent.large.aid.don } \\
\text { percent.other.don } \\
\text { other.don.source.info } \\
\text { percent.don.basic } \\
\text { percent.don.simple } \\
\text { percent.don.complex } \\
\text { percent.don.high.spec } \\
\text { percent.don.when.arrived.new } \\
\text { percent.don.when.arrived.used } \\
\text { percent.don.when.arrived.refurb } \\
\text { percent.don.when.arrived.obs } \\
\text { how.often.don.arrive.spare.parts } \\
\text { how.often.don.arrive.user.man } \\
\text { how.often.don.arrive.maint.man } \\
\text { how.often.don.arrive.user.train } \\
\text { how.often.don.arrive.maint.train } \\
\text { how.often.don.arrive.maint.support } \\
\text { don.tagged.parts.only } \\
\text { level.of.consult.don } \\
\text { requirements.consulted.don } \\
\text { more.don.info }\end{array}$ & $\begin{array}{c}\text { s } \\
\text { s } \\
\mathrm{s} \\
\mathrm{s} \\
\mathrm{str}-\mathrm{n} \\
\mathrm{o} \\
\mathrm{o} \\
\mathrm{o} \\
\mathrm{o} \\
\mathrm{o} \\
\mathrm{o} \\
\mathrm{o} \\
\mathrm{o} \\
\mathrm{o} \\
\mathrm{o} \\
\mathrm{o} \\
\mathrm{o} \\
\mathrm{o} \\
\mathrm{o} \\
\mathrm{n}(\mathrm{di}) \\
\mathrm{o} \\
\mathrm{n}(\mathrm{mr}) \\
\mathrm{str}-\mathrm{n}\end{array}$ & $\begin{array}{c}0-5 \\
0-5 \\
0-5 \\
0-5 \\
0-5 \\
0-5 \\
0-5 \\
0-5 \\
0-4 \\
0-4 \\
0-4 \\
0-4 \\
0-4 \\
0-4 \\
0,1 \\
0-6 \\
7 \text { total }\end{array}$ \\
\hline
\end{tabular}




\section{Appendix D}

D.1 Removed Infrastructure Questions 


\section{Infrastructure}

This section examines the hospital's infrastructure, and the department responsible for infrastructure maintenance. Sometimes this department is called the physical plant. Infrastructure includes the following systems:

1. power

2. medical gas (medical air, oxygen, nitrous oxide, nitrogen and carbon dioxide)

3. sterilization

4. water

5. heating, ventilation and air conditioning (HVAC)

1. What is the name of the department responsible for infrastructure maintenance at your hospital?

2. In your opinion, is the staffing of this department adequate?
Yes
No
Don't know

3. If the infrastructure maintenance department and the medical equipment maintenance department are separate, which department is responsible for the following infrastructure systems? If maintenance of a system is shared, check both.

Power
Medical Gas
Sterilization
Water
Heating, Ventilation and
Air Conditioning (HVAC)
Vehicles

4. What sources of power does your hospital have? Check all that apply:

Electricity

Generator(s)

Solar and batteries

Other (please specify)

5. Is electricity your main source of power?
Ores
No
Don't know

6. Does your hospital have uninterruptible power supplies (UPS)?
Yyes
No
Don't know

If yes, which critical devices do the UPS devices support? List all:

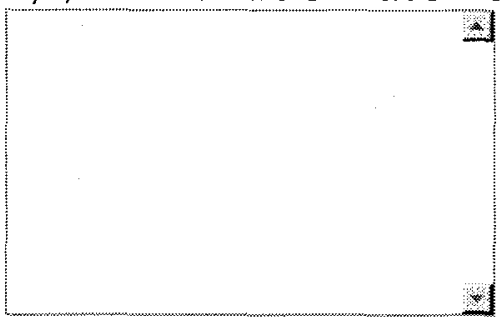

Figure D-1: Page 1 - Removed Infrastructure Section 
7. Medical gases can be delivered to bedside devices through piping, or stored in canisters right next to the device. Are your medical gases piped, stored in canisters, or both?
Piped
stored in canisters
Both
Don't know

8. If medical gas flow is disrupted, is there an alarm system?
Ores
№
Don't know

9. Does your hospital use autoclaves (steam sterilizers) for sterilization?
Yres
No
Don't know

10. If yes, how many autoclaves are functional (as a percentage of how many you have)?

Large / Standalone

Table Top

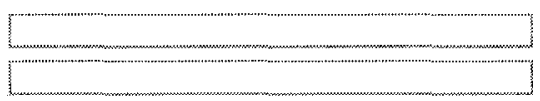

11. Which quality tests are performed on the autoclaves? Check all that apply:

$\nabla$ spore tests

Special temperature sensitive tape tests

Pressure monitored vs. time

Other (please specify)

12. Do you have an alternate sterilization method?

Yres $\bigcirc$ no $\quad O$ Don't know

If yes, what method?

13. Who supplies your hospital's water system?

Public / municipal water service

Private supplier

$\bigcirc$ Hospital-owned well

Other (please specify)

14. Is there a water management team at your hospital?
Yres
No
Don't know

15. The power system fails when there is a power outage; the medical gas system fails when piped gas flow is disrupted. How often do the infrastructure systems fail at your hospital?

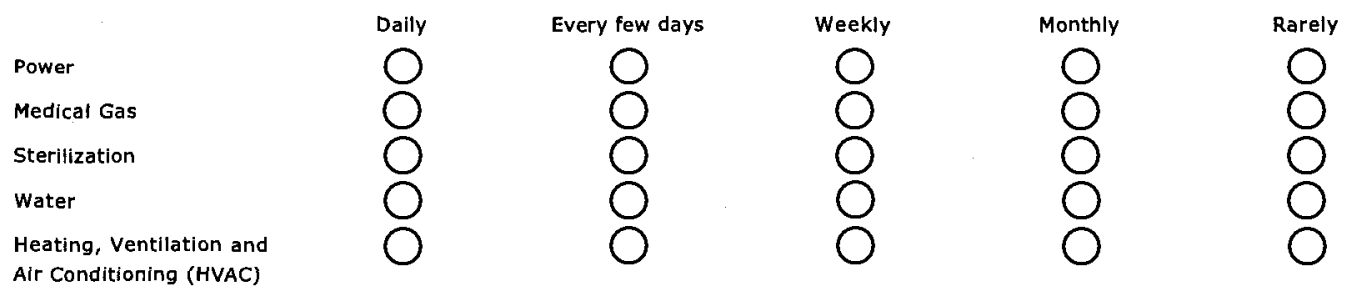

